\title{
ONLINE APP TO DEVELOP POSITIVE AFFECT IN ADOLESCENTS \\ Positive Approaches to Life: A Smartphone-Administered \\ Self-Help Program for Adolescents
}

By

\section{SARAH HUDSON}

\author{
A thesis \\ Submitted to Victoria University of Wellington \\ in fulfilment of the requirements for the degree of \\ Masters of Science in Psychology
}

Victoria University of Wellington

2015 


\begin{abstract}
Psychological well-being has traditionally been viewed as the absence of psychopathology. However, there is an increasing focus on the development of psychological skills and resources, which may both promote psychological well-being and buffer the impacts of stress. There is a promising amount of research demonstrating that brief, positive, psychological interventions are effective in increasing psychological well-being and reducing psychopathology in individuals (Sin \& Lyubomirsky, 2009). While the mechanisms behind successful positive psychology interventions (PPIs) are not well understood, it has been posited that positive, intentional activities may effect change by increasing positive emotions, cognitions and behaviours, which in turn lead to positive psychological outcomes. These interventions have traditionally targeted adults, and thus substantially fewer interventions have been conducted with adolescent samples (Mitchell \& VellaBrodrick, 2009). Additionally, successful programmes have often not been widely implemented due to high resource cost for therapists and teachers. Researchers have suggested it might be worthwhile to improve methodological designs by using nontraditional approaches of delivery, i.e. smartphones, for psychological interventions (Munoz, 2012).
\end{abstract}

The present study was designed to: 1) to investigate whether a smartphone technology delivering positive, intentional activities had a significant influence on levels of well-being in an intervention group when compared to a control group; and 2) to construct a mediational model to inform the relationships between core constructs of psychological well-being and emotions (e.g., subjective happiness, adaptive coping, and resilience). The study included 72 participants, aged 10-15 years, who were recruited from six schools in the wider Wellington region. Participants operated a smartphone-based application that required them to complete four modules designed to cultivate positive emotions. Contrary to predictions, two multivariate repeated measures analyses of variance (MANOVA) indicated that participants who completed the app did not display increases in positive emotion or of positive psychological outcomes compared to the control group.

The mediational model showed that adaptive resources might lead to greater psychological well-being in adolescents. In particular, the model indicated that higher adaptive coping resources lead to increased psychological well-being through the variable of increased resilience. These results indicate that adaptive coping strategies may play a key role 
in positive adolescent development. The limitations of the study are discussed and recommendations were made for future research to determine the efficacy of smartphone applications in psychological research with adolescents. 


\section{Acknowledgements}

This thesis is the result of hard work on behalf of a number of people. I would like to thank my supervisors, Assoc. Prof. Paul Jose and Dr Jaimee Stuart, for their advice and guidance during the experiment, and in the writing of this thesis. I would also like to express my gratitude to the participants who generously donated their time to help test the app, without whom there would have been no data to analyse. Finally, I would like to thank Al Abenoja for his practical assistance in releasing the app to the iTunes App Store, which meant that it could be distributed to participants. 


\section{Table of Contents}

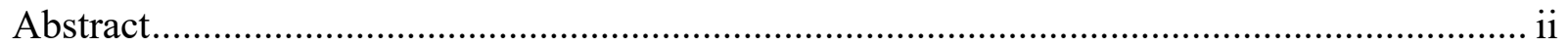

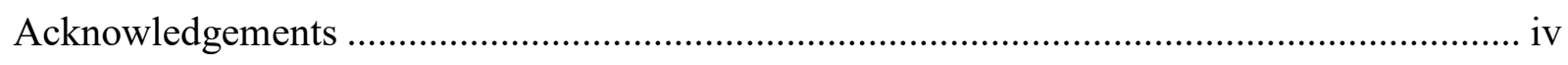

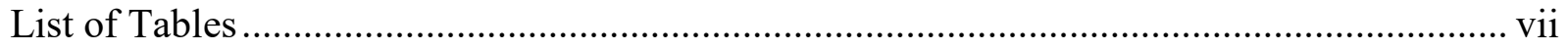

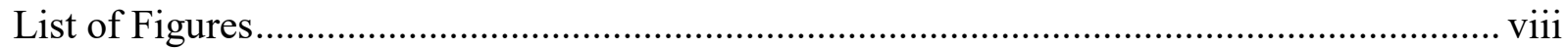

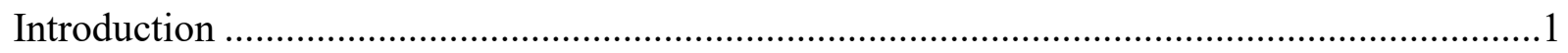

Background to the Problem and the Aims of this Study .............................................. 1

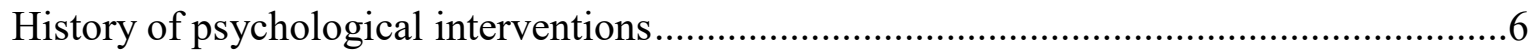

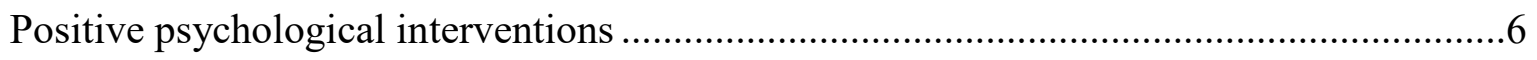

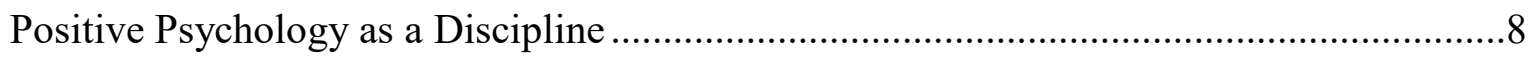

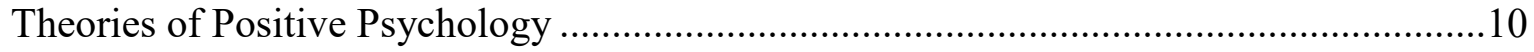

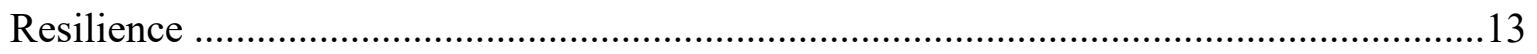

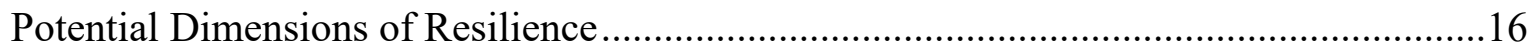

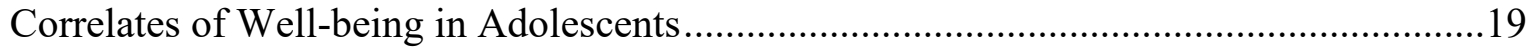

The Problem of Dissemination of Interventions........................................................22

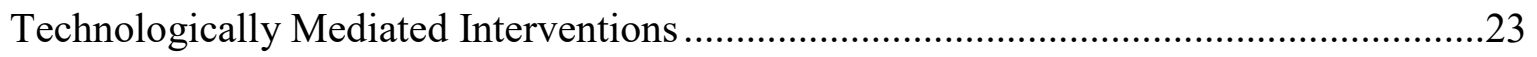

The Present Intervention: The 'Happy Wings' Smartphone Application .........................26

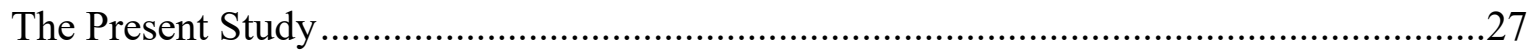

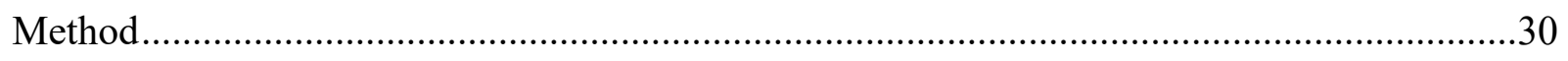

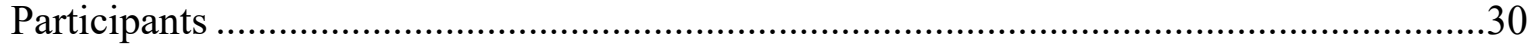

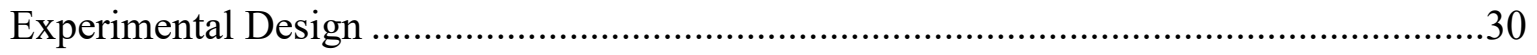

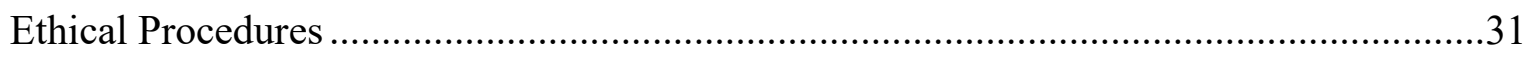

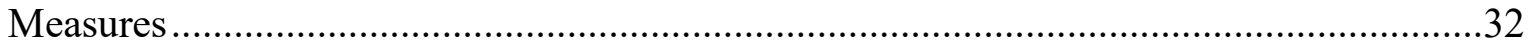

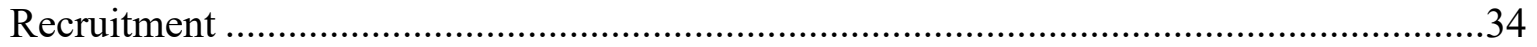

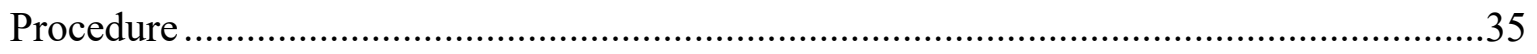

Development of the Happy Wings iPhone Application..................................................38

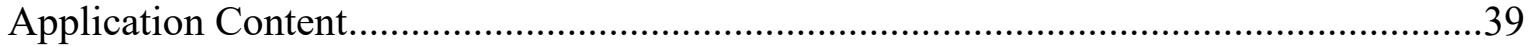

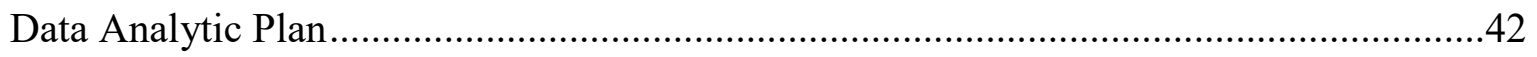

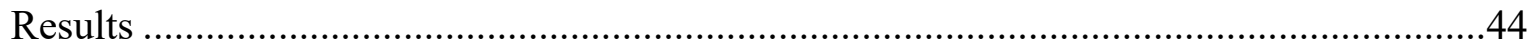

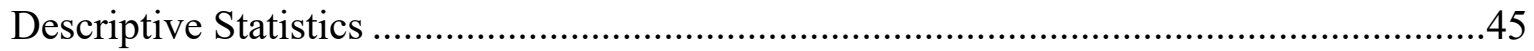

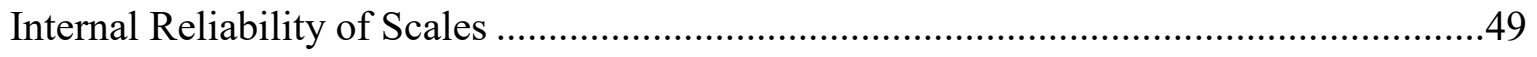




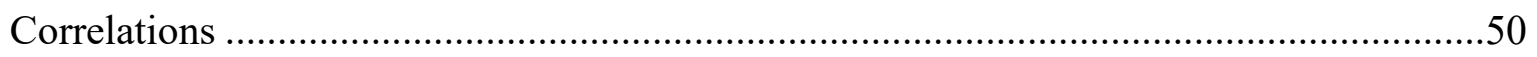

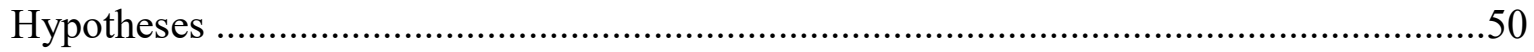

Group Differences in Positive Emotions: Hypothesis 1 .................................................51

Group Differences in Resilience, Well-being, and Happiness: Hypothesis 2 …….............54

Mediation of the Relationships between Adaptive Coping and Resilience and Positive

Outcomes of Subjective Happiness, Aggression, Depression,

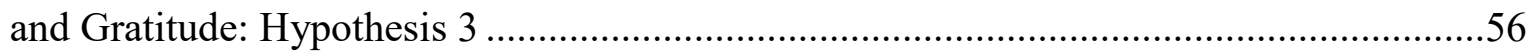

Descriptive Analysis of Data Captured by the App ........................................................58

Quest 1. 'Happy Album': Photo-taking Activity..................................................................59

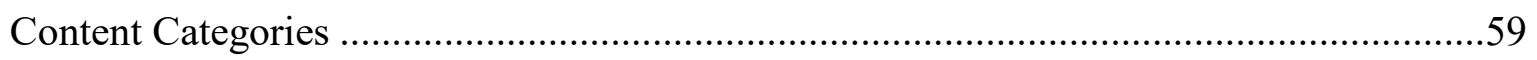

Quest 2. 'Your Strengths' (Part 1).............................................................................61

Quest 2. 'Character Strengths' Part 2. Ideal Future Selves ..............................................63

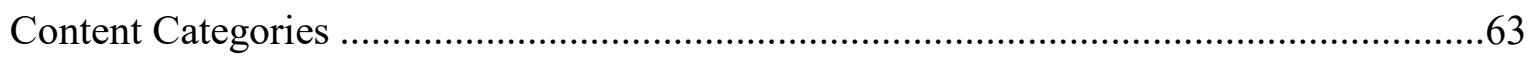

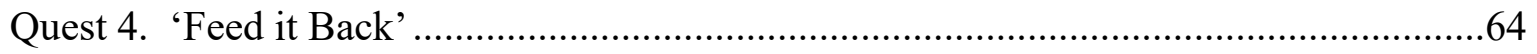

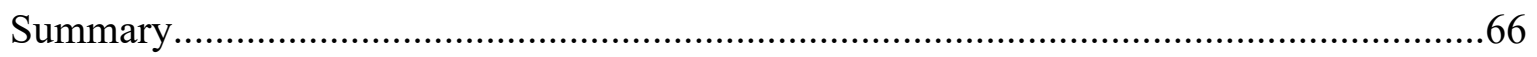

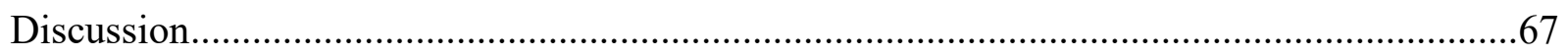

Group Differences in Positive Emotions at Post-Intervention, Gratitude,

Savouring and Self-esteem: Hypothesis 1

Group Differences in Psychological Well-being Variables, Resilience,

Happiness and Reduced Depression: Hypothesis 2 ……................................................70

Mediation of the Relationships between Adaptive Coping and Psychological

Well-being, (Subjective Happiness, Gratitude, and Reduced Depression

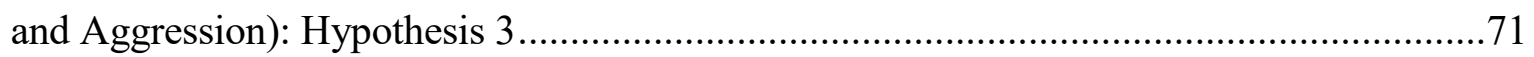

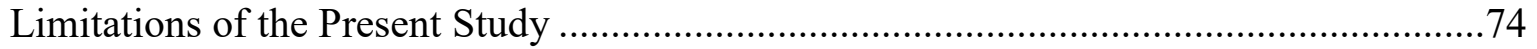

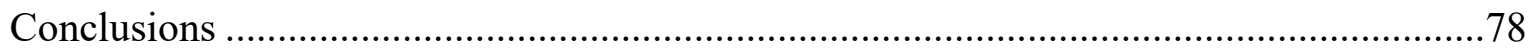

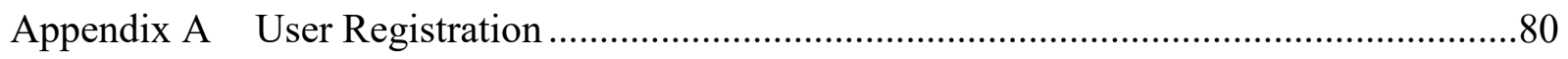

Appendix B Evaluation of Participants' Feelings about the App ...........................................8

Appendix C Participant and Parent Consent Form ...............................................................96

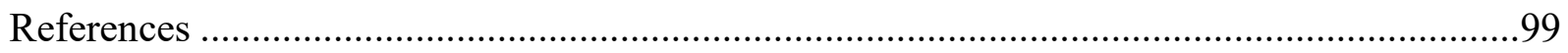




\section{List of Tables}

Table 1 Gender, Type, Decile, Number of Students and Authority of

School that Participated in testing the App

Table 2 Control group means (M) and standard deviations (SD) of dependent variables at times $\mathrm{T} 1$ and $\mathrm{T} 2$.

Table 3 Experimental group means and standard deviations of dependent

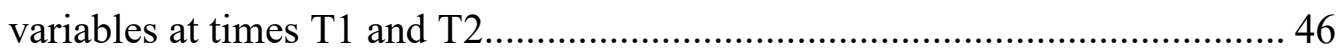

Table 4 Correlations among scales used in the present study at Time 1 ..................... 47

Table $5 \quad$ Correlations among scales used in the present study at T2 ........................ 48

Table 6 Information on all scales used in the survey............................................. 49

Table 7 Results from multivariate tests with savouring, gratitude and self-esteem as DVs ....................................................................... 51

Table 8 Results from univariate tests with savouring, gratitude and selfesteem as the DV 53

Table 9 Multivariate results with depression, resilience, happiness and social anxiety as DVs

Table 10 Results from univariate tests with depression, resilience, happiness and social anxiety as the DV ................................................. 55

Table 11 Percentage of each Quest completed by individuals ................................... 58

Table 12 How participants responded when asked to record what made them happy about their photos.

Table 13 Domain name, total statements available, number of statements selected, and example statement.

Table 14 How participants responded when $\{\mid$ CL6 $\mid\}$ asked what it would look like if they had achieved their goals in 12 months' time:

Table 15 How participants responded when asked to write a letter of gratitude 65

Table B.1 How participants responded when asked what prevented them from completing the app. 


\section{List of Figures}

Figure 1. Time and Number of Participants Who Received the Intervention.

Figure 2. Path model for adaptive coping, resilience, and outcomes of subjective happiness, aggression, depression and gratitude for the total sample. All path coefficients represent standardised regression weights.

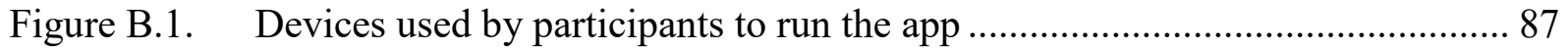

Figure B.2. How participants responded when asked where the app got stuck ................ 88

Figure B.3. How participants responded when asked if they remembered to do the app every day.

Figure B.4. Reasons participants gave when asked why they felt motivated to complete the app.

Figure B.5. shows how participants responded when asked to rate the level of difficulty of the quests

Figure B.6. shows how participants responded when about activity length. 92

Figure B.7. This shows how participants responded when asked how much they enjoyed the app.

Figure B.8. This shows how participants responded when asked which Quest they enjoyed the most (1-4).

Figure B.9. How participants responded when asked what age group they would recommend the app for. 


\section{Introduction}

\section{Background to the Problem and the Aims of this Study}

Traditional views on mental health focus on solving problems and reducing the presence of psychopathology, which contribute to poor mental health outcomes (Diener, 2000; Notter, 2013; Seligman \& Csikszentmihalyi, 2000). However, proponents of positive psychology assert that measuring negative affective states (e.g. anxiety and depression) provides a one-sided view of mental health, because it fails to account for the positive affective states (e.g. happiness and life satisfaction) that are required for optimal human functioning (Seligman \& Csikszentmihalyi, 2000). Positive psychology was developed as a result of the dissatisfaction with this onesided conventional model of mental health. The traditional problem-focused view in psychology has meant that programmes for young people have been generally focused toward the reduction of psychopathology (Csikszentmihalyi, 2000). Despite apparent changes in the view of psychological well-being in the last decade, mental health interventions for adolescents still tend to focus on addressing specific symptoms of maladaptive behaviour (e.g. using cognitive behavioural therapy to reduce anxiety or depression) (Notter, 2013), and programmes targeted toward both increasing wellbeing and reducing the presence of maladaptive outcomes are scarce by comparison.

Understanding how to increase psychological well-being among adolescents is important due to its associations with positive mental health, protective factors and other indicators of successful life outcomes. These indicators include academic achievement, relationship quality, resilience, and adaptive coping strategies.

However, research studies of interventions designed to increase adolescent well-being are still few in number compared to those developed for adults, and currently prevention programmes targeting maladaptive outcomes are more widely cited and discussed. A review of the literature shows that intervention studies targeting wellbeing in young people are a phenomenon that has emerged over the last decade. This new research shows that Positive Psychology Interventions (PPIs) can be successful in increasing well-being by teaching skills - such as enhancing positive emotions and building adaptive resources (e.g. individual character strengths) - that promote positive cognitions and behaviours that, in turn, result in more successful life outcomes and fewer negative ones (Froh, Kashdan, Ozimkowski, \& Miller, 2009; Froh, Sefick, \& Emmons, 2008). 
Despite the potential of positive psychological interventions (PPIs) to create positive change, currently few successful interventions for adolescents have been tested, identified, and delivered to large groups of adolescents beyond those participants involved in the initial evaluation of the intervention. Research indicates that the high resource cost for psychologists' and teachers' time to deliver interventions may explain why they are not more widely distributed (Schueller \& Parks, 2012). These limitations mean that programmes do not reach as many individuals as they could, yet one of the key goals of positive psychology is to maximise optimal functioning for as many individuals as possible. Some researchers have suggested that alternative methods of delivery, such as technologically mediated interventions may be an effective way of disseminating PPIs to large groups of individuals at a low cost (Parks, 2014; Sergeant \& Mongrain, 2014). There is a growing body of research to support the use of such methodologies, however, given the significant potential for technology to advance the accessibility and engagement of PPIs, at present these programs are underutilised (Wang et al., 2005).

Furthermore, a review of the literature shows that the mechanisms behind the change created by PPIs are not well understood (Notter, 2013; Sergeant \& Mongrain, 2013), and that pathways to well-being through resilience have often not been directly investigated. Historically it has been inferred that psychological outcomes (e.g. resilience) have increased due to enhanced positive outcomes (i.e. The Penn Resiliency Program) (PRP; Gillham, et al., 2007). Despite such studies, the literature shows there is a need for increased investigation of the mechanisms behind successful PPIs (Lyubomirsky \& Layous, 2013; Sergeant \& Mongrain, 2014). In line with this view, researchers have gained a better understanding of features that may impact on the success of PPIs (Lyubomirsky \& Layous, 2013). Yet without further investigation into the processes, which help effect change in successful PPIs, we still lack a sound understanding of the longitudinal processes by which positive intentional activities lead to increased psychological well-being.

Accordingly, research studying the pathways to well-being in adolescents now emphasises the need to investigate the mechanisms that effect change from a longitudinal perspective, in order to examine how well-being is impacted over time. In particular, a recent study by Notter (2013) has explored how mediational paths led to both increased well-being outcomes and decreased depression in a sample of adolescents. 
Notter's (2013) doctoral dissertation examined the efficacy of a positive psychology intervention among 134 high school students in New Zealand. Notter compared the impact of two different programs on adolescent outcomes, including depression and well-being (i.e. self-acceptance, positive relations with others, resilience and subjective happiness). Students were assigned to either the: 1) Kiwi Ace programme (Adolescents Coping with Emotions), 2) PAL programme (the Positive Approaches to Life), or 3) a no treatment control condition. Both programmes consisted of 12 one-hour sessions, but Kiwi Ace used CBT techniques and social skill development, and was targeted towards increasing coping skills in young people, whereas PAL consisted of positive psychological activities that were designed to foster happiness and cultivate positive emotion. PAL consisted of multiple PPI components (including gratitude, savouring, and character strengths among others). The results of Notter's (2013) study revealed that individuals who participated in Kiwi Ace reported lower depression and higher psychological wellbeing at immediate post-test, at six months, and one year later as compared to the control group. Those individuals who completed Kiwi Ace reported higher satisfaction with life and subjective happiness at the six-month follow-up, but not at post-test or one year later. Students who completed PAL reported not only lower depression and higher psychological well-being, but also more satisfaction with life and subjective happiness (post-test, six months, and one year later as compared to the control group). These findings indicate that the CBT-based intervention (targeting coping skills) resulted in decreased depression and increased well-being, whereas the positive psychology programme PAL (which incorporated several PPIs) resulted in both decreased depression as well as persistent and long-lasting increases in psychological well-being, subjective happiness and satisfaction with life.

Notter's study (2013) showed emotional regulation strategies to be key for developing resilience. The strategies included building emotional resources, and those that lead to positive cognition and behaviour such as gratitude, building relationships, individual character strengths, and savouring experiences. The aim of Notter's study was to enhance protective factors in adolescents, with a view to fostering positive outcomes and resistance against negative outcomes. Specifically, Notter's (2013) study showed that there were several mediating variables that operated between the positive intentional activities in the PAL programme, and the resultant positive outcome of resilience. These mediators were: 
happiness, satisfaction with life, and gratitude, and these findings supported research that shows positive emotions build resilience (Cohn et al., 2009; Tugade \& Fredrickson, 2004). Notter's (2013) study was unique, as it compared the effects of two group-based programmes (one teaching CBT 'cognitive behavioural therapy' strategies designed to reduced depression, and the other designed to teach the skills needed to adaptively regulate emotion). Notter's (2013) study illustrated that building positive emotions has lasting effects on resilience, which may be above and beyond that of preventative programmes. The study called attention to the importance of enhancing strengths and adaptive behaviours in order to promote positive change, and indicated the interventions used in PAL (Notter, 2013) to be a useful resource for work with adolescents in conjunction with, or separate from, preventative methods. Given the potential benefits for resources such as PAL to positively benefit adolescents, it is likely that wider implementation of similar programmes would be worthwhile. It has been suggested that the dissemination of PPIs might be achieved via online modes of delivery, and studies have shown promise for such programmes (i.e. using the Internet) (Manicavasagar, 2014; Parks, 2014).

However, it does not appear that any study has successfully implemented an online intervention in a smartphone format to give young people the tools to regulate positive emotion and ultimately increase resilience and well-being. There is evidence that online tools may be as effective (if not more so) in engaging individuals with intervention programmes. For example, a number of studies have provided evidence that online computer-based selfhelp interventions are more effective than control conditions (Gellatly et al., 2007; Marks, Cavagnagh, \& Gega, 2007; Newman et al., 2011). Furthermore, online tools offer a costeffective way of condensing training content into a manageable format for large groups of young people, ultimately meaning that online interventions may have a wider reach than conventional face-toface ones. Of particular interest to the current investigation is the question of delivering PPIs to the public. Specifically, the present research was directed at examining the translation of elements of an effective group-based programme (Notter's PAL programme, 2013) into a more accessible medium (smartphone). The adaptation of positive psychology techniques applied in an online format (i.e. disseminated via the Internet or smartphone) are known as ‘online positive psychology interventions' (OPPIs), and researchers 
have acknowledged that PPIs may be ideal for online delivery (Schueller \& Parks, 2012), due to the brevity of the strategies that such interventions use (i.e. gratitude diaries).

In order to investigate the relationship between positive intentional activities, positive emotion and psychological well-being in adolescents, this thesis will examine how a set of three positive psychological interventions (delivered in the four quests in the 'Happy Wings' app) which are aimed to increase positive emotion and cultivate individual character strengths, may impact adolescent well-being. The following will first review the literature on psychological interventions and subsequently define theoretical constructions of psychological well-being. Next, key theories of positive psychology will be defined and described as potential explanations for the efficacy of PPIs. Then, the constructs of gratitude, savouring, character strengths, happiness, coping, and resilience will be discussed, before an exploration of the potential predictive value of these constructs on well-being. Finally, possible online methodologies of delivering positive psychology interventions will be examined.

This literature will provide the foundation for the current investigation of whether an online PPI aimed to increase positive emotion and cultivate individual character strengths would positively impact adolescent well-being. We sought to examine whether an existing positive psychological intervention for youth (Notter's PAL programme, 2013) could be effectively developed into a set of online modules covering three elements of positive emotion regulation, specifically: gratitude, savouring, and building individual character strengths. This study showed that learning to cultivate positive emotions such as gratitude and happiness were more effective in building resilience for adolescents at risk of depression than CBT-based techniques. Notter's study further revealed possible pathways to increased well-being and resilience for young people through a facilitator-led positive psychological intervention. Specifically, involvement in PAL led to increased resilience scores through increases in happiness, gratitude and satisfaction with life. As Notter's (2013) PAL programme was group-based and facilitator-led, the present study is a natural extension of her work, as it explores an alternate method of delivering similar content to adolescents.

Notter's (2013) study's results were congruent with previous literature suggesting that developing strategies for promoting and regulating positive affect can have on-going benefits, beyond safe-guarding against maladaptive behaviour (i.e. depression and anxiety). Other such positive intervention studies have found similar results, showing that school-based 
programmes can help meet academic, emotional and social needs of young people while also encouraging well-being (Gillham, Reivich, Freres, Chaplin, Shatté, Samuels, Litzinger, Lascher, Gallop, \& Seligman, 2007; Wassef, Ingham, Collins, \& Mason, 1995). These findings guide the current study, as they suggest that positive psychological interventions may be an effective way of boosting individual resilience and positive outcomes in adolescence.

\section{History of psychological interventions}

Deficit versus strengths-based model. The traditional view of mental health has been deficit-based rather than strength-focused. Many treatments have been developed for psychological disorders, directed toward reducing the presence of psychopathology, as it contributes to poor mental health outcomes (Diener, 2000; Notter, 2013; Seligman \& Csikszentmihalyi, 2000). Efficacy has been established for cognitive behavioural therapy (CBT) for treating disorders such as anxiety and depression (Birmaher et al., 1996). Research shows these traditional treatments have been primarily targeted toward the reduction of maladaptive outcomes, and do not specifically target the skills and resources that foster wellbeing (Norrish \& Brodrick, 2009; Notter, 2013). Although these treatments have a number of strengths, proponents of positive psychology assert that measuring negative affective states provides a one-sided view of mental health, as psychopathology is only one component of optimal mental health (Rashid, 2009). Research suggests that developing positive affective states (e.g. happiness and life satisfaction) may promote optimal human functioning (Seligman \& Csikszentmihalyi, 2000) by helping individuals to foster the tools and resources to respond to challenges (Fredrickson, 1998; 2001). Evidence shows that positive mental functioning is more than simply the absence of psychopathology (Diener, 1984; Notter, 2013), but researchers have argued that enhancing an individual's psychological resources improves their ability to cope with difficulties by building skills and resources, which protects them from negative influences and increases their psychological well-being over time (Notter, 2013).

\section{Positive psychological interventions}

With the recognition of the benefits of positive affective states, practitioners have focused on developing strategies aimed at increasing happiness. Interventions developed specifically to target positive psychology constructs associated with wellbeing (i.e. gratitude) have been shown to improve successful life outcomes such as happiness, adaptive coping 
resources, and resilience, and these programmes have collectively been called positive psychology interventions (PPIs) (Seligman, Rashid \& Parks, 2006). PPIs have been described by Sin and Lyubomirsky (2009) as the programmes, practices or strategies 'aimed at cultivating positive feelings, positive behaviours, or positive cognitions' (Sin \& Lyubomirsky, 2009). Positive psychology intervention programmes are different to conventional prevention programmes because they seek to identify and enhance the strengths within individuals that can foster adaptive strategies, rather than purely focusing on reducing the practice of maladaptive strategies such as rumination or self-blame (Notter, 2013).

Findings from positive psychological research provide evidence that if individuals are taught to use effective emotion regulation strategies (where they can elicit, maintain and moderate their emotions), psychological well-being may be promoted (Seligman, Steen, Park, $\&$ Peterson, 2005). Some of the most successful and well-documented positive psychology interventions have focused on gratitude, savouring, and individual character strengths interventions that have been shown to improve well-being in both adult and adolescent samples. Sin and Lyubomirsky (2009) reviewed the growing body of research that shows that PPIs can work well in their meta-analysis that reviewed the results from 49 PPI studies, and found that $96 \%$ of these studies reported improvements in well-being. Sin and Lyubomirsky also found that out of 25 PPI studies targeting the reduction of depressive symptoms, PPIs successfully did so $80 \%$ of the time (Sin \& Lyubomirsky, 2009). This work has been supported by a more recent meta-analysis by Bolier et al. (2012) who reviewed 39 studies (a total of 6,139 participants), and found support for the efficacy of PPIs. Their work showed PPIs to be successful at increasing well-being and reducing depression for periods of between three to six months, and showed that the positive change effected by PPIs might be sustainable. The weaknesses of Sin \& Lyubomirsky and Bolier et al.'s (2013) studies were that there was a shortage of randomised controlled trials available for review. This was due in part to the fact that many PPI studies have not used control groups (Wood, Froh, \& Geraghty, 2010), and often studies have not been followed up over time (Rosenthal, 1991). Given this paucity of evidence, the current study will endeavour to provide a controlled study, where a wait-list control group will be used, and participants from both control and intervention groups will be tested before and after the intervention. 
Understanding the nature and trajectory of successful PPIs has become increasingly important given the potential for new mental health opportunities (Mitchell et al., 2009). Due to the mixed success rates from PPI studies, it has become evident that there is not sufficient understanding of the factors that predict successful PPIs (Layous, Chancellor, \& Lyubomirsky, 2014). In line with this idea, researchers have asserted that future PPI studies should conduct more detailed examinations of the features of successful programmes to identify the conditions, populations, and factors most conducive for their success (Lyubomirsky \& Layous, 2013). Although studies have provided support for the use of PPIs for increasing well-being, critics of positive psychology suggest that the field is overly simplistic, failing to account for individual differences, for example; those individuals that use pessimism as an adaptive strategy to help them plan and perform under pressure (Norem \& Chang, 2002; Schwartz \& Grant, 2011). This perspective facilitates consideration of factors in PPIs, which can negatively reduce well-being. Taken together, these works indicate that more examination of the mechanisms behind successful PPIs is warranted. Thus, a standard of high quality programmes may be delivered to individuals in the future.

\section{Positive Psychology as a Discipline}

Positive psychology is the study of optimal healthy human functioning, particularly the emotions, cognitions and processes which support happiness and mental well-being (Gable \& Haidt, 2005). Positive psychology emerged, in part, as a counter response to views of mental health that are focused toward addressing or preventing maladaptive behaviour (Seligman \& Csikszentmihalyi, 2000). It has been argued that the absence of maladaptive behaviour is not synonymous with happiness and optimal functioning (Huebner et al., 2009), and given that individuals without adaptive strengths and resources may be at higher risk of poor mental health outcomes (Notter, 2013), a better understanding of the variables and processes leading to optimum functioning is needed (Linley, Joseph, Harrington, \& Wood, 2006).

There is evidence to suggest that there are different routes to well-being and depression (Diener \& Emmons; 1984). In line with this, Notter's (2013) study was consistent with the broaden and build theory (Fredrickson, 1998; 2001), and revealed there are numerous pathways to positive outcomes and well-being in adolescents. This study indicates that since different interventions affect well-being differently, it may be worthwhile to consider using different strategies to achieve specific outcomes. Therefore, there is a need for programmes to 
be designed specifically to increase well-being, instead of relying on preventative programmes to increase well-being by proxy of relieving psychopathology. Much more longitudinal research is needed into how interventions targeting different constructs of well-being may impact individuals' future psychological functioning.

Subjective happiness (psychological well-being). Happiness is the goal of positive psychology (Diener \& Diener, 1996). It is characterised by the experience of more positive affective states than negative ones, plus the sense of having achieved desires and goals (Tkach \& Lyubomirsky, 2006). In the positive psychological literature, happiness is commonly referred to as subjective well-being, or well-being (Diener, Suh, Lucas \& Smith, 1999). Well-being has been operationalised by Diener as 'both cognitive and affective selfevaluation of one's life and experiences' (Diener, 1994, p 4). Components of well-being have been reported to be three distinct but related constructs: 1) high frequency of positive affect, 2) low frequency of negative affect, and 3) high level of life satisfaction (Diener et al., 1999).

Ultimately, combining these factors would seem to result in genuine and sustainable happiness (Vella-Brodrick, Park, \& Peterson, 2009; Carruthers \& Hood, 2004). The consensus among positive psychologists is that happiness may result from developing individual strengths, positive emotions and achieving one's goals (VellaBrodrick, Park, \& Peterson, 2009). In keeping with this view, it follows that individuals with high well-being have lots of positive emotions, few negative emotions and a generally positive view of events in their lives (Diener, 1994). These findings indicate that positive psychologists should develop strategies and deliver programmes that can: 1) teach individuals to cultivate positive emotions (such as gratitude), and 2) foster adaptive strategies to increase their psychological resources (such as individual character strengths). In sum, if these programmes are effective, they may both prevent dysfunction and enhance well-being (Notter, 2013).

Research has focused on exploring traits common to happy individuals and identifying the precursors to happiness (Diener, 2000). Investigation of the features and behaviours of happy people has shown they display positive emotions such as gratitude, optimism and hope for the future (Lyubomirsky, 2001). This notion is supported by studies that show these constructs have been widely studied among positive psychologists as pre-cursors to happiness, and have also been associated with resilience and well-being (Masten, 2001; Werner \& Smith, 
1992). Happy individuals have been shown to obtain more successful life outcomes (including work, relationships and physical health), and to develop advantageous personal attributes such as self-esteem, creativity and coping (Lyubomirsky \& Layous, 2009; Lyubomirsky et al., 2005), and exhibit less psychopathology (Abbott et al., 2006; Diener \& Seligman). These results have endorsed the importance of developing happiness, and have led positive psychologists to believe that interventions targeting constructs found to occur in naturally happy individuals, if successful, may result in sustained increases in happiness and well-being (ref).

Well-being interventions. In agreement with the focus on happiness increasing strategies, positive psychologists have identified intentional positive activities as a successful way to increase happiness and well-being. Happiness was traditionally thought to develop largely as a result of genetic factors (Apley, 1971). However, genetic factors alone have been argued to be an inadequate predictor of how happiness develops. Lyubomirsky, Sheldon, and Schkade (2005) challenge theories that happiness is purely genetically determined, and assert happiness can be intentionally enhanced. Their three-factor model posits that $40 \%$ of the variance in happiness can be explained by intentional activity. This finding may indicate that people may be able to learn to successfully increase happiness if they are taught effective strategies (i.e. regulating positive emotions by practising gratitude). These findings have implications for psychologists interested in amplifying adolescent wellbeing, as they indicate that intentional strategies used in PPIs work. This approach may be especially useful for adolescents learning to adjust to this tumultuous developmental phase. A well-documented theory that explains how cultivating positive emotions works, is Fredrickson's $(1998 ; 2001)$ broaden-and-build theory of positive emotions.

\section{Theories of Positive Psychology}

Frederickson's broaden and build theory of positive emotions. Fredrickson's broaden and build theory explains how the experience of positive emotions may lead to increased resilience, psychological well-being, and future successful life outcomes (Fredrickson, 1998; 2001). The model suggests that the experience of positive emotion (i.e. happiness and joy), promotes adaptive thoughts and behaviours that if repeated over time, result in cognitive changes that broaden individuals' 'thought-action tendencies,' i.e. gives individuals a sphere of new possibilities in thought and action (Fredrickson, 2001). Fredrickson asserts that these 
benefits occur momentarily, while individuals are experiencing positive affect (Fredrickson, 1998; 2001). Studies have supported the effects of positive emotions on cognition, for instance increased focus (Derryberry \& Tucker, 1994), flexible thinking and memory (Isen, 1987), and on social resources (Oatley \& Jenkins, 1996), and intellectual resources (Bryan, Mathur, \& Sullivan, 1996). These works indicate that the experience of positive emotions helps to equip individuals with skills and resources to help them function in the face of adversity. These findings indicate positive emotions may promote multiple areas of optimal functioning, and findings suggest that one indicator of optimal functioning is resilience. A closer look at both PAL (Notter, 2013) and the present intervention reveal that their activities have the functionality to provoke positive emotional experiences. For instance, learning to practice gratitude (Froh et al., 2008), a habit that may help individuals to learn to regulate positive emotions, leading to higher well-being, fewer depressive symptoms and thus psychological resilience (Fredrickson, 2001). It is important to note that both Notter's PAL programme (2013), and the present app were based on Fredrickson's broaden and build model. As it has been widely established that positive emotion is key for resilience, the role of both negative and positive emotion will be discussed in this thesis, including the importance of emotional regulation.

Fredrickson, Cohn, Coffey, Pek, and Finkel (2008) have empirically assessed the broaden-and-build theory (Fredrickson, 2001). The authors taught 139 participants to build positive emotion through a loving-kindness meditation PPI, where they were prompted to increase positive feelings towards themselves and others. Following six one-hour sessions, those individuals who practiced the loving-kindness meditation reported higher levels of positive emotion when compared to a control group. These results were then associated with increased adaptive resources (i.e. positive social relationships, self-acceptance and physical health) (Fredrickson et al., 2008). This study supported the idea that the development of personal resources followed increased positive emotion, and that these resources had the potential to be built upon for continued increases in well-being and successful outcomes in future.

Positive and negative emotions. In order to understand Frederickson's theory of positive emotion, the constructs of positive and negative emotion need to be defined. An emotion can be described as a subjective experience that occurs with biological and behavioural changes. Emotion involves thoughts, physiological changes and behavioural 
changes. According to Frederickson, an emotion is usually the result of an individual assessing the personal meaning of an event (Frederickson, 2001). She states that this may happen consciously or unconsciously, and that this 'appraisal' results in immediate responses within the individual (cognitive processes, facial expression, and subjective experience), for instance, contentment or love (Fredrickson, 2001).

Negative emotions can play an adaptive role for individuals (Frederickson, 2001), for example, the narrowing of attention that occurs in a situation of threat (e.g. flight or fight) (Tugade, Fredrickson, \& Barrett, 2004). Over the long term, negative emotions have been shown to lead to enhanced performance and growth (Norem \& Chang, 2002). However, despite their adaptive role, it has been widely recognised that if negative emotions linger, or occur more frequently than adaptive coping responses to stress, the effects may be detrimental for psychological well-being (Clark \& Watson, 1991). Research has shown negative emotions to be related to maladaptive behaviours such as anxiety and depression if an individual cannot adaptively manage stress (Nolen-Hoeksema, 1991). Depressed individuals exhibit less positive emotion and more negative emotion after a negative event, than do non-depressed individuals (Nolen-Hoeksema, 1991). Increased positive emotions can 'undo' or buffer individuals from the negative effects of stress (Fredrickson \& Levenson, 1998). These studies indicate that both negative and positive emotions have adaptive benefits, thus it is an individuals' ability to adaptively respond to situations that determines outcomes. In line with this view, the next section will consider the impact of an individual's ability to regulate emotions during stressful situations, and how this may impact on their happiness and wellbeing.

Emotional regulation. Emotional regulation refers to an individual's ability to regulate their emotions by bringing out, intensifying, or denying them (Gross, 2002). Regulation of emotion can also refer to the way people intentionally change their emotional reactions, and processes they use to navigate the intensity (Gross, 2002). It refers to using conscious and intentional strategies following an emotional experience (Gross, Richards, \& John, 2006). It has been shown that individuals with more developed emotional regulation skills have more control over how they interpret emotional experiences and express their emotions (Gross et al., 2006, Thompson, 1994). This ability to effectively manage emotion is important for an individual's optimal functioning, as people who report more positive emotion 
and less negative affect are shown to be happier (Diener et al., 1999). The ability to regulate emotion should not be underestimated, as those individuals with highly developed emotion regulation skills have been shown to actively choose to experience more positive emotions and fewer negative emotions (Fredrickson, 2001).

Research indicates that the ability to regulate emotions using intentional strategies is a skill that can be taught (Davidson, 2000; Tugade \& Fredrickson, 2007). These findings provide evidence for the use of the positive intentional strategies that are commonly used in PPIs (e.g. gratitude, savouring, optimism, and character strengths). The literature shows that individuals who have learned such skills experience positive consequences for well-being, resilience and other successful life outcomes (McCullough, Kilpatrick, Emmons, \& Larson, 2000; Fredrickson, 2000).

This perspective has been supported by previous studies that have shown recent emotional regulation is a skill found in highly resilient individuals (Notter, 2013).

\section{Resilience}

Research has indicated that positive emotions are central to resilience (Cohn et al., 2009; Werner \& Smith, 1992; Wolin \& Wolin, 1993), as they provide individuals with the ability to cope with negative emotions and life events (stressful situations) (Davidson, 2000). A study by Tugade and Frederickson (2004) found that individuals who reported high levels of resilience also reported more positive emotion when experiencing a stressful life event. Furthermore, longitudinal studies show that positive emotions play a role in developing longterm positive resources such as increased resilience and flourishing (Fredrickson, 2003). Cohn and Fredrickson (2006) assert that individuals who experience more positive emotion show greater psychological well-being and future successes (Cohn \& Fredrickson, 2006).

Therefore, positive emotions are key for buffering individuals against the harmful physical and psychological effects of stress, and may influence future wellbeing and success (Folkman \& Moskowitz, 2000; 2004). Additionally, individuals who experience higher levels of positive emotions evidence subsequently improved psychological outcomes compared to their less positive peers (Fredrickson \& Levenson, 1998; Fredrickson, Mancuso, Branigan, \& Tugade, 2000). It is likely that developing adaptive resources may play a protective role for individuals, by way of building resilience so they can more easily deal with negative events in the future (Folkman \& Moskowitz, 2000; 2004). Sin and Lyubormirsky provided evidence for 
this phenomenon known as the 'undoing hypothesis.' Their study found that in eighty percent of studies using intentional activities designed to increase positive emotion, that when positive emotion increased, depressive symptoms decreased (Sin \& Lyubormirsky, 2009). These findings indicate that some PPIs can serve a dual function of both increasing positive emotions and decreasing negative affect (Sergeant \& Mongrain, 2014). As mentioned above, Frederickson's $(1998 ; 2001)$ theory explains that the benefits of positive emotions lead to the development of lasting skills and resources, (i.e. adaptive coping strategies) that have been found in resilient individuals (Coutu, 2002; Dumont \& Provost, 1999; Everall et al., 2006; Jones \& Bright, 2001).

Relationship between resilience and adaptive coping. Although the constructs of resilience and adaptive coping seem to be related as they both promote the use of adaptive skills and resources, the literature indicates that they are distinct concepts. Adaptive coping refers to the ability to negotiate stress and to prevent harm (Lazarus, 1993), and research shows that individuals who use adaptive coping strategies also display improved life outcomes (Compas et al., 2001; Folkman \& Moscowitz, 2000). While adaptive responses to stress are important, resilience encompasses a broad set of 'resilient' strategies, arguably including adaptive coping (Masten, 2014). That is, resilience refers to one's ability to 'bounce back', or adaptively respond to situations, in a way that leaves the individual to further develop their adaptive strategies (Waller, 2001). Previous research indicates that the relationship between resilience and coping should be further examined, due to the fact that factors commonly found in resilience research for young people, often involve the development of effective coping strategies. These conceptualisations, including Fredrickson's (1998; 2001) theory, indicate that it is possible that adaptive coping strategies, resilience, and positive emotion in adolescence may influence feelings of psychological well-being and adaptive behaviours later in the life course (Masten, 2014).

Resilience as a process. There are a number of studies which link positive emotional experience to resilience (Tugade et al. 2004). In a study by Hjemdal, Friborg, Stiles, Martinussen, and Rosenvinge (2006), the researchers measured the associations between resilience with positive and negative indicators of mental health (e.g. positive relationships and aggression, respectively). The study showed that high levels of positive attitude were correlated positively with the strategies of reinterpretation and problem solving, but negatively 
with avoidance coping, and high levels of helplessness/alienation were related positively to avoidance. Such studies seek to understand the mechanisms that may promote well-being and reduce maladaptive outcomes. An implication of Hjemdal et al.'s (2006) work is that researchers can identify the relationships between protective and risk factors, as measuring these dynamics may inform PPIs on how resilience can be enhanced (Notter, 2013). In Hjemdal et al.'s (2006) study, 15 protective factors were found to contribute to increased resilience, and the authors concluded it is likely that resilience can be enhanced via promotion of protective factors. In adolescents, Notter (2013) explicitly sought to build resilience through supporting the development of protective factors by building students' capacity for positive emotions, and found the construct of resilience was fostered by a variety of different variables (satisfaction with life, subjective happiness, gratitude). Notter's (2013) study showed that using positive intentional activities to enhance well-being and happiness seems to 'broaden and build' a young person's ability to weather stressful events (Fredrickson, 1998; 2001).

Literature on the working mechanism of psychological resilience has shown that resilience is promoted by fostering constituent aspects of resilience, (i.e. adaptive coping or increasing positive emotion), as these positive emotional strategies promote resilience, which in turn supports the development of greater well-being. For example, individuals' personal resources (i.e. coping skills (Benzies \& Mychasiuk, 2009), pro-social behaviour, and selfregulation) are closely related to the positive emotional experiences that contribute to resilience (Masten \& Coatsworth, 1998).

It may be possible that these protective factors can be developed in order to enhance resilience (Masten et al., 1991). It has been hypothesised that interventions that emphasise adaptive behaviours and personal coping resources will be effective in creating change, as they will help individuals foster self-regulation to protect themselves from future adversity (Olsson et al., 2003).).

Positive psychology interventions and resilience. PPIs have been developed with the aim of fostering psychological resources to increase well-being and in turn psychological resilience (Masselink, 2013; Notter, 2013). Research has shown resilience to be linked with improved recovery from stress, and positive psychological well-being in intervention studies (Fredrickson \& Levenson, 1998; Fredrickson, Mancuso, Branigan, \& Tugade, 2000). 
Resilience-building programmes placed in schools such as the Penn Resiliency Programme (PRP) (Seligman et al., 2009) have assessed and found improvements on self-reported measures of well-being and learning, which the researchers concluded showed enhanced resilience among the students. It has been suggested that the constructs of coping and resilience are related (Campbell-Sills, Cohan, \& Stein, 2005), and that resilience is a natural by-product of human adaptation (i.e. adapting or coping with negative stressors) (Masten, 2001).

Results from resilience interventions indicate that resilience can be increased by using PPIs to target protective factors, as research has shown that building positive assets and resources in adolescents buffers the negative effects of stressors (Masten, 2001; Masten et al., 1988).

However, a review of the resilience research indicates there is not yet a consensus about how to measure and operationalise resilience (Notter, 2013). Notter (2013) has asserted that programmes such as The Penn Resiliency Programme (PRP), (Seligman et al., 2009) have often not measured resilience directly, but rather measured the change in factors associated with resilience (e.g. mitigation of risk factors), as an indication of enhanced resilience. Notter has argued that more direct measurement of the mechanisms that constitute resilience is needed. The present study assessed several key constructs of positive psychology that are thought to underlie resilience (Masten, 2001), e.g. gratitude, savouring, and individual character strengths. Positive psychologists have been concerned with measuring these constructs, as they have been seen as adequate predictors of well-being.

\section{Potential Dimensions of Resilience}

Gratitude. The theory behind gratitude demonstrates that those who show thanks and appreciate events and experiences are happier (Froh, Yurkewicz, \& Kashdan, 2009). This, in turn, indicates that there is an avenue that we can use to promote happiness. Gratitude has been described as an orientation towards noticing and appreciating the positive outcomes or experiences in life (Wood et al., 2008), and has been significantly associated with positive affect, life satisfaction, happiness, optimism, social support, pro-social behaviour and an enhanced sense of community (Froh, Yurkewicz, \& Kashdan, 2009; Emmons \& Sheldon, 2002). People with higher levels of gratitude have been shown to report more positive outcomes and higher life satisfaction and well-being (Froh et al., 2010). 
A number of studies suggest that gratitude is an adaptive psychological response that helps to promote positive outcomes such as social relationships (Algoe, Haidt, \& Gable, 2008).

Savouring. Savouring is the ability to appreciate and enhance enjoyable experiences. Bryant and Veroff (2007) assert that the savouring process promotes gratitude because focusing on positive things that we attribute to others tends to foster a grateful and positive state. Research shows that being able to savour positive experiences can increase an individual's existing happiness, by prolonging the experience of positive emotions that make people feel good. Savouring can also contribute to positive well-being in the future (Bryant, 1989; Bryant \& Veroff, 2007). Also, research shows that those individuals who more regularly savour past positive events displayed significantly higher well-being than people who tended to reflect less about positive and more about negative events (Bryant \& Veroff, 2007).

While savouring has a tendency to be automatic, there is evidence to suggest individuals can learn the practice and use this intentionally (Notter, 2013). Interventions targeting savouring by prompting individuals to enjoy the moment (for example by 'counting blessings') have been shown to predict well-being and happiness (Jose, Lim, \& Bryant, 2012), and other savouring interventions have predicted decreased depression in clinical and nonclinical samples (Seligman, Rashid, \& Parks, 2006; Hurley \& Kwon, 2012). In sum, efforts to increase savouring have been shown to promote positive emotions and happiness.

Positive Interventions for Adolescents. As outlined above there is a growing body of intervention research around increasing well-being. However, the majority of studies seeking to increase well-being and decrease rates of depression have targeted adults (Notter, 2013). There is a paucity of research around whether the above interventions work with adolescents. Therefore, it is important to consider the existing programmes for adolescents, and to identify the gaps in the research base for innovations for the future. Related research and current methods used to deliver these programmes are discussed below, before suggestions are made for alternate ways to deliver these programmes by making use of online technology. I will first consider the role of identifying character strengths as an intervention.

Character strengths. Character strengths are defined as "a pre-existing capacity for a particular way of behaving, thinking, or feeling that is authentic and energising to the user, 
and enables optimal functioning, development and performance” (Linley, 2008, p. 9). Proctor, Maltby, and Linley (2009) reported that people who used their strengths more frequently reported higher levels of subjective well-being, confidence, self-esteem and psychological vitality. Interventions that develop character strengths have the capacity to increase an individual's well-being and reports of happiness (Seligman et al., 2005).

Peterson and Seligman, (2004) stated that there are intrinsically valued traits, characteristics and behaviours of individuals (e.g. persistence and love of learning), which, when practiced, predict higher well-being (Peterson \& Seligman, 2004). These strengths have been classified in an inventory named Values in Action ('VIA') (Seligman \& Peterson, 2001), with the aim of classifying positive mental states in a similar way as the DSM-4 has done for maladaptive states. Thus, the inventory can be used to help individuals reach their optimum potential by identifying new or more frequent ways to use one's strengths. Studies have shown that helping individuals develop their strengths is predictive of increased well-being and higher self-esteem (Proctor, Maltby, \& Linley, 2009).

Research has investigated the mechanism by which individual character strengths may lead to well-being. Linley et al. (2010) have demonstrated that there is a connection between well-being and individual character strengths, because the strengths prompt individuals to progress goals and meet needs relating to positive relationships and competence. Others have focused on the impact of using strengths in decreasing the likelihood of depression and increasing life satisfaction (Peterson \& Peterson, 2008).

Theory and research regarding methods of increasing psychological wellbeing have provided considerable grounding in the literature that has focused on the adult population. As previously discussed, adolescence is a period of transition that prepares individuals for adulthood. This period has the potential to foster adaptive resources to promote optimal mental health. Therefore, a review of the research that has been extended into interventions targeted toward youth is important to examine, with the aim of considering impacts of developmental factors on outcomes.

Interventions with adolescents. Evidence exists to suggest positive psychology interventions developed for adolescents that cultivate the constructs of savouring (Chadwick, 2012); gratitude (Froh, Sefick, \& Emmons, 2008), and character strengths (Proctor et al., 2011) can positively impact on adolescent wellbeing by lowering stress. Research shows that 
cultivating these skills builds emotional and social resources (Weissberg, Kumpfer \& Seligman, 2003). Furthermore, researchers argue that adolescence is an ideal time to foster adaptive coping strategies, because it is a life period marked by changes in cognitive processes and behaviours (Park, 2003). Positive education has been defined by Seligman, Ernst, Gillham, Reivich, and Linkins (2009) as an approach to education that fosters traditional academic skills and skills for happiness and well-being. Considerable evidence has accumulated to suggest that positive education programmes predict adolescent wellbeing, social relationships, and academic performance (Seligman et al., 2009). Additionally, research shows that the skills for regulating positive emotions and resilience can be taught successfully to adolescents in the school environment, without detracting from academic outcomes (Seligman et al., 2009). A review of the literature indicates that teaching well-being alongside academic pursuits may promote learning and academic achievement (Bernard \& Walton, 2011; also see Durlak, Weissberg, Dymnicki, Taylor, \& Schellinger, 2011 for a review).

Coping in adolescence. Adolescence is a period of development where individuals are at risk of developing maladaptive psychological or social behaviours (Rutter, Graham, Chadwick, \& Yule, 1976). Despite this danger, adolescence has also been described as a period of flexible thinking and change. As adaptive coping is a stable indicator of well-being, it has been one of the most regularly targeted constructs in youth well-being programmes. Compas et al. (2001) defined coping as an ability to adapt to situations by using personal skills and resources. Lazarus and Folkman (1984) laid out a model of coping where cognitive processes act to interpret the experience and help the individual construct a useful response. They describe cognitive appraisals as a function where individuals evaluate the significance of events. Notably, the coping process has usually focused on the outcomes of psychopathology and coping. It may be important to examine how constructs such as coping may be related to well-being, in order to better understand better how coping may be fostered in adolescents, as current findings are unclear about the development of adaptive coping skills. Compas et al. (2001) have suggested longitudinal data should be examined to enhance understanding of coping in adolescent well-being.

\section{Correlates of Well-being in Adolescents}

Teaching gratitude to adolescents. The effects of gratitude interventions with adolescents have been shown to be associated with many positive outcomes, and have been 
shown to be an effective way of producing grateful thoughts and feelings (Emmons \& McCullough, 2003; Sheldon \& Lyubomirsky, 2006). Gratitude has been significantly related to successful longer-term outcomes such as positive affect, satisfaction with life, optimism and pro-social behaviour, self-esteem and well-being (Froh, Yurkewicz, \& Kashdan, 2009). Froh et al. (2010) argue that gratitude increases well-being by promoting positive social integration, which is associated with better academic outcomes, life satisfaction, self-esteem and happiness. The most successful indicators of gratitude as a precursor to happiness in young people have been found in intervention studies using the 'gratitude journal' and 'gratitude letter' (Emmons \& McCullough, 2003; Sheldon \& Lyubomirsky, 2006). Froh, Sefick, and Emmons (2008) implemented a gratitude intervention in high schools with samples numbering over 200 students. They found that using 'counting blessing' interventions, where 11-, 12- and 13-year-olds were asked to keep a daily gratitude journal for two weeks vs. a daily hassles journal for two weeks, resulted in an increase in gratitude, optimism, and life satisfaction (compared to students in hassles and control condition).

While the efficacy of gratitude interventions has been established in a growing number of studies with adolescents, evidence has suggested that benefits of some programmes targeting gratitude may not be equally effective for all individuals. A study by Froh, Kashdan, Ozimkowski, and Miller (2009) compared the effects of a gratitude intervention, showing that levels of gratitude increased more for those individuals lower in positive affect, than those individuals with higher affect at baseline. This result indicated possible floor effects, meaning that it is possible that interventions may be more effective for targeting maladaptive symptoms. What needs further work is exploration of the mechanism behind the paths from gratitude to wellbeing. Some research by Froh, Sefick, and Emmons (2008) has identified possible pathways using mediation analyses, showing that gratitude promotes social integration by enhancing pro-social behaviour. However, the considerable literature to link gratitude and positive well-being and life outcomes (Froh, Sefick, \& Emmons, 2008; Froh et al., 2010) suggests it would be worthwhile to investigate strategies and interventions to target it amongst adolescents. Thus, in the current study gratitude was a central component of the intervention. The most successful indicators of gratitude as a precursor to happiness in young people have been found in intervention studies using the 'gratitude journal' and 'gratitude letter' feelings (Emmons \& McCullough, 
2003; Sheldon \& Lyubomirsky, 2006), so it is of interest to investigate how these activities translate to an online format.

The effects of 'letter of gratitude' interventions have shown results consistent with positive effects of gratitude journaling (Dickerhoof, Boehm, \& Sheldon, 2001; McCabe, Bray, Kehle, Theodore \& Gelbar, 2011). Toepfer, Cichy, and Peters (2011) found that participants who were asked to express their gratitude to others in a letter of thanks, showed increased happiness and well-being and decreased depressive symptoms compared to control groups. Moreover, research also showed that benefits of letter writing occurred both when participants were asked to share their letter of gratitude with the recipient (Froh et al., 2008, Seligman et al., 2005), and when participants were asked to keep their letter to themselves (Boehm et al., 2011; Lyubomirksy et al., 2011). These studies showed gains in personal resources were a consequence of taking part in the PPI, and it is likely that these improvements would lead to sustained well-being over time. Therefore, the contention that gratitude interventions in youth have a positive impact was supported. Research suggests that such interventions may be especially appropriate for adolescents, as it is a time when they become aware of the impact of their own and others behaviour (Park \& Peterson, 2006). Although increasing gratitude may be an effective way to enhance psychological well-being in adolescents, there are other constructs of positive emotions, such as savouring, that have shown to promote successful outcomes.

Teaching savouring to adolescents. While research about savouring has generally targeted adults, some studies have considered the value of using savouring strategies with adolescents (Chadwick, 2012; Gentzler, Morey, Palmer, \& Yi, 2012). These studies provided evidence that savouring worked in much the same way with young people as it did with adults (Cafasso et al., 1994; Chadwick, 2012). A study by Cafasso, Bryant, and Jose (1994) found that increased ability to savour was related to higher well-being in young people between ten and thirteen years of age. Savouring positive experiences was examined in a sample of 82 high school students aged 16 to 18 years (Meehan, Durlak, \& Bryant, 1993). Meehan et al.'s (1993) study showed a relationship between psychological well-being and adolescents' selfreported ability to savour positive events. This study suggests that individuals who intentionally savoured by focusing on positive events may be able to create a shift in wellbeing. 
Research indicates that effects of savouring endure over time. Gentzler and colleagues (Gentzler, Palmer \& Yi, 2012) conducted research with an adolescent population and showed that maximising responses to positive events by sharing, reflecting and celebrating resulted in intensified positive feeling when measured four months later (Gentzler et al., 2012). In addition to gratitude and savouring, research has examined the use of adolescents' individual character strengths as a method for increasing psychological well-being (Seligman et al., 2005).

Teaching character strengths to adolescents. Using character strengths (e.g. gratitude, hope, and love) have been shown to be associated with higher academic and prosocial outcomes for adolescents (Park \& Peterson, 2008). Character strengths (i.e. honesty, persistence, and love) have also been found to buffer individuals from the negative effects of stress (Park \& Peterson, 2009), and can shield adolescents from mental illness and anti-social behaviour (Notter, 2013). Research indicates that identifying strengths may help interpersonal interactions, school engagement and enjoyment of life for adolescents (Seligman, 2009). Duck and Seligman (2005) conducted a study examining the character strength self-discipline and found that this strength predicted academic performance more strongly than did IQ (Waters, 2011). Furthermore, a study by Linley, Nielsen, Wood, Gillett, and Biswas-Diener (2010) showed individuals using strengths were more successful at achieving their goals and had a greater associated well-being and happiness.

Together, these findings provide a strong rationale for the successful use of character strengths-building interventions with adolescents in order to promote wellbeing and protect adolescents from maladaptive outcomes. Research indicates that developmentally, adolescence is an optimal time to develop character strengths, as it is a time when character becomes more defined (see Hart \& Carlo, 2005; Park \& Peterson, 2006). Louis (2011) makes a distinction between two main types of strengths intervention, namely talent identification and strength development. Louis (2011) also asserts that talent identification guides individuals to acknowledge and identify their strengths. And in the opposite direction, strengths development enhances strategies to develop existing talents (Louis, 2011).

The relationship between methods of increasing psychological well-being and adolescents is of particular interest in this study. As discussed, prior research has found a strong relationship between PPIs and psychological well-being. The positive relationships 
have been replicated in studies with adolescents, in particular, PPIs targeting gratitude (Froh et al., 2008), savouring (Meehan, Durlak, \& Bryant, 1993), and individual character strengths (Seligman, 2009) have been found to show increases in well-being and adaptive resources. These findings indicate that adolescence is a period where PPIs can create positive change. In sum, such interventions show promise with adolescents, but there are far fewer intervention studies for young people as compared to adults (Mitchell \& Vella-Brodrick, 2009). As there is a potential for behaviours acquired in adolescence to shape the trajectory of one's life, more studies in this area are warranted. Additionally, successful programmes have often not been widely distributed due to high resource cost for therapists and teachers. Researchers have suggested it might be worthwhile to improve methodological designs, using non-traditional approaches to delivery due to the opportunity of accessibility and reduced cost (Munoz, 2012).

\section{The Problem of Dissemination of Interventions}

Positive psychology interventions for adolescents that have successfully reduced psychopathology have often been delivered at a high cost, using resources such as teachers, school counsellors and psychologists for delivery over sustained periods (e.g. Kazdin \& Blase, 2011; Merry, McDowell, Wild, \& Cunliffe, 2004; Notter, 2013). Researchers have identified the need for direct providers to develop new methodologies in order to extend the reach of their programmes with the aim of improving adolescent well-being on a wider scale (Manicavasagar et al., 2014). There are still major questions in regard to how PPIs can be delivered to the public and in which formats they will work best (Parks, 2014). There has been a call in the literature to identify individuals who will most likely benefit from particular formats and exercises (Dickerhoof; 2007; Mongrain, 2009). Given the potential power of PPIs to increase well-being on a large scale, there is a need to identify innovative and low cost ways of delivering these interventions (Parks, 2014).

\section{Technologically Mediated Interventions}

In order to address barriers preventing wider dissemination to the public, researchers have called for innovative approaches to the delivery of PPIs (Manicavasagar, 2014; Parks, 2014; Wang et al., 2005). They have suggested that the use of online (computer-based or smartphone) interventions may be a cost-effective way of providing training content (Sergeant $\&$ Mongrain, 2014). Such interventions can be brief, self-administered, automated and self- 
directed, and require less supervision from the clinician and researcher (Bolier et al., in press; Kazdin \& Blase, 2011; Lyubomirsky \& Layous, 2013). These features mean that online positive psychology interventions (OPPIs) could have a wider reach than conventional, facetoface interventions (Kazdin \& Blase, 2011, Munoz, 2012).

A number of OPPIs have been developed which make use of the Internet for delivery (e.g. Mitchell, Stanimirovic, Klein, \& Vella-Brodrick, 2009; Mongrain, Chin, \& Shapira, 2011; Seligman, Steen, Park, \& Peterson, 2005; Sergeant \& Mongrain, 2011; Shapira \& Mongrain, 2010). Additionally, there is some preliminary evidence demonstrating that these online positive psychology interventions (OPPIs) impact well-being and depression in predictable ways (Andersson \& Cuijpers, 2009; Mitchell et al., 2009; Shapira \& Mongrain, 2010). An evaluation of the delivery of these online programmes yielded mixed efficacy, a review of five OPPIs by Mitchell and VellaBrodrick (2010) found that three successfully increased well-being and reduced depression, but two were ineffective. Additionally, Parks (2013) found that although their online optimism programme was successful, high rates of attrition meant a much reduced sample size. Two points can be drawn from these findings. The mechanisms behind OPPIs, like PPIs, are not well understood compared to what is needed to develop successful programmes in the future. Furthermore, there may be some features of OPPIs that make them subject to high attrition, and therefore decrease the sample size and efficacy of the intervention study.

Technologically mediated interventions with adolescents. Since 2012, a CBT program has been made available in New Zealand as a computer-based self-help intervention for 12-19 year olds seeking help for depression. This computer program, named SPARX ('smart, positive, active, realistic, X-factor thoughts'), conveys CBT concepts in the format of a video game developed for adolescents by Merry et al. (2012). SPARX has been shown to be effective in two trials with adolescents experiencing depression, and has been evaluated to be as effective as face-to-face counselling-based treatment for the reduction of depression and anxiety and the enhancement of well-being for at least three months (Merry et al., 2012). The innovative format of an intervention run as a computer game resulted in high levels of satisfaction and completion rates (Fleming, Dixon, \& Merry, 2012; Merry et al., 2012). However, SPARX is targeted toward depression reduction for clinical samples and does not directly focus on teaching skills to enhance well-being. Further, there does not seem to be an equivalent program for young 
people, run on a smartphone. The lack of such a program is significant, given the growing number of adolescent smartphone users (Davidson et al., 2014), and the potential for appeal and engagement to this demographic (Campbell, Roberts \& Wellness Cooperative Research Centre, 2013). Another study (Manicavasagar, 2014) trialled an OPPI that was delivered via a website. The website was named 'Bite Back', and it was designed to increase well-being and reduce maladaptive outcomes in a sample of 235 Australian adolescents aged 12-18 years (Manicavasagar, 2014). The study demonstrated that the format was successful in increasing well-being and reducing depression compared to the control condition.

Choice of smartphone methodology. To date, no school-based or publicly accessible PPIs have been found that are administered by students in a self-directed fashion on their smartphones. The present intervention will add to the literature base on non-traditional methods of delivering PPIs by trialling a new programme format in which the intervention can be technologically-mediated (through smartphones) and self-directed by the participant. The three activities adapted from PAL (Notter, 2013) were chosen because they were seen to be appropriate to run as self-directed activities. All of the activities in the three modules are based on Notter's programme and have been shown to be previously successful for adolescents.

Data from recent studies show that smartphone and tablet usage is growing in New Zealand: $90 \%$ of the New Zealand population is predicted to own a smartphone and $78 \%$ are predicted to own a tablet by 2018. Miller (2012) argues that smartphones have already replaced a large number of devices and asserts that, like the Internet, smartphones have potential to transform psychological research methods. They can be used to collect data quickly and easily from a large number of participants in virtually any geographical location.

Some researchers have proposed that this medium may be especially appropriate for children and adolescents (Merry, 2012). This view is supported by Prensky (2001) who argues adolescents thrive in an adapted learning environment, one high in "media-rich" content and interactions to hold their attention. In sum, since a number of studies that have used online interventions show benefits with respect to cost, dissemination and participant engagement, the decision was made in the present case to use the engaging communication medium of the smartphone. 
Need for the present study. Prior to the present study, there have been few interventions seeking to enhance positive emotion and resilience in young people (Notter, 2013). Even fewer have been designed specifically for adolescents in an online format (Parks, 2013). The computer game "SPARX", described above, was designed for sub-clinical populations of depressed teenagers, unlike the current intervention which is directed at all adolescents (i.e. individuals aged from 10-15 years). Furthermore, only one known online well-being intervention (Manicavasagar et al., 2014) has successfully used more than one positive psychology intervention, as the majority of programmes have been single component interventions (Manicavasagar et al., 2014), and the successful OPPI ("Bite Back”) was run as a web site. Consequently it is important to trial whether a smartphone intervention can provide similar benefits as facilitator-led PPIs, and as with other OPPIs, the potential benefits for dissemination, cost and engagement with the online version may be significant. The present study provides some preliminary findings as to whether an OPPI can be run as a selfdirected app, and the results will contribute to the literature base on the use of OPPIs with young people.

Notter (2013) argues that programmes that are successful in increasing wellbeing and reducing depression often neglect to measure the mechanisms that explain the process (Notter, 2013). Positive psychologists have suggested that PPIs help build resilience that protects individuals from maladaptive outcomes, and promotes positive psychological well-being (Fredrickson, 1998; 2001). However, few studies have examined the mechanisms by which resilience is developed and the process by which it may lead to positive psychological outcomes (Contu, 2002). Even fewer studies have employed the use of longitudinal data, which has prevented researchers from identifying predictive relationships, and has limited understanding of the complex developmental pathways of developing well-being in adolescents.

\section{The Present Intervention: The 'Happy Wings' Smartphone Application}

The three constructs of savouring, gratitude, and identifying and developing individual character strengths were used to formulate the activities adapted for use in the current intervention. As the above-mentioned interventions have been shown to be among the most successful in the literature, the chief aim of the present study was to adapt these into activities delivered via smartphone technology. Notter's (2013) intervention programme was used as a 
guide to develop the current intervention, I adapted the aspects of PAL that were judged as both the most effective and most suitable to be self-directed (the components regarding gratitude, savouring and individual character strengths). The two chief aims of the study were: 1) to deliver these three components in an app to adolescents in order to increase their ability to promote and regulate positive emotion, and 2) to examine whether any increase in positive emotions would impact positive psychological well-being indicators at a later point in time.

\section{The Present Study}

The present study was designed primarily to test whether an intervention delivering three positive psychological interventions (gratitude, savouring, and strengths) could increase scores on measures of positive emotions, and resultantly lead to changes in psychological well-being indicators (increases in resilience and subjective happiness, and decreases in depression). The study used a wait-list control design to measure differences between the intervention group as compared to the control group.

The second aim was to determine whether and how several key constructs to positive psychology were related, and to evaluate the course, prediction, and impact of these constructs in pathways to well-being for adolescents. In particular, the relationships between the variables of adaptive coping, resilience, gratitude, happiness, depression, and aggression on well-being were examined. Also, based on previous theory (Masten, 2001), it was predicted that greater resilience would mediate the relationship between adaptive coping and psychological well-being.

Prior to the present study, there were no known studies that empirically examined the impact of a smartphone-mediated positive psychology intervention aimed at fostering positive emotion in a community sample (i.e. normally functioning) of adolescents. The research was expected to explore the potential for well-being interventions to promote positive psychological skills and resources that may have lasting positive consequences for their lives (Norrish \& Brodrick, 2009). The current study built upon Notter's (2014) PAL programme by adapting it into a set of three online activities that were aimed to increase positive emotions and raising awareness of individual character strengths in adolescents.

The two main goals were to: 1) test a smartphone app as a new format to deliver three PPIs to adolescents, and investigate the efficacy of this app for improving psychological well- 
being; and 2) to test a proposed mediational model involving temporal relationships between adaptive resources, positive emotions and indicators of psychological well-being. We sought to replicate findings from the literature relating to correlates of youth well-being. Three broad predictions were made.

1. Research by Notter (2013) showed that a school-based intervention programme was successful in teaching strategies aimed at building a capacity for positive emotions in adolescents. Notter's (2013) PAL programme indicated that using positive intentional activities to cultivate positive emotions such as: gratitude, savouring and individual character strengths was effective increasing their scores on these emotions. Therefore, we hypothesised that using an abbreviated version of Notter's PAL programme would effectively increase scores on positive emotions. We predicted that individuals who completed the three activities in the app would report more positive emotions, namely gratitude (Froh et al., 2008), savouring (Cafasso et al., 1994), and character strengths (Proctor et al., 2011), as compared to their peers assigned to the wait-list control group.

2. Fredrickson's $(1998 ; 2001)$ broaden and build theory helps to explain the relationship between positive resources and future well-being. Her research found that positive emotions expand cognitive pathways and promotes the development of adaptive skills and resources. Building a capacity for positive emotions has been shown to predict an increase in resilience (Cohn et al., 2009; Tugade \& Fredrickson, 2004), well-being (Fredrickson, Mancuso, Branigan, \& Tugade, 2000), and subjective happiness (Lyubomirsky \& Layous, 2013), and to predict a decrease in depression (Layous et al., 2011). Further, intervention studies have found positive intentional activities to be associated with increases in positive psychological resources such as happiness (Lyubomirsky, Sheldon, \& Schkade, 2005) and resilience (Gillham et al., 2009; Notter, 2013).

Therefore, we hypothesised that increasing positive emotions would increase the positive psychological resources of subjective happiness and resilience, and reduce the negative outcome of depression.

3. Notter's (2013) research found that there are several different routes to positive psychological well-being in adolescents. However, this research also indicated 
that the mechanisms underlying change were not altogether clear, and recommended more research into the developmental pathways to well-being. Since the present study obtained longitudinal research, it was used to identify key meditational variables that predict different constructs of well-being. Research on adaptive resources in adolescents would lead one to believe that the possession of adaptive resources at time one would lead to increased psychological outcomes (i.e. resilience) at time two. Specifically, guided by Fredrickson's (1998; 2001) research, it was expected that more adaptive coping resources in adolescence would predict increased reports of resilience (Fredrickson, 1998; 2001; Notter, 2013), which would then be expressed through higher self-reports of positive outcomes and lower negative outcomes. 


\section{Method}

\section{Participants}

Participants were 72 young people (42 of whom were in the control group, and 30 in the experiment group), aged 10-15 years and recruited from high schools and full primary schools. Twenty-four participants were female and participants predominantly identified as NZ European $(\mathrm{N}=63)$, with smaller numbers identifying as Asian $(\mathrm{N}=4)$, and Other $(\mathrm{N}=5)$.

Six schools in the Greater Wellington Region participated in the study. The schools ranged from decile 5 to decile 10, and students were drawn from three school types: public, single-sex and co-educational. The demographics of the participating schools are given in Table 1.

Table 1

Gender, Type, Decile, Number of Students and Authority of School that Participated in testing the App

\begin{tabular}{llccl}
\hline Gender & School Type & Decile & $\begin{array}{c}\text { No. of } \\
\text { Students }\end{array}$ & Authority \\
\hline 1. Co-Ed & Secondary & 5 & 3 & State \\
2. Co-Ed & Intermediate & 9 & 9 & State \\
3. Single-Sex (M) & Secondary & 9 & 10 & State-Integrated \\
4. Co-Ed & Primary & 9 & 13 & State \\
5. Single-sex (M) & Secondary & $8-10$ & 30 & Private \\
6. Co-ed & Full - Primary & 10 & 7 & State \\
\hline
\end{tabular}

\section{Experimental Design}

This section describes information pertaining to the experimental design and ethical procedures in the study. Next the measures used here are described, followed by methods of recruitment and experiment procedure. Afterward, an explanation of the user interaction with the app will be given, before a description of the development of the app. Lastly, the content 
of the app will be presented, followed by the plan for analysing the quantitative and qualitative data.

The intervention (administration of the app "Happy Wings") was conducted using a wait list control experimental design (Elliott \& Brown, 2002). Participants were placed in either the experimental or control group. The control group functioned as an untreated comparison group during the study, and they subsequently received the intervention. All participants received the pre-test measure at the same time; the experimental group then received the app while the control group waited. Then both groups were tested again with the same measure, and then the control group received the app.

\section{Ethical Procedures}

Ethical approval was given by the School of Psychology Human Ethics Committee under delegated authority of Victoria University of Wellington's Human Ethics Committee, reference number 0000020972 , before any data collection occurred.

Written assent was obtained from participants, and because they were under 16, consent was also obtained from a parent or guardian. The contact details of the school counsellor or chaplain were provided on the information sheets handed out with the surveys so individuals could connect with support people if desired (see Appendix C for consent and information forms).

The written data entered into the app was stored in a private (passwordprotected) online database $^{1}$. The principal researcher alone had access to data stored in this database. Participants' names were automatically re-coded to participant IDs before being sent to cloud storage. Participant IDs were determined by the participant's 'username', which was randomly assigned by the researcher at the initial meeting. Participants entered their designated user IDs into the app when logging in for the first time, and again on their post-test survey measure in order to protect confidentiality so all data became anonymous eventually. The file containing names and IDs was deleted upon completion of the study.

Demographic and contextual questions. Demographic questions (age, gender, and ethnic group membership) were asked in the Time 1 data collection.

1 This database ran on an independently arranged cloud database service (Avos Cloud), which was arranged to store large amounts of data. 


\section{Measures}

Measures used in the present study were created using a top-down approach by which the definition of the construct was first defined and relevant literature reviewed before a list of measures or items was generated. The items and measures were then reviewed in the interest of maximising the relevance and accuracy of questions to the functional definition.

The Ways of Savouring Scale. The Ways of Savouring Scale (Bryant \& Veroff, 2007) consists of nine items that provide an assessment of the degree to which an individual deepens and lengthens the experience of enjoying a positive event. The scale includes both positively-worded (e.g., "I reminded myself how lucky I was to have this good thing happen to me") and negatively-worded items (e.g., "I thought about how things might never be this good again"), which were reverse-scored.

Responses are indicated on a seven-point Likert scale, from $1=$ strongly disagree to $7=$ strongly agree. Higher scores indicate higher levels of savouring. This scale $(\alpha=0.74)$ reached an acceptable level of internal consistency. Jose, Lim, and Bryant (2012) have conducted research validating the psychometric validity of this scale.

The Gratitude Questionnaire - Six-Item Form (GQ-6). The Gratitude Questionnaire (McCullough, Emmons, \& Tsang, 2002) consists of six items, which assess an individual's ability to experience gratitude in their everyday life. The scale includes both positively-worded (e.g. "I have so much in life to be thankful for") and negatively-worded items (e.g., "when I look at the world, I don't see much to be grateful for"), which were reverse-scored. Participants were asked to report their level of agreement using a seven-point scale: 1 = "Strongly Disagree"; 2 = "Disagree"; 3 = "Somewhat Disagree"; 4 = "Neither Agree Nor Disagree"; 5 = "Somewhat Agree"; 6 = "Agree"; and 7 = "Strongly Agree". Higher scores indicate greater levels of gratitude. This scale $(=.71)$ reached an acceptable level of internal consistency.

Research has shown this scale to be psychometrically sound for use with both adults

(Emmons \& McCullough, 2004; Emmons, 2007) and children (Froh, Emmons, Huebner, Jinyan, \& Giacomo, 2011).

The Subjective Happiness Scale (SHS). The Subjective Happiness Scale (Lyubomirsky \& Lepper, 1999) consists of four items, which assess global subjective happiness. These included two items that ask individuals to rate their own happiness relative to 
peers; for example, "Some people are generally very happy. They enjoy life regardless of what is going on, getting the most out of everything. To what extent does this characterisation describe you?", and conversely, "Some people are generally NOT very happy. Although they are not depressed, they never seem as happy as they might be. To what extent does this characterisation describe you?" Responses are indicated on a three-point Likert scale, with responses ranging from 1 = "Not At All", 2 = "Some", 3 = "A Great Deal". The third item asks individuals to rate their own happiness independently; for example, "In general I consider myself" 1 = "Not A Very Happy Person", 2 = "A Little Happy", 3 = "Neither Happy Nor Unhappy", 4 = "A Happy Person", 5 = "A Very Happy Person”. The fourth item asks individuals to rate their happiness as compared to peers "Compared with most of my peers I consider myself" 1 = "Less Happy", to 7 = More Happy". Higher scores indicate elevated levels of subjective happiness. This scale $(=.68)$ reached a close-toacceptable level of internal consistency. The SHS has demonstrated adequate internal consistency, and has been shown to be valid in 14 studies involving more than 2000 participants (Lyubomirsky \& Lepper, 1999).

The Resilience Scale (RS). The Resilience Scale (Wagnild \& Young, 1993) contains 14 items, which assess the degree to which individuals bounce back or recover from stressful events. The scale included positively-worded questions, including "I usually manage one way or another" and "I am determined". Responses are indicated on a seven-point scale, with responses ranging from $1=$ "never" to 7 = "everyday". Higher scores indicate greater levels of resilience. This scale $(=.92)$ reached an excellent level of internal consistency. Research shows the RS to be one of the most reliable and valid measures of resilience used across the world (Wagnild, 2009).

The Rosenberg Self-Esteem Scale (RSES). The Rosenberg Self-Esteem Scale (Rosenberg, 1965) contains 10 items, which assess the degree to which individuals think highly of themselves. The scale included both positively-worded (e.g., "On the whole, I am satisfied with myself") and negatively-worded items (e.g., "I feel I do not have much to be proud of'), which are reverse-scored. Responses are indicated on a five-point scale, with responses ranging from $1=$ "not at all" to $5=$ "all the time". Higher scores indicate higher levels of self-esteem. This scale $(=.75)$ reached an acceptable level of internal consistency. The RSES is considered a reliable and valid quantitative tool for self-esteem assessment (Tomaka et al., 1993), and has been used widely across the world (Schmitt \& Allik, 2005). 
The Neuro-QOL Item Bank v1.0-Pediatric Depression - short form. (Cella

$\&$ the PROMIS Health Organisation, 2013) consists of nine items, which assess the degree to which children and adolescents experience the negative emotional state of depression. The scale included negatively worded items (e.g., "I felt like everything in my life went wrong" and "It was hard for me to have fun"). Responses are indicated on a five-point Likert scale, with responses ranging from $1=$ "never" to $5=$ "all of the time". Higher scores indicate deeper levels of depression. This scale $(=.90)$ reached an acceptable level of internal consistency. The Neuro-QOL short form was developed with extensive qualitative research with patients and experts for use with clinical samples (Cella, 2010).

The Ways of Coping Scale (WOCS). The WOCS (Chua, Milfont, \& Jose, 2014) consists of 15 items, which assess the actions young people take when facing problems. The scale included items representing both adaptive (e.g. "I try to change the situation to fix the problem") and maladaptive coping strategies (e.g. "I think 'I must have serious problems otherwise I wouldn't feel this way". Responses are indicated on a five-point scale, with responses indicating the amount with which individuals engaged in those actions, ranging from $1=$ "Never or almost never" to 5 = "Always or almost always". Higher scores indicate higher levels of adaptive or maladaptive coping. Both of the above dimensions of coping ( = .78 and $=.74$ respectively) reached acceptable levels of internal consistency. The WOCS has been validated in use with over 1,774 pre adolescents and early adolescents (Chua et al., 2014).

\section{Recruitment}

The first step in recruiting participants was to contact 50 school principals from high schools and full primary schools in the Greater Wellington Region directly via email to propose the terms of the study. For those who did not respond to the email within two weeks, phone contact was attempted using contact numbers of principals, deputy principals and, in some cases, school counsellors. The researcher then met with eight school principals who were interested in order to discuss the study timeframe and requirements. During these meetings, the researcher supplied flyers to advertise the study around the school, plus the mandatory consent forms for students and parents to sign (see Appendix C). In total, five principals agreed to allow their pupils to participate in the study. Once the forms had been 
distributed and returned by students to the school office, the researcher collected them. The interested students from the five recruited schools were assigned to the experiment group.

The second recruitment round encompassed additional schools in the Greater Wellington Region. In this round the researcher recruited a large number of participants from one boys-only school. The number of students from this school equally matched the number of students in the experimental group, and this group therefore constituted the control group. Using the above contact methods exhausted all possible local schools; namely 40 schools were contacted within a four-month period, which exhausted the sampling frame. An all-male control group was not optimal, but was the only option available at the time of recruitment, as the quasiexperiment was not successful in allocating equal numbers of boys and girls to the experimental and control groups due to lack of resources and time.

\section{Procedure}

Pre-test procedure. The pre- and post-test measurements were administered in electronic format using Qualtrics Online Survey Software (Qualtrics, Provo, UT). The survey software was also used to automatically distribute the pre- and post-test measures to individuals using a panel feature, which the researcher set to automatically administer user identification (ID) codes to all participants via email. Participants were asked to enter their user ID at the top of their survey in order to ensure anonymity. The survey took approximately 15 minutes to complete, and once finished, was automatically recorded into the Qualtrics database. Only participants who completed this survey within the seven-day period before the intervention were able to participate in order to ensure that completion periods were comparable. Twelve students did not complete this survey, and were excluded from further analyses.

Intervention. The intervention for the experimental group was run for two weeks from 13 November 2014 to 27 November 2014 (Figure 1 shows date of app administration for all participants). The researcher contacted the school principals from each site to arrange an appropriate time to meet with the students for an orientation session. Because there were varying number of students participating from each school, participants were met in groups ranging in size from 5 to 15 students, and there were 10 meetings held in total.

Each orientation session was administered during a 50-minute school lunchtime session. During this meeting the researcher described the study and provided an explanation 
regarding the structure of the app. The researcher outlined what the activities were and how long they would take to complete per day. The researcher then helped students access a Wi-Fi connection via the author's personal mobile Wi-Fi hotspot ${ }^{2}$, so they could access the iTunes App Store without using their monthly download limits of cellular data. Once connected, the researcher assisted participants with searching for the "Happy Wings" app and downloading it to their iPhones. The researcher then instructed participants to enter their designated user ID into the empty text box 'Name' in the login page (see Figure 2) in order to maintain confidentiality. Participants were asked to open the app every day, and to complete the available exercise. They were told that this process would take between six and eight days.

Post-test measurement. After eight days the researcher emailed participants, asking them to complete the post-test survey using the same panel feature in Qualtrics that distributes user IDs to participants. Participants were asked to enter their user ID at the top of their survey in the same way as the pre-test survey, and their surveys were automatically uploaded upon completion.

When all participants in the experimental group had completed the post-test survey, the researcher arranged meetings with the participants in the wait-list control group. The same procedure utilised for the experimental group was used for the control group. Participants in this waiting-list control group interacted with the Happy Wings app during a two-week period, from 27 November to 11 December 2014.

In order to provide the participants in the control group with the same opportunity as those in the experimental group, they were also assisted with uploading the app to their phones and complete it over a 6-8 day period if they wished. In order to do this, they were subject to the same download procedure as the experiment group.

All participants were debriefed after completing the app and final survey measure, and issued with a $\$ 15$ voucher. Participants were also entered in a draw to win one of two Apple iPod Touches, and these prizes were awarded at the completion of the study.

2 Tethering is the sharing of an Internet connection from one device to another (in the context of mobile phone or tablet computers). 


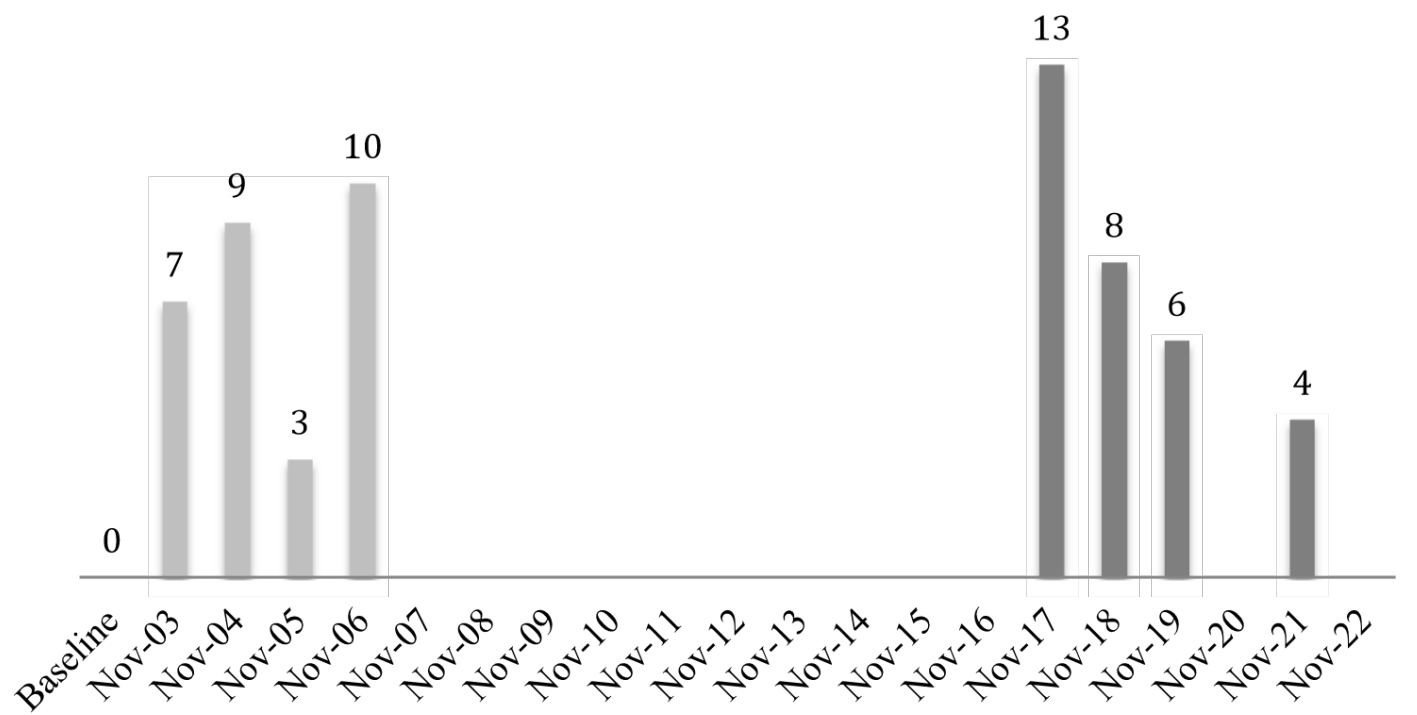

Figure 1. Time and Number of Participants Who Received the Intervention

User interaction with the application. In order to download Happy Wings to their iPhones or iPads, participants were required to login to the iTunes store by entering the Apple ID attached to their existing iTunes account. They were then required to enter "Happy_Wings" in the search bar of iTunes and to download the application onto their device (this process took between one and five minutes). An Internet connection was required to download the app; however, the app would run without such a connection once downloaded into the user's iPhone or iPad.

After the download process had been completed, participants touched the app icon on their screen to open it (see Screen Capture 1). They were then shown a "flash screen" that included the app title and logo (see Screen Capture 2) (all screen captures are displayed in Appendix A). This screen remained visible for 1.5 seconds before participants were presented with an introductory screen. The introductory screen contained two sentences of text, which introduced the app (see Screen Capture 3). The participant then touched the arrow icon located at the bottom right hand corner of the screen to move on; this method of moving on was consistent throughout the app. On the next screen participants were asked to fill in their personal details: user ID, date of birth, and gender (Screen Capture 4). This information was automatically stored in the cloud database.

Participants then progressed to the fifth screen, which contained text greeting them and asking them to tap their iPhone screen to "hatch" their egg (see Screen Capture 5). After 
touching the onscreen picture, the egg cracked and a picture of a bird was revealed. This screen also included text informing participants that their bird was hungry, followed by a question asking them if they could make the bird "grow" (Screen Capture 6). After reading this information, participants moved on to the following screen, which contained text telling participants that the bird had "always dreamed of flying", and asked participants to swipe ${ }^{3}$ the screen to move their bird (Screen Capture 7). When participants swiped, their bird moved from the left to the right side of the screen. Subsequently they were presented with a new screen containing text stating the bird needed food to grow (Screen Capture 8). Participants pressed the arrow on the bottom right hand corner of the screen to proceed and were presented with the "progress screen", a screen that listed all four quests, and marked quests completed with a tick (see Screen Capture 9).

Participants could select Quest 1 from the progress screen in order to proceed. Subsequent quests were "locked" to ensure participants completed each quest in the predetermined order (1 through 4$)$.

\section{Development of the Happy Wings iPhone Application}

\section{Happy Wings "Quests”}

The content of the Happy Wings app was separated into four quests:

Quest 1: Happy Album;

Quest 2: Your Strengths;

Quest 3: Be Happy;

Quest 4: Feed It Back.

These four modules were based on the Positive Approaches to Life (PAL) program (Notter, 2013) and modified by the author with input from clinical and academic staff in the School of Psychology at Victoria University of Wellington.

Advice was also gained from staff in the School of Engineering and Computer Science, and the Massey University School of Design ${ }^{4}$.

3 Swipe to navigate - just like thumbing a page in a book.

${ }_{4}$ Dr Taehyun (James) Rhee, Head of The School of Engineering and Computer Science, at VUW and colleagues; Rachel Reidel, Wellbeing Educator, Student Counselling Service at VUW; and Dr Deirdre Brown, Senior Lecturer, School of Psychology, VUW. 
After the development of content, app developers from a freelancing web site were identified to write the code for Happy Wings. The author elected to develop the app for one platform only, choosing Apple because it was considered to be the most desirable mobile operating company used among adolescents ${ }^{5}$. While Happy Wings was coded by the developers, a cloud database ${ }^{6}$ was also designed for the purposes of transferring data directly from the app into a secure online database (the particular information that was stored is outlined below).

Pilot testing. The app was then tested with Year 9 students from a co-educational college in the Greater Wellington Region. As part of this testing process, students were shown a partial copy of the app consisting of the proposed screens, but no content was revealed during this initial testing. Following the initial pilot, various changes (i.e. design features, such as the colour scheme inside the app) were considered in accord with students' suggestions, and these changes were incorporated into the final version of the Happy Wings app. Upon final coding, the app was submitted to the iTunes store, meaning that it could be downloaded for free by those with appropriate Apple devices.

\section{Application Content}

Quest 1: Happy Album. After selecting the first quest, Quest 1, participants were shown a screen introducing Happy Album. This screen included text outlining how to progress successfully through the quest (the requirement in this case being the taking of one photograph every day for three consecutive days (Screen Capture 10). Participants then proceeded to the next screen, which contained text that instructed participants to take a photograph. Participants could capture an image by selecting the "+” icon, which immediately linked them to their iPhone/iPad camera. After taking a photo, participants were given the option to "retake" or "save" their photo (Screen Capture 11). The saved photos were automatically uploaded to the cloud database, and participants could not change these once they had been saved. The timer on the app constrained participants to upload a single photo each day. If they tried to move on to the next quest before completing Quest 1, they

5 Happy Wings is an iOS app; iOS is owned by Apple; and iOS apps are available from the iTunes app store. The apps can run on various models of $i$ Phone and $i$ Pad.

${ }_{6}$ A database that is run on a cloud-computing platform. 
were presented with the "uh-oh" screen, which repeated the instructions (see Screen Capture 47).

After the three days were completed, participants were shown their "photo album", which consisted of all three photos taken (Screen Capture 12). They were then asked to recall what they had liked or made them feel happy about each photo, and were asked to record the memory in the empty text box beside each of the photos.

This procedure was repeated for all three photos (Screen Capture 13.1, 13.2, and 13.3), and these text entries were automatically stored in the cloud. After participants had annotated each photo, they were presented with a screen saying "Completed!"

(Screen Capture 14). Participants were then directed back to the progress screen (Screen Capture 15).

Quest 2: Your Strengths. Participants selected Quest 2: Your Strengths by touching the icon for this second quest on the progress screen (Screen Capture 15). The first screen in Quest 2 provided a definition of "strengths" as defined in the Happy Wings app (Screen Capture 16). Participants then proceeded to the next screen, which illustrated four examples of individual character strengths (Screen Capture 17). After viewing this page, participants were presented with a screen instructing them to create their "strengths profile" (Screen Capture 18). Participants then moved to the next screen where they were able to identify those of the listed strengths that they felt they possessed. This strengths checklist was presented as a series of six screens including multiple strengths per domain: family, school, friends, extra stuff, and personal attributes. For example, an item from the school domain read: "There is at least one subject at school in which I do very well". The statements corresponding to each domain are displayed in Screen Captures 19, 20, 21, 22 and 23. Participants were able to select as many (or as few) statements as they liked by touching the check box to create a "tick" icon beside the statement in question. After selecting items on the screen, they were able to move to the next checklist. All statements selected were automatically recorded.

After completing the checklist, participants were presented with a screen containing text congratulating them on doing so, and informing them that they would now be shown their "profile" (Screen Capture 24). This profile was illustrated on one screen with the five strength domains displayed as differently-coloured bird icons. 
Domains where participants had selected strengths were highlighted (Screen Capture 25). Text at the top of the screen instructed participants to click on the bird to "find out more info". When participants did this, they were presented with a screen listing all items they had selected under each domain (Screen Capture 26, which illustrates specifically the Personal domain). Participants could use the left and right arrows at the bottom of the screen to go back and forth between screens. When they had finished viewing their results for all domains, they touched the right-facing arrow icon, which took them to a screen containing practical suggestions for building on weaker character strengths so as to make them stronger (Screen Capture 27).

For the second part of Quest 2, participants were asked to visualise what their life might comprise of one year into the future. They were asked to choose words which best described what kind of person they would be if they had achieved their goals. Participants entered between four and six words in empty text boxes displayed on the screen (Screen Capture 28), which were automatically recorded. After filling in the boxes, they moved on to the next screen, which indicated that they had completed their profile, and would be shown the results (Screen Capture 29). Participants were then presented with a screen asking them to identify which character strengths they would need in order to become their best possible selves, and they could touch the screen to highlight as many strength domains as they wished (Screen Capture 30). Participants were then presented with a screen containing text congratulating them, and saying they had now unlocked Quest 3 (Screen Capture 31). They then needed to 'swipe' their bird across the next screen, in order to return to the progress screen (Screen Capture 32).

Quest 3: Be Grateful. Participants touched the textbox Quest 3: Be Grateful on the progress screen (Screen Capture 33), to select the next quest. They were then presented with a screen introducing the quest (Screen Capture 34). Participants then proceeded to the next screen where they were asked to record three things for which they were thankful (Screen Capture 35). In each of the three text boxes there were past, present and future-oriented prompts to help participants answer the question. For example:

"What was the best thing that happened last week?";

"What are you grateful for today?"; and

"What would make you happy if it happened next week?" 
Similar to the "Happy Album", this exercise was repeated for three days, with different prompts each day (Screen Captures 35, 36, and 37). Once participants had completed the three days, they were presented with a screen congratulating them and informing them they had completed the quest. They could then view their entries by scrolling through to each page using the right-facing arrow button (Screen Capture 38). Participants were then presented with a screen indicating that they had completed Quest 3, and unlocked Quest 4 (Screen Capture 39). They touched the arrow icon and were returned to the progress screen (Screen Capture 40).

Quest 4: Feed It Back. Participants touched the text box Quest 4: Feed It Back on the progress screen to select this quest (Screen Capture 40). This action took participants to the introductory screen, which contained three sentences of text giving an overview of the quest (Screen Capture 41). Participants moved to the next screen, where they were asked to enter text identifying the person to whom they were grateful in the empty text box and to fill out the other text box to describe why they were grateful to that person (Screen Capture 42). Participants could select either "save!" to save the message to the app or "send!" to send the message via text message instantly through the app (Screen Capture 43). Participants were then presented with a screen, which informed them they had completed the quest (Screen Capture 44). They then proceeded to the next screen and were presented with a "goodbye" message stating that as a result of their work in the app, their bird was able to fly. This screen included a text prompt and arrow icon on the screen asking them to "swipe to move your bird". Upon touching the bird to move it across the screen, the bird "flew" by disappearing off the screen and came back to "hover" centre screen (Screen Capture 45).

\section{Data Analytic Plan}

Data analysis. The study used a quasi-experimental randomised control design in which pre-tests and post-tests on both experimental and control participants were taken. The treatment by time interaction was examined for the outcome measures, specifically, the gratitude, subjective happiness, self-esteem, depression and aggression measures, in order to determine whether the treatment group improved on the positive outcomes and showed a decrease in the negative outcomes relative to the control group over time. In addition, a mediation model (see Jose, 2013) was employed to determine whether the proposed mediator, resilience, significantly explained the effect of adaptive coping on the cluster of outcome variables (e.g. wellbeing). 
The primary hypothesis was that the experimental group would report significantly higher levels of the positive emotions and outcomes and lower levels of the negative outcomes as compared to participants in the control group after the intervention had been administered. This hypothesis was tested using two multivariate analyses of variance (MANOVA), one testing the constructs directly related to the content of the app (savouring, gratitude and selfesteem) and the other testing more distal outcomes (depression, resilience, happiness, and social anxiety).

The secondary hypothesis was that the construct of resilience would mediate the relationship between adaptive coping and well-being. In this case, path analysis was used to examine the direct and indirect effects between adaptive coping and the outcomes of depression, subjective happiness, gratitude and aggression as mediated by resilience. Path analysis was used as an efficient method for examining these numerous relationships.

Qualitative methodology. Qualitative methods were used to analyse the openended text data that was stored in the online database for each student. The two main goals were: 1) to examine participant responses to the activities embedded within the app in order to better understand their experiences with the app, and to give depth to the research findings; and 2) to identify whether there were any problems or issues with the app, and to see what percentage of activities had been completed, in order to gain an insight into the acceptability of this app for adolescents.

The qualitative data that was analysed came from the following parts of the app: Quest 1 "Happy Album”, Quest 2 "Your Strengths", and Quest 4 "Feed It Back". The written responses were stored for all text entered, but photos were not stored in order to ensure confidentiality. Due to a technical difficulty, much of the open-ended data solicited for Quest 3 "Be Grateful" was lost. Responses from Quests 1, 2 and 4 were analysed using the computer software NVivo (Version 10) for content analysis (Braun \& Clarke, 2006). NVivo was chosen because it allows a systematic approach to data, including efficient thematic organisation and word searches, which would not be possible in a thorough way if done by hand. The following steps were used in the analysis of individuals' app data:

Step 1: Describing themes and identifying patterns. Once data had been exported from the cloud database to individual Excel files, Nvivo (Version 10) was used to examine data and retrieve instances of each emergent theme (for Quests 1, 2, and 4). These instances were then 
reviewed, responses were coded, and percentages calculated to display the frequency of attributions made to each category. Emergent themes were described in the following section, where segments of text from individuals are presented below as typical examples of concepts.

Themes were explored in three sections of the app:

Quest 1 "Happy Album”;

Quest 2, "Your Strengths" (Part 2) "Imagine yourself one year from now"; and

Quest 4 "Feed It Back"

Step 2: Identifying completion rates. Completion rates were calculated for each quest in the app. These were based on the 16 activity points that were available for text entry (for Quests 1,2, and 4). For example, the instruction "take one photo" = 1 activity point. A "completion score" was calculated for each participant, in order to show how many total activity points they had completed out of a possible $16,(16 / 16=100 \%$ complete $)$. Those individuals who entered only their name, user id, gender and date of birth were given a score of zero, and excluded from the qualitative analysis.

Evaluation of participant feedback. On the final session of the programme, each student filled out a feedback form and contributed to an online discussion forum about how they experienced the intervention. The responses were coded for thematic content, and their data yielded information about the subjective responses of participants to the intervention, both positive and negative.

\section{Results}

The primary goals of this study were to create and test a novel online intervention for adolescents, and then to determine its impact on positive emotions (increased gratitude, savouring, and self-esteem). The study sought to determine if the positive emotions would in turn result in an increase in psychological well-being (increased resilience, well-being, and happiness, and decreased depression). The secondary goal of the study was to use a mediational model to test the predictive relationships over time among adaptive coping resources at Time 1, and psychological well-being indicators (i.e. resilience, subjective happiness, gratitude, reduced depression and reduced aggression) at Time 2. In line with these goals, this results section will first relate the findings comparing the intervention and control groups, before communicating results regarding the mediational model. 


\section{Descriptive Statistics}

Descriptive statistics by group (i.e. control or experimental) at T1 and T2 were calculated for all 71 participants (42 of whom were in the control group, and 30 in the experiment group). The means and standard deviations by group at T1 and T2 for all the scales and subscales in the survey are shown in Tables 2 and 3.

Table 2

Control group means $(M)$ and standard deviations $(S D)$ of dependent variables at times T1 and $T 2$

\begin{tabular}{lcccc}
\hline & \multicolumn{2}{c}{$\mathrm{T} 1$} & $\mathrm{~T} 2$ \\
\cline { 2 - 5 } & $\mathrm{M}$ & $\mathrm{SD}$ & $\mathrm{M}$ & $\mathrm{SD}$ \\
\hline Savouring & 4.54 & 0.78 & 4.65 & 0.86 \\
Gratitude & 2.83 & 0.26 & 3.04 & 0.26 \\
Happiness & 4.88 & 0.96 & 4.95 & 1.03 \\
Resilience & 3.91 & 1.18 & 4.14 & 1.09 \\
Self-Esteem & 3.58 & 0.46 & 3.51 & 0.51 \\
Social Anxiety & 2.20 & 0.80 & 2.18 & 0.73 \\
Depression & 1.79 & 0.57 & 1.82 & 0.73 \\
Coping Adapt & 3.23 & 0.74 & 2.96 & 0.61 \\
Coping Mal & 2.31 & 0.64 & 2.41 & 0.54 \\
Aggression & 1.74 & 0.77 & 1.84 & 0.98 \\
\hline
\end{tabular}


ONLINE APP TO DEVELOP POSITIVE AFFECT IN ADOLESCENTS

Table 3

Experimental group means and standard deviations of dependent variables at times T1 and T2

\begin{tabular}{lcccc}
\hline & \multicolumn{2}{c}{$\mathrm{T} 1$} & \multicolumn{2}{c}{$\mathrm{T} 2$} \\
\cline { 2 - 5 } & $\mathrm{M}$ & $\mathrm{SD}$ & $\mathrm{M}$ & $\mathrm{SD}$ \\
\hline Savouring & 4.46 & 0.99 & 4.53 & 0.88 \\
Gratitude & 2.81 & 0.19 & 3.00 & 0.32 \\
Happiness & 4.90 & 0.83 & 4.73 & 1.07 \\
Resilience & 3.71 & 1.32 & 3.84 & 1.43 \\
Self-Esteem & 3.62 & 0.45 & 3.55 & 0.44 \\
Social Anxiety & 2.30 & 0.92 & 2.45 & 0.80 \\
Depression & 1.96 & 0.76 & 1.95 & 0.65 \\
Coping Adapt & 3.17 & 0.83 & 2.78 & 0.66 \\
Coping Mal & 2.44 & 0.62 & 2.60 & 0.56 \\
Aggression & 1.75 & 0.75 & 2.01 & 0.99 \\
\hline
\end{tabular}


Table 4

Correlations among scales used in the present study at Time 1

\begin{tabular}{lcccccccccc}
\hline & 1. & 2. & 3. & 4. & 5. & 6. & 7. & 8. & 9. & 10. \\
\hline 1. Gratitude & 1 & .328 & .497 & -.241 & .056 & -.126 & .432 & -.085 & .232 & .333 \\
2. Savouring & .328 & $1 * *$ & $.460^{* *}$ & $-.247^{*}$ & -.070 & -.225 & $.409^{* *}$ & -.140 & $.194^{*}$ & $.167^{* *}$ \\
3. Self-Esteem & $.497^{* *}$ & .460 & $1 * *$ & $-.604^{*}$ & -.172 & -.293 & $.369^{* *}$ & -.257 & .329 & .378 \\
4. Depression & $-.241^{* *}$ & $-.247^{* *}$ & -.604 & $1^{* *}$ & .286 & $.521^{*}$ & $-.314^{* *}$ & $.499^{*}$ & $-.167^{* *}$ & $-.200^{* *}$ \\
5. Aggression & $.056^{*}$ & $-.070^{*}$ & $-.172^{* *}$ & .286 & $1^{*}$ & $.508^{* *}$ & $-.112^{* *}$ & $.275^{* *}$ & -.020 & .018 \\
6. Cope (mal) & -.126 & -.225 & -.293 & $.521^{*}$ & .508 & $1^{* *}$ & -.260 & $.500^{*}$ & -.098 & -.235 \\
7. Cope (adapt) & .432 & .409 & $.369^{*}$ & $-.314^{* *}$ & $-.112^{* *}$ & -.260 & $1^{*}$ & $-.133^{* *}$ & .212 & $.332^{*}$ \\
8. Social Anxiety & $-.085^{* *}$ & $-.140^{* *}$ & $-.257^{* *}$ & $.499^{* *}$ & .275 & $.500^{*}$ & -.133 & 1 & -.361 & $-.169^{* *}$ \\
9. Happiness & .232 & .194 & $.329^{*}$ & $-.167^{* *}$ & $-.020^{*}$ & $-.098^{* *}$ & .212 & -.361 & $1 * *$ & .475 \\
10. Resilience & $.333^{*}$ & .167 & $.378^{* *}$ & -.200 & .018 & -.235 & .332 & $-.169^{* *}$ & .475 & $1^{* *}$ \\
\hline
\end{tabular}

**. Correlation is significant at the 0.01 level (2-tailed).

*. Correlation is significant at the 0.05 level (2-tailed). 
Table 5

Correlations among scales used in the present study at T2

\begin{tabular}{|c|c|c|c|c|c|c|c|c|c|c|}
\hline & 1. & 2. & 3. & 4. & 5. & 6. & 7. & 8. & 9. & 10. \\
\hline 1. Gratitude & 1 & $.289 *$ & $.255^{*}$ & -.090 & -.076 & -.227 & $.295^{*}$ & -.011 & $.258^{*}$ & $.450^{*}$ \\
\hline 2. Savouring & $.289 *$ & $1 * *$ & $.486^{* *}$ & $-.311^{* *}$ & -.172 & $-.410 * *$ & .111 & $-.235^{*}$ & .218 & .225 \\
\hline 3. Self-Esteem & $.255^{*}$ & $.486^{* *}$ & $1 * *$ & $-.579 *^{*}$ & -.187 & $-.418 * *$ & .019 & -.290 & $.572 * *$ & $.356^{* *}$ \\
\hline 4. Depression & -.090 & $-.311^{* *}$ & $-.579 * *$ & $1 * *$ & .222 & $.419 *^{*}$ & .086 & $.458 * *$ & $-.378^{* *}$ & -.141 \\
\hline 5. Aggression & -.076 & $-.172^{*}$ & -.187 & .222 & $1^{*}$ & .217 & .086 & .148 & .031 & -.031 \\
\hline 6. Cope (mal) & -.227 & $-.410 * *$ & $-.418^{* *}$ & $.419^{* *}$ & .217 & $1 * *$ & .060 & $.301^{* *}$ & -.226 & -.062 \\
\hline 7. Cope (adapt) & $.295^{*}$ & .111 & $.019^{*}$ & .086 & .086 & .060 & $1^{*}$ & .153 & $.233 *$ & $.264^{*}$ \\
\hline 8. Social Anxiety & -.011 & $-.235^{*}$ & $-.290^{* *}$ & $-.458^{* *}$ & .148 & $.301^{*}$ & .153 & 1 & -.281 & -.159 \\
\hline 9. Happiness & .258 & .218 & $.572^{*}$ & $-.378^{* *}$ & $-.031^{*}$ & -.226 & $.233^{*}$ & -.283 & $1 * *$ & $.513^{* *}$ \\
\hline 10. Resilience & $.450^{*}$ & .225 & $.356^{* *}$ & -.141 & -.031 & -.062 & .264 & -.159 & .513 & $1 * *$ \\
\hline
\end{tabular}

**. Correlation is significant at the 0.01 level (2-tailed).

*. Correlation is significant at the 0.05 level (2-tailed). 


\section{Internal Reliability of Scales}

Cronbach's alpha $(\boldsymbol{\alpha})$ was used as a measure of the internal consistency of the scales employed in the current study. Most of Cronbach's alphas were found to be adequate (see Table 1), but the Cronbach's alpha was marginally acceptable for the measure of subjective happiness $(\alpha=.68)$.

Table 6

Information on all scales used in the survey

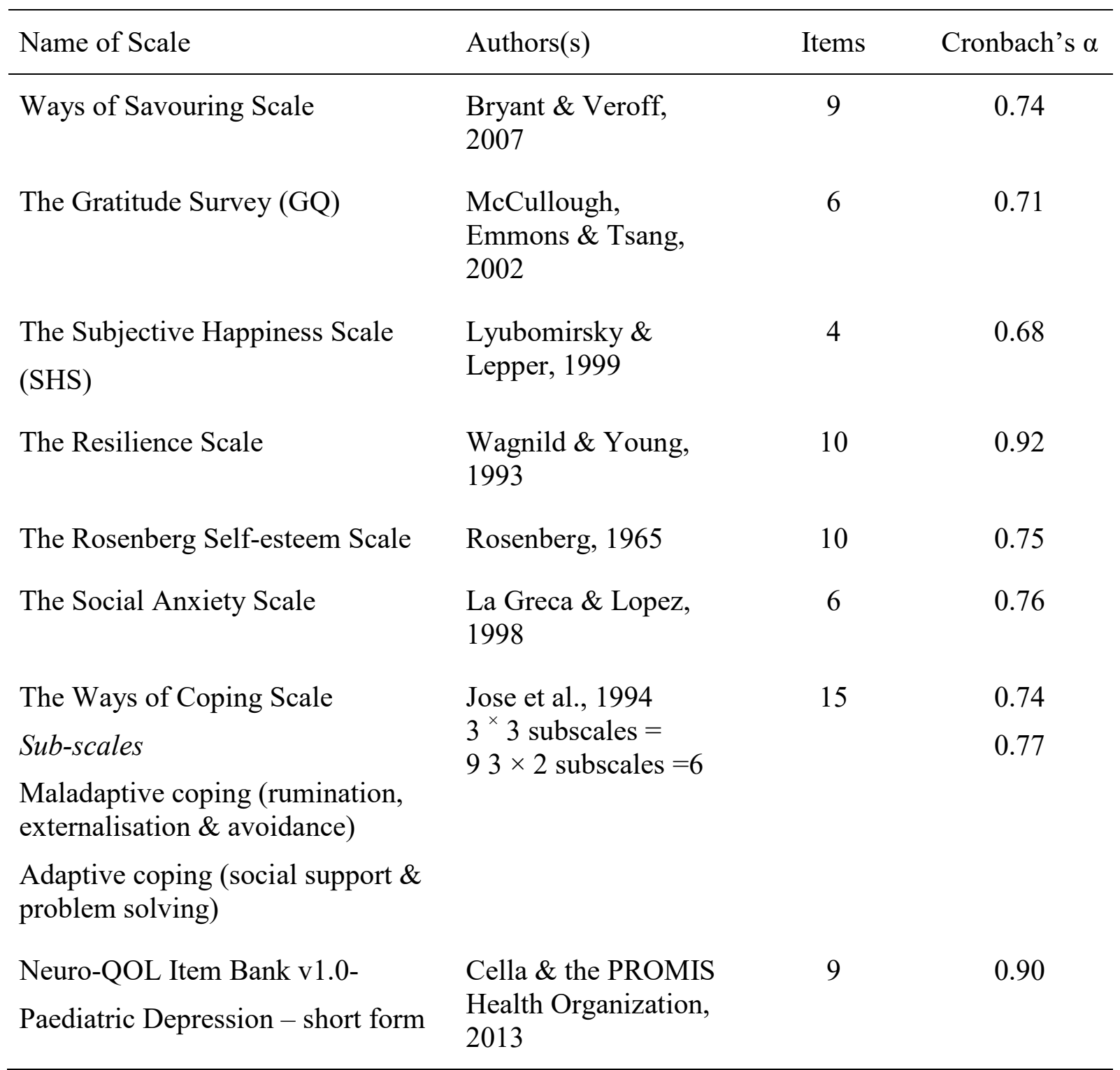




\section{Correlations}

Correlations between all variables at T1 and T2 were calculated. As illustrated in Tables 4 and 5, and as anticipated, the majority of variables were significantly correlated. As expected, gratitude was positively related to the positive outcomes of savouring, self-esteem, adaptive coping, happiness and resilience, and gratitude was inversely related to the maladaptive outcome of maladaptive coping. Savouring was positively related to positive outcomes of gratitude, self-esteem, adaptive coping, happiness and resilience. As expected, self-esteem was positively related to happiness and resilience. Also in line with predictions, depression was positively related to the maladaptive outcomes of social anxiety, aggression and maladaptive coping, and depression was inversely related to happiness and self-esteem. As expected, maladaptive coping was related to the maladaptive outcome of social anxiety.

Missing data. All missing data were imputed using the expectationmaximization (EM) algorithm (Dempster, Laird, \& Rubin, 1977). The EM algorithm is a valid iterative method, which generates maximum likelihood estimation of the probability density for incomplete data. This procedure was used for all scales.

Missing data were found to be "missing at random", and amounted to less than five percent of all data. Results presented here were similar for both the original dataset (with missing values) and the imputed dataset.

\section{Hypotheses}

To remind the reader, the objectives of the data analysis undertaken here were to address three key research hypotheses:

1. The app was expected to increase positive emotions (gratitude, savouring, selfesteem); and

2. The app was expected to increase psychological outcomes (subjective happiness, resilience and reduced depression).

3. A mediational analysis was expected to reveal that resilience would mediate the relationship between adaptive coping, and the positive outcomes of subjective happiness, gratitude, and the reduced negative outcomes of depression and aggression. 


\section{Group Differences in Positive Emotions: Hypothesis 1}

Two multivariate analyses of variance (MANOVAs) were run in order to test the first two hypotheses. The dependent variables were tested in two different MANOVAs in order to reflect a distinction between proximal constructs directly related to the content of the app (savouring, gratitude and self-esteem) separately from those that were more distal (depression, resilience, happiness, and social anxiety). In the first analysis, a three-way repeated measure multivariate analysis of variance (MANOVA) was conducted to determine the effects of intervention condition (experimental versus control), time (TI versus T2), and age category (under-13 versus over-13) on the three dependent variables of savouring, gratitude, and self-esteem.

The multivariate effects for time $(F(3,132)=7.984, p<.001$; Wilk's $\lambda=.846$, partial $\left.\eta^{2}=.154\right)$ and age $\left(F(3,132)=3.201, p<.05 ;\right.$ Wilk's $\lambda=.932$, partial $\left.\eta^{2}=.068\right)$ were found to be statistically significant. Table 5 shows the results from the multivariate tests. Contrary to the main prediction of the study, no significant differences were found with respect to the interaction of time and intervention condition. These findings indicate that after completing the app, participants in the experimental group did not rate their positive emotions higher on the measures of gratitude, savouring and self-esteem, as compared with participants in the control group at Time 2 .

Table 7

Results from multivariate tests with savouring, gratitude and self-esteem as DVs

\begin{tabular}{lcccccc}
\hline Effect & $\begin{array}{r}\text { Wilks } \\
\text { lambda }\end{array}$ & $\mathrm{F}$ & $\begin{array}{c}\text { Hypothesis } \\
\mathrm{df}\end{array}$ & Error df & Sig. & $\eta^{2}$ \\
\hline Condition & .995 & $.206^{\mathrm{b}}$ & 3 & 132 & .892 & .005 \\
AgeCat & .932 & $3.201^{\mathrm{b}}$ & 3 & 132 & .026 & .068 \\
Time & .846 & $7.984^{\mathrm{b}}$ & 3 & 132 & .000 & .154 \\
Condition * AgeCat & .958 & $1.942^{\mathrm{b}}$ & 3 & 132 & .126 & .042 \\
Condition * Time & .998 & $.067^{\mathrm{b}}$ & 3 & 132 & .977 & .002 \\
AgeCat* Time & .975 & $1.134^{\mathrm{b}}$ & 3 & 132 & .338 & .025 \\
Condition * AgeCat * Time & .971 & $1.295^{\mathrm{b}}$ & 3 & 132 & .279 & .029 \\
\hline
\end{tabular}


Univariate results. Univariate analyses were run in order to examine the effects of condition, age category, and time separately on gratitude, savouring, and self-esteem scores. The $F$-values for these univariate ANOVAs and their accompanying effect sizes, calculated as partial eta squared $\left(\eta^{2}\right)$, together with the means and standard deviations for the first MANOVA are presented in Table 8.

Univariate results revealed a significant effect for time on gratitude $(F(1,134)=22.50$, $p<.05$; Wilk's $\lambda=1.45$, partial $\left.\eta^{2}=0.229\right)$. Participants' scores on gratitude increased from $\mathrm{T} 1(M=2.83, S D=.23)$ to $\mathrm{T} 2(M=3.02, S D=.29)$. This finding indicates that after completing the first outcome measure, participants recorded higher gratitude scores regardless of whether they had received the intervention or were in the control group. Univariate analyses also revealed a significant effect for age category on gratitude $(F(1,134)=5.127, p<$ .05 ; partial $\left.\eta^{2}=.037\right)$. Participants' scores on gratitude were higher for older participants ( $M$ $=2.99, S D=.31)$ compared to younger participants $(M=2.89, S D=.25)$. No predictions were made for these variables so these results are treated as unexpected.

Exploratory analyses. Because significant results were found for time and age category, follow-up analyses were run. A significant interaction between condition and age on gratitude was identified $\left(F(1,134)=4.677, p<.05\right.$; partial $\left.\eta^{2}=.034\right)$. This result indicates that participants' scores for gratitude were lower for the intervention $(M=2.88, S D=.20)$ compared to control group $(M=3.03, S D=.27)$ for younger people, and in contrast were higher for the intervention group $(M=3.21, S D=.39)$ compared to the control group $(M=$ $3.05, S D=.26$ ) for those in the older age category. This result suggests that the intervention may have had the expected impact on older participants, but not for younger participants. Univariate results revealed that the effect of time, age category, and condition on savouring and self-esteem were not significant (see Table 8). 
Table 8

Results from univariate tests with savouring, gratitude and self-esteem as the DV

\begin{tabular}{|c|c|c|c|c|c|}
\hline & & Df & $\mathrm{F}$ & Sig. & Partial $\eta_{2}$ \\
\hline \multirow[t]{3}{*}{ Condition } & Savouring & 1 & .118 & \multirow{2}{*}{.732 .978} & \multirow{2}{*}{.001 .000} \\
\hline & Gratitude & 1 & .001 & & \\
\hline & SE & 1 & .500 & .481 & .004 \\
\hline \multirow[t]{3}{*}{ Age Cat } & Savouring & 1 & 3.454 & \multirow{2}{*}{.065 .025} & \multirow{2}{*}{.025 .037} \\
\hline & Gratitude & 1 & 5.127 & & \\
\hline & SE & 1 & 1.893 & .171 & .014 \\
\hline \multirow[t]{3}{*}{ Time } & Savouring & 1 & .310 & .578 & \multirow{2}{*}{.002 .144} \\
\hline & Gratitude & 1 & 22.502 & .000 & \\
\hline & SE & 1 & .702 & .404 & .005 \\
\hline \multirow[t]{3}{*}{ Condition * Age Cat } & Savouring & 1 & .821 & \multirow{2}{*}{.367 .032} & \multirow{2}{*}{.006 .034} \\
\hline & Gratitude & 1 & 4.677 & & \\
\hline & $\mathrm{SE}$ & 1 & .170 & .681 & .001 \\
\hline \multirow[t]{3}{*}{ Condition $*$ Time } & Savouring & 1 & .140 & \multirow{2}{*}{.709 .873} & \multirow{2}{*}{.001 .000} \\
\hline & Gratitude & 1 & .026 & & \\
\hline & SE & 1 & .045 & .831 & .000 \\
\hline \multirow[t]{3}{*}{ Age Cat $*$ Time } & Savouring & 1 & .552 & \multirow{2}{*}{.459 .112} & \multirow{2}{*}{.004 .019} \\
\hline & Gratitude & 1 & 2.556 & & \\
\hline & SE & 1 & .117 & .733 & .001 \\
\hline Condition * Age Cat * & Savouring & 1 & .009 & \multirow{2}{*}{.926 .205} & \multirow{2}{*}{.000 .012} \\
\hline \multirow{2}{*}{ Time } & Gratitude & 1 & 1.624 & & \\
\hline & SE & 1 & 2.187 & .142 & .016 \\
\hline
\end{tabular}




\section{Group Differences in Resilience, Well-being, and Happiness: Hypothesis 2}

A second three-way repeated measures MANOVA was conducted to determine the effect of intervention condition (experimental versus control), time (TI vs. T2), and age category (under 13 vs. over 13) on the four distal dependent variables: depression, resilience, happiness, and social anxiety. The multivariate main effect for experimental condition by age category was found to be significant $\left(F(4,131)=3.833, p<.001\right.$; Wilk's $\lambda=.895$, partial $\eta^{2}$ $=.105)$. Table 8 shows the results from the multivariate tests. It was hypothesised that scores on resilience and happiness would increase and scores on depression and social anxiety would decrease between T1 and T2 for the experimental group. However, no significant differences were found with respect to the interaction of time and intervention conditions, which was one of the main hypotheses of the current study. The results presented in Table 9 show that this prediction was not supported.

Table 9

Multivariate results with depression, resilience, happiness and social anxiety as DVS

\begin{tabular}{lcccccc}
\hline Effect & $\begin{array}{c}\text { Wilks' } \\
\text { Lambda }\end{array}$ & F & $\begin{array}{c}\text { Hypothe } \\
\text { sis df }\end{array}$ & Error df & Sig. & $\begin{array}{c}\text { Partial } \\
\eta^{2}\end{array}$ \\
\hline Condition & .978 & .735 & 4 & 131 & .570 & .022 \\
AgeCat & .895 & 3.833 & 4 & 131 & .006 & .105 \\
Time & .992 & .261 & 4 & 131 & .903 & .008 \\
Condition * AgeCat & .985 & $.514^{\mathrm{b}}$ & 4 & 131 & .726 & .015 \\
Condition * Time & .997 & $.086^{\mathrm{b}}$ & 4 & 131 & .987 & .003 \\
AgeCat * Time & .992 & $.273^{\mathrm{b}}$ & 4 & 131 & .895 & .008 \\
Condition * AgeCat * Time & .953 & $1.604^{\mathrm{b}}$ & 4 & 131 & .177 & .047 \\
\hline
\end{tabular}

Univariate results. Univariate analyses were run in order to examine effects of condition, age, and time on depression, resilience, happiness, and social anxiety scores. Univariate results revealed that age category yielded a significant main effect on depression scores $\left(F(1,134)=4.392, p<.05\right.$; partial $\left.\eta^{2}=.032\right)$. Table 9 shows that younger participants 
reported higher scores on depression $(M=1.95, S D=.68)$ than did older participants $(M=$ $1.73, S D=.65)$. This result was not predicted and is presented here for the purpose of describing the data completely. The effect of time and condition on depression was not significant. Furthermore, univariate results revealed that the effect of time, age category, and condition on resilience, happiness, and social anxiety were not significant (see Table 10).

Table 10

Results from univariate tests with depression, resilience, happiness and social anxiety as the DV

\begin{tabular}{|c|c|c|c|c|c|c|}
\hline & & $\mathrm{DF}$ & MS & $\mathrm{F}$ & Sig. & Partial $\eta^{2}$ \\
\hline \multirow[t]{4}{*}{ Condition } & Dep & 1 & .310 & .690 & .407 & .005 \\
\hline & Resilience & 1 & 2.770 & 1.773 & .185 & .013 \\
\hline & Happiness & 1 & .352 & .358 & .551 & .003 \\
\hline & SocAnx & 1 & .908 & 1.381 & .242 & .010 \\
\hline \multirow[t]{4}{*}{ Age Cat } & Dep & 1 & 1.975 & 4.392 & .038 & .032 \\
\hline & Resilience & 1 & 1.204 & .770 & .382 & .006 \\
\hline & Happiness & 1 & .181 & .183 & .669 & .001 \\
\hline & SocAnx & 1 & 1.065 & 1.621 & .205 & .012 \\
\hline \multirow[t]{4}{*}{ Time } & Dep & 1 & .005 & .012 & .914 & .000 \\
\hline & Resilience & 1 & .811 & .519 & .473 & .004 \\
\hline & Happiness & 1 & .004 & .004 & .952 & .000 \\
\hline & SocAnx & 1 & .025 & .039 & .844 & .000 \\
\hline \multirow[t]{4}{*}{ Condition * Age Cat } & Dep & 1 & .809 & 1.799 & .182 & .013 \\
\hline & Resilience & 1 & .021 & .013 & .908 & .000 \\
\hline & Happiness & 1 & .110 & .112 & .738 & .001 \\
\hline & SocAnx & 1 & .651 & .990 & .322 & .007 \\
\hline
\end{tabular}




\begin{tabular}{|c|c|c|c|c|c|c|}
\hline & & DF & MS & $\mathrm{F}$ & Sig. & Partial $\eta^{2}$ \\
\hline \multirow[t]{4}{*}{ Condition $*$ Time } & Dep & 1 & .014 & .032 & .859 & .000 \\
\hline & Resilience & 1 & .138 & .089 & .766 & .001 \\
\hline & Happiness & 1 & .153 & .156 & .694 & .001 \\
\hline & SocAnx & 1 & .179 & .272 & .603 & .002 \\
\hline \multirow[t]{4}{*}{ AgeCat $*$ Time } & Dep & 1 & .168 & .374 & .542 & .003 \\
\hline & Resilience & 1 & .351 & .225 & .636 & .002 \\
\hline & Happiness & 1 & .091 & .092 & .762 & .001 \\
\hline & SocAnx & 1 & .255 & .387 & .535 & .003 \\
\hline \multirow[t]{4}{*}{ Condition $*$ Age Cat $*$ Time } & Dep & 1 & 1.241 & 2.759 & .099 & .020 \\
\hline & Resilience & 1 & .247 & .158 & .691 & .001 \\
\hline & Happiness & 1 & .404 & .410 & .523 & .003 \\
\hline & SocAnx & 1 & .012 & .018 & .893 & .000 \\
\hline
\end{tabular}

\section{Mediation of the Relationships between Adaptive Coping and Resilience and Positive Outcomes of Subjective Happiness, Aggression, Depression, and Gratitude: Hypothesis 3}

It was expected that adaptive coping would be positively predictive of resilience, and that resilience, in turn, would positively predict indicators of psychological well-being at T2. A path model was constructed to test the mediation hypothesis posed (Schumacker \& Lomax, 1996). In order to conduct path model analyses, the SEM program AMOS 22 (Arbuckle, 2009) was used. The model was pruned to obtain a data-based model (Kline, 2005) by removing the statistically nonsignificant paths. Standardised regression coefficients are reported in Figure 2. Condition (experimental vs. control) was covaried out of all variables included in the model in order to remove the (small) influence exerted by experimental condition.

Direct effects. It was found that after controlling for the effect of experimental condition $(b=-.056)$, adaptive coping was a significant predictor of resilience $(\beta=.478, p<$ $.05)$. In the next step, resilience was found to be a significant predictor of gratitude $(\beta=.126, p$ 
$<.05)$, subjective happiness $(\beta=.191, p<.05)$, a significant negative predictor of depression $(\beta$ $=-.161, p<.05)$; however, resilience did not significantly predict aggression $(\beta=.114, p<.05)$.

Indirect effects. The bootstrapping option in AMOS was utilised to estimate the indirect effects proposed in the model. It was found that once resilience was entered as a proposed mediator, adaptive coping was no longer a significant direct predictor of gratitude ( $\beta$ $=.149, \mathrm{p}=.087)$, subjective happiness $(\beta=.048, \mathrm{p}=.431)$ or significant (negative) predictor of depression $(\beta=.026, p=.811)$. These results support the mediational hypothesis showing that resilience fully mediated the effects of adaptive coping on the psychological outcome variables.

The bootstrapping estimation function supported the presence of three statistically significant indirect effects: 1) Adaptive coping to Resilience to Happiness, indirect effect = .091 , standard error $=.039,95 \% \mathrm{CI}=[.027, .183], \mathrm{p}=.002 ; 2)$ Adaptive coping to Resilience to Depression, indirect effect $=-.077$, standard error $=.070,95 \% \mathrm{CI}=[-.198,-.015], \mathrm{p}=.008$; and 3 ) Adaptive coping to Resilience to Gratitude, indirect effect $=.060$, standard error $=.054$, $95 \% \mathrm{CI}=[.009, .169], \mathrm{p}=.012$. The fourth path proved to be non-significant: Adaptive coping to Resilience to Aggression, indirect effect $=.054$, standard error $=.101,95 \% \mathrm{CI}=[-$ $.026, .241], \mathrm{p}=.143$.

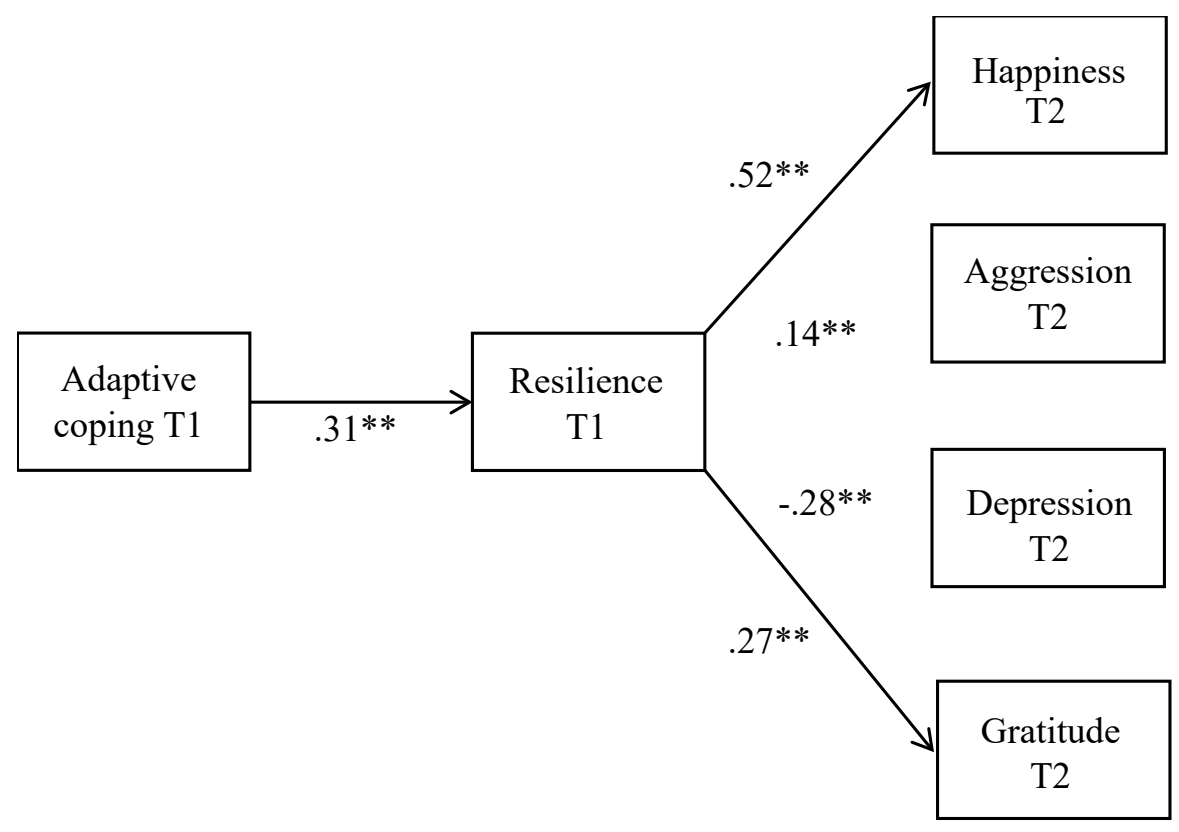

Figure 2. Path model for adaptive coping, resilience, and outcomes of subjective happiness, aggression, depression and gratitude for the total sample. All path coefficients represent standardised regression weights. 
The results demonstrated that resilience played a crucial mediational role between adaptive coping on the one hand and positive psychological outcomes on the other hand. According to the present findings, almost all of the effect of adaptive coping on the indicators of wellbeing was transmitted through the mediating variable of resilience.

\section{Descriptive Analysis of Data Captured by the App}

Informed by the qualitative research method 'grounded theory' (Strauss \& Corbin, 1990), qualitative methods were used to gain an understanding of participants' experience of the app, as well as to identify dominant patterns or themes that emerged from the data (see method section, p. 61 for more details). The topics explored in the qualitative results below are concerned with the identified themes that are relevant to the literature, and rates of completion for each quest. First, the percentage of the app that participants completed is reported for all quests. Second, the data collected from each activity in the app will be discussed, and thematic analysis will be conducted for all text responses in order to identify dominant patterns from the data.

Completion percentages. It was important to examine what percentage of the app was completed as it was hoped that this would provide some indication of whether the selfdirected app was an appropriate format to deliver this intervention. Findings showed that on average individuals completed $79.7 \%$ of the app, and $36.8 \%$ of the sample completed $100 \%$ of the app. These findings indicate that individuals who engaged with the app completed the majority of activities (see Table 5).

Table 11

Percentage of each Quest completed by individuals

\begin{tabular}{lcccc}
\hline$\%$ Completed & Quest 1 & Quest 2 & Quest 3 & Quest 4 \\
\hline $100 \%$ & 54 & 63 & 18 & 36 \\
Partially complete & 0 & 0 & 2 & 2 \\
Did not complete & 14 & 5 & 48 & 30 \\
\hline
\end{tabular}

** Partially complete: individual took three photos but commented on fewer than three Themes 
The purpose of this part of the analysis was to discover the themes that emerged when individuals responded to the text directions and prompts that were given in the app. It was of interest to the researcher that participants identified particular groups (i.e. parents, friends or teachers) or objects and experiences in their social worlds. This approach was intended to assist in understanding schemas accessed by adolescents. Themes are discussed below using quotations from individual responses to illustrate the young person's attitudes and feelings about the positive aspects in their lives. A brief summary of the qualitative analysis follows the description of themes.

\section{Quest 1. 'Happy Album': Photo-taking Activity.}

Individuals were asked to 'take one snap' a day to earn berries. After three days had passed, individuals were instructed to reflect on their photos and record what they had liked about them and why. The purpose of asking participants to take photos was to invite them to savour the moment, effectively prolonging a positive experience or event by capturing it on their smartphone camera. The purpose of asking individuals to reflect was intended to incentivise them to savour the moment again by replaying the positive emotion they had first experienced when taking the photo. The reason for examining these responses was to identify patterns or emergent themes. It was hoped that this information would provide insight into particular categories of items or experiences that made individuals happy and what was important to them.

\section{Content Categories}

Six broad themes were derived from the data:

1. Friends

2. Sport and leisure

3. Abstract thought

4. Animals

5. Academic achievement or learning

6. Family

Each theme is listed in Table 5 and each is presented with a frequency score to illustrate how many times the category was mentioned. This is followed by examples of quotations from the data to illustrate the participants' attitudes and feelings. A brief summary 
of the qualitative analysis follows the description of themes. Table 6 shows that overall, individuals produced the highest number of attributions targeted toward friends, followed by sport, abstract thought, school achievement and family. Each of these categories will be discussed below:

Friends. Individuals attributed feelings of happiness towards friends more frequently than the other categories (e.g. "My friend [NAME] makes me really happy because he is a very good friend"). Individuals also referred to the importance of communication with their friends (i.e. "My iPhone made me happy because I could communicate with mates on it" or appreciating a friend because they were "fun to hang out with".

Sport . Individuals made 16 references to sport or exercise as events or experiences that made them feel good (e.g. "it made me want to go out and play soccer"; "This is my mountain bike. I love mountain biking so much because it gives me lots of adrenalin, and also how I feel happy when I'm riding in the forests and hills").

Abstract thought. Individuals sometimes displayed instances of abstract thought when reflecting on their photos (e.g. "I like the scenery and how it is a familiar place for me with good vibes"). This finding is consistent with developmental research that indicates early adolescents typically think in concrete ways but begin to develop abstract thinking (Piaget, 1950). Given that the samples used here were aged between 10 and 15 years of age, which is the time that adolescents start to, develop abstract thought, our findings may be reflective of the sample starting to think in an abstract manner.

Animals. Individuals spoke about animals or pets as making them happy, and providing a sense of comfort (e.g. "I like my cat and he makes me feel comfortable"; "My dog is so important to me"), and security (e.g. "She's always there to help me and I know she'll always make me feel good and make me laugh").

Academic/learning. Individuals spoke about school work or academic pursuits; for example learning new skills (e.g. "I like how I learned how a computer works and customising the different parts"), and displayed an interest in reading (e.g. "Reading always makes me happy. It takes me to a different place separate from all my problems").

Family. There were fewer references to family than the other listed categories (four instances). The purpose of examining the number of references to this category was because family is described as a key protector for adolescents in the literature. The fact that there were 
fewer references to family is consistent with literature that indicates adolescence is a period of change in interactions between family members, with adolescents seeking autonomy and developing a sense of independent self (Phinney, Kim-Jo, Osorio, \& Vilhjalmsdottir, 2005).

Table 12

How participants responded when asked to record what made them happy about their photos.

\begin{tabular}{|c|c|c|}
\hline Thematic Category & Frequency & Characteristic Response \\
\hline Friends & 19 & $\begin{array}{l}\text { My friends make me happy because they're } \\
\text { always there when I need them. They always } \\
\text { support me and make me feel welcome. }\end{array}$ \\
\hline Sport & 17 & These are my running shoes and I like to run. \\
\hline Abstract thought & 16 & $\begin{array}{l}\text { Imagine that the picture was actually of a } \\
\text { guitar. Music makes me happy and I like being } \\
\text { able to share it with other people. }\end{array}$ \\
\hline Animals & 15 & $\begin{array}{l}\text { I love my horse because he is cool, reliable and } \\
\text { trustworthy; when I am around him I feel safe. }\end{array}$ \\
\hline Academic/ learning & 8 & $\begin{array}{l}\text { This is the college I attend. I am a top grade } \\
\text { student and I love it here. }\end{array}$ \\
\hline Family & 4 & $\begin{array}{l}\text { My mom is always making jokes, being silly and } \\
\text { making me happy. }\end{array}$ \\
\hline
\end{tabular}

It was important to examine the total number of photos taken to establish whether individuals had completed the activity (see Table 5). Findings showed that 165 photos were taken by the 55 individuals who completed the app. Almost all $(\mathrm{N}=160)$ of these photos received comments. This finding shows that the majority of individuals who took photos commented on all of them, and it also indicated that they completed the activity. These findings suggest that individuals substantially engaged in this activity, and it was appropriate to deliver this exercise via smartphone in this sample.

\section{Quest 2. 'Your Strengths' (Part 1)}

It was important to examine how many individual character strengths the individuals felt they had. It was hoped responses would illuminate domains where individuals were 
confident. Percentages were calculated to show an average number of statements per person, out of a possible 18, that individuals were able to select. On average, individuals checked 14.49 statements out of $18(80.51 \%)$, (see Table 7$)$.

Table 13

Domain name, total statements available, number of statements selected, and example statement.

\begin{tabular}{lccl}
\hline Domain & $\begin{array}{c}\text { No. of } \\
\text { Statements }\end{array}$ & $M$ & Example of positively worded statement \\
\hline School & 4 & 3.24 & $\begin{array}{l}\text { There is at least one subject at school I do very } \\
\text { well in. }\end{array}$ \\
Family & 3 & 2.75 & $\begin{array}{l}\text { I have a good and strong relationship with one } \\
\text { of my adult relatives. }\end{array}$ \\
Friends & 3 & 2.75 & $\begin{array}{l}\text { I have close friends. } \\
\text { Personal }\end{array}$ \\
Extra & 5 & 3.60 & $\begin{array}{l}\text { I can enjoy good things that happen in my life. } \\
\text { I have a hobby or hobbies. }\end{array}$ \\
\hline
\end{tabular}

Findings showed that individuals identified the highest number of statements in the friends domain (e.g. "I am liked by other students") followed by extra (e.g. "I am good at sports or other physical things"), followed by school (e.g. "I can communicate clearly to teachers in class") and family (e.g. "I find it easy to talk to my family"). Participants identified fewer strengths in personal (e.g. "I find it easy to express my emotions") than in any of the other domains. This result may indicate a reluctance to observe aspects of the self in the personal domain. These statements included: "I like to laugh", "I can manage tough times", "I can enjoy good things that happen in my life", "I find it easy to express my emotions", and "I find it easy to trust others". It is noteworthy that there were five statements in the personal domain, as compared to the other domains where there were three to four statements. It is possible that the low score may have been due to the fact that individuals did not wish to check five statements, as it may have been the case that this felt like more of a commitment than checking three or four, as was required in the other domains. 


\section{Quest 2. 'Character Strengths' Part 2. Ideal Future Selves}

This activity was not compulsory; settings in the app meant participants could proceed without entering a response in this section. The optional nature of this choice meant it was important to examine the percentage that individuals completed as a low rate of completion may have indicated a low level of engagement that in turn would impact on the success of the app.

Participants had been instructed to enter 'at least four' words to describe themselves if they had reached their goals in 'one year's time'. This activity was designed for up to six words to be entered, with the aim of not restricting those individuals who wished to enter more than four words. Findings showed that out of six text boxes available, $73.0 \%$ of participants entered more than four words, $22.2 \%$ entered four, and 5.0\% entered less than four. These frequencies indicate that the majority of individuals completed the maximum number of text boxes that were available, and this result suggests that participants were properly engaged in this activity (and the app in general).

\section{Content Categories}

Six themes were derived from the data: (1) Sport (2); Academic; (3) Humour; (4) Happy; (5) Creative; and (6) Friends/Popular/Outgoing. Responses are displayed in Table 2. Results showed that most commentary revolved around acquiring skills and improving existing expertise in sport (e.g. "Excellent at netball”); this category was mentioned twice as much as next category, which was academic (e.g. "Good at school work”). Having good relationships with friends/being popular or outgoing, and being funny were equally mentioned (11\%). Lastly, being happy or fulfilled was mentioned $(8.0 \%)$ of the time, and possessing artistic or creative abilities (7.0\%).

These findings indicate that sport (Blomfield \& Barber, 2009), peer relations (Brown, 1990), and development of the self (Erikson, 1968) were salient to individuals. These topics have been previously identified as typical concerns of early adolescents. 
Table 14

How participants responded when $\{|C L 6|\}$ asked what it would look like if they had achieved their goals in 12 months' time:

\begin{tabular}{lcl}
\hline Thematic Category & Frequency & Characteristic Response \\
\hline Sport & 25 & better at swimming \\
Academic & 13 & excelling in the A stream \\
Fun/funny & 11 & fun to be around \\
Friends/ popular & 11 & $\begin{array}{l}\text { liked by others/ easy to make } \\
\text { friends }\end{array}$ \\
Happy/fulfilled & 8 & happy with life \\
Artistic/creative & 7 & creative \\
\hline
\end{tabular}

* Other categories that were mentioned less than 5\% of the time included: physical attractiveness, time management, caring for others, career, creative pursuits, technology, talent and cooking.

\section{Quest 4. 'Feed it Back'}

Participants were asked to write a letter of gratitude to someone who had been kind or had helped them. The main recipients of participants' letters of gratitude were stored in the app and identified. The purpose of this task was to see if participants identified particular groups of individuals, and to identify any such patterns. It was hoped that this information might provide an indication of who is important to adolescents. Four major recipient groups were derived from the data: (1) Friends, (2) Parents, (3) Teachers and (4) Others (see Table 9). The table shows who the recipients were, and provides an example of the kinds of commentary participants wrote for each category. 
Table 15

How participants responded when asked to write a letter of gratitude

\begin{tabular}{|c|c|c|}
\hline Category & Frequency & Example Letter of Gratitude \\
\hline Friends & 11 & For being there when I need you and always making me laugh. \\
\hline Mum & 11 & $\begin{array}{l}\text { To Mum: Thank you for always being there for me. Even if it's } \\
\text { taking me to my activities, to supporting me in tough times, I will } \\
\text { always love you :) }\end{array}$ \\
\hline Dad & 5 & $\begin{array}{l}\text { Dad: I am so grateful for your support in sports and everything I } \\
\text { do. }\end{array}$ \\
\hline Parents & 4 & $\begin{array}{l}\text { I am grateful for my parents as they do a lot for me: they have } \\
\text { bought me things, they feed me, they put a roof over my head, } \\
\text { and they pay for my education. When I am stuck they will help } \\
\text { me and they also give me lots of love. }\end{array}$ \\
\hline Teacher & 2 & $\begin{array}{l}\text { To (science teacher): I am grateful because you have taught me } \\
\text { well in science and helped me think strategically. }\end{array}$ \\
\hline Other & 3 & $\begin{array}{l}\text { Thank you for _me and telling me about being an electrician. } \\
\text { It has inspired me to do many of my projects. All the things you } \\
\text { tell me are intriguing and inspiring. }\end{array}$ \\
\hline
\end{tabular}

Findings indicate that letters of gratitude were written most frequently to Mum and friends. Other frequent categories mentioned were Dad, both parents together, teachers, and other. These findings are consistent with previous developmental literature (Erikson, 1968; Jose, Ryan, \& Pryor, 2012). It is notable while 36 individuals completed the letter of gratitude, 30 did not complete this activity. This could be due to the fact that a large number of participants (47\%) became stuck while they were attempting to complete Quest 3: Be Grateful. It is possible that students abandoned the app after becoming stuck, and so did not proceed to Quest 4. Alternately, perhaps they did not enjoy this activity, or found it difficult to identify someone to whom they felt grateful. It is noteworthy that on the feedback form this quest was identified as the least favourite (only $10 \%$ of participants identified this quest as their favourite). 


\section{Summary}

Overall, the findings from the qualitative analysis are consistent with previous research findings and hypotheses based on developmental theory. A recurrent theme throughout the responses was Friends, which suggests that peers are centrally important for this sample of adolescents, a finding congruent with numerous empirical demonstrations (McGraw et al., 2008; Steinberg, 2010). As discussed above, participants spoke about their friends making them happy, providing support when needed, and making them laugh. Friends were described most often in Quest 1, out of the three quests. It may be that the interactive nature of this first activity and the fact that the app was downloaded at school prompted the first comments to be more focused toward peers. It is notable that this finding conforms to previous research that has shown that adolescents depend significantly on their peer groups in order to savour positive events and experiences (Meehan, Durlak, \& Bryant, 1993).

Research suggests that adolescents function across more than one social context, and that multiple domains influence them at one time (Bronfenbrenner, 1979). Adolescents in the present study mentioned multiple contexts. Alongside friends, another dominant theme mentioned throughout was sport, along with other domains such as family and school. The importance of examining connectedness among adolescents with important groups of people has been suggested in previous research by Jose et al. (2012) and others, where connectedness in various domains has been shown to have lasting positive consequences for well-being. Their study (Jose et al., 2012) illustrated the importance of examining adolescent social connectedness across multiples domains, with a view to developing strategies to build better and stronger connections with other people.

Importantly, the findings in the present study indicate that most adolescents in the study were significantly engaged with completing the tasks conveyed by the app. The results indicated that most individuals completed a large portion of the app. The responses collected indicate that most of the questions were answered appropriately. Since almost all of the text entered by participants corresponded to the questions posed in the app, we can conclude that most participants took the tasks seriously and endeavoured to participate to the best of their abilities. We believe that the app used in the current intervention has potential for effective data collection with adolescents in future psychological research.

The main quantitative findings from the intervention study are discussed in the next chapter. 


\section{Discussion}

The first aim of the present study was to investigate whether the positive, intentional activities delivered in the app had a significant influence on levels of wellbeing in an intervention group who completed the activities when compared to a control group who did not. The second aim of this investigation was to construct a mediational model that would inform the relationships between constructs of psychological well-being and emotions. It was hypothesised that resilience would mediate the relationship between adaptive coping and increased psychological wellbeing outcomes (i.e. subjective happiness, gratitude, less depression and less aggression). This thesis reports the results of this endeavour. The following section will describe the interrelationships found in this research between constructs of wellbeing, and review the mechanisms underlying the pathways from adaptive resources to positive psychological well-being in adolescents.

\section{Group Differences in Positive Emotions at Post-Intervention, Gratitude, Savouring and Self-esteem: Hypothesis 1}

It was expected that the application (app) would have a direct effect on the specific emotions targeted by the study, such as gratitude, savouring and self-esteem. It was also anticipated that the app would positively impact on the constructs of resilience, subjective happiness and depression. Notter (2013) found a statistically significant increase in positive emotions and adaptive behaviour within a group of similarly aged adolescents who participated in her facilitator-led PPI named PAL (Notter, 2013). Her work indicated that delivering positive, intentional activities aimed at fostering positive emotions led to increased resilience and well-being (Frederickson, 1998; 2001). The present study utilised the same content as PAL (Notter, 2013), but adapted it into three separate interventions to target the constructs that were measured (gratitude, savouring, and individual character strengths).

However, the present findings were inconsistent with results from previous studies that supported the efficacy of PPIs in adolescents (Froh, Sefick, \& Emmons, 2008; Notter, 2013). In previous literature, the use of positive, intentional activities have been associated with increased well-being and decreased depressive symptoms (Boiler et al., 2013; Sin \& Lyubomirsky, 2009). However, in direct contrast, the present results indicated that adolescents who received the intervention did not report higher levels of gratitude, savouring, 
or self-esteem compared to those individuals in the control group. Instead, it would appear that there were no appreciable differences based on intervention status.

This prediction was based on prior research that has shown cultivating positive emotion helps to build adaptive resources (Frederickson, 1998; 2001). Studies show that teaching the components of gratitude, savouring, and individual character strengths have successfully cultivated positive emotion and psychological well-being in adolescents (Froh et al., 2008; Toepfer, Cichy, \& Peters, 2011). Similar positive, intentional activities have enhanced well-being in both group-based (Notter, 2013) and online formats (Manicavasagar, 2014). It may have been that the non-significant intervention effect resulted from the brevity of the activities. The current intervention involved five to ten minutes of exercises per day, over six to eight days. Although evidence demonstrates that brief online interventions are successful in developing psychological well-being (e.g. Lyubomirsky, Dickerhoof, Boehm, \& Sheldon, 2008; Sin \& Lyubomirsky, 2009), it seems that most PPI and OPPI studies have typically examined the efficacy of more comprehensive, longer-running interventions (Shapira, 2009). Hence, future work should examine the impact of intervention lengths and determine which are most appropriate for specific populations. This information will have implications for increasing efficacy for short OPPIs, such as the current study.

A second explanation could be that features of the activities (e.g. fit between the person and activity) moderated and attenuated the success of the current intervention. In other words, it could be the case that this intervention was appropriate for some individuals and not others, due to the suitability of the exercises for each participant. In the present study, the results indicated that the app might have impacted on older and younger participants differently. Older participants' scores were higher on the gratitude measure following the app while the reverse pattern was obtained for younger participants. In light of this finding, it could be argued that the app was more appropriate for older participants. Furthermore, future research must conceptualise intervention activities in a way that takes into consideration the relationship between age and intervention efficacy.

The findings of the present study are consistent with previous research that demonstrates the importance of determining the optimal features, dosage and conditions under which interventions work best (Lyubomirsky \& Layous, 2013). The findings reported here suggest the importance of determining the correct intervention features for a specific sample. 
Past literature has indicated that interventions with a higher number of activities have resulted in larger increases in well-being than when fewer activities were diluted over the course of a week. Lyubomirsky, Sheldon, and Schade, (2005) found that individuals who practised five acts of kindness every day for six weeks showed larger increases in well-being than those who performed five acts over the week. The present intervention indicates that activities that do not involve much 'time on task' may not be as effective as the original longer parent programmes. For example, the PAL programme by Notter (2013) involved 12 onehour class sessions with some required homework as well. Participants in the present study, in contrast, would have spent about 30 minutes in total on the Happy Wings app. Despite this fact, it should be noted that research by Lyubomirsky et al. (2005) has found that shorter interventions can be optimally effective. That is, a PPI that required counting blessings frequently (three times per week) was less effective than a PPI with a smaller requirement (once per week). Taken together, these works indicate that determining the optimal dosage for PPI activities is difficult.

Furthermore, results differ significantly between individuals and for different activities (Lyubomirsky \& Layous, 2013). Specifically, individual preferences, as reported in the feedback forms (see Appendix B), were unclear in regard to a minimum or maximum threshold of activity involvement. One might naively expect adolescents to share some preferences for activity and intervention duration. However, the present results indicated that participants gave very different responses when asked to provide feedback on whether the app was a good length (see Appendix F), including: "too long" 13\%, "ok" 33\%, "good length" $43 \%$, "too short" $6 \%$. These findings show that some participants were happy with the length, but also that participants provided answers on opposite ends of the scale. A case could be made that these results are congruent with the notion that the fit between person and activity is variable between individuals (Sin \& Lyubomirsky, 2013). The present results seem to indicate that New Zealand adolescents hold very different perceptions of the proper length of an ideal PPI.

These results suggest that it is important to determine the features of the person and the activity (and their interactions) that influence PPI success to enhance intervention efficacy (Sin \& Lyubomirsky, 2013). It has been proposed in previous literature that participants' level of enjoyment of PPI activities is predictive of the frequency at which they will complete 
activities (Schueller, 2010) and therefore how much happiness they will attain from the intervention (Lyubomirsky, 2008) (see Sin \& Lyubomirsky, 2013 for a comprehensive review). The present study takes the position that the specific individual preferences of individuals should be taken into consideration. This will allow the intervention effects of those individuals for whom the intervention was successful to be measured as distinct from other participants (i.e., those who reported non-usage of the app). Further, the specific requirements of individuals for whom the intervention was not optimal should be identified, as identification of these individuals may provide insights for the improvements of OPPIs in future.

Considerable evidence exists that shows that intervention features impact on their efficacy (i.e. as indicated by significant effects on well-being indicators). In addition to the impact of features of the intervention itself, the literature indicates that features of the individual also moderate intervention success (i.e., an individual's affective state). Studies suggest that an individual's affect at the time of intervention may predict intervention success; for example, individuals experiencing low positive affect or experiencing some depressive symptoms may benefit more from PPIs (Fredrickson et al., 2009; 1998; Froh, Kashdan, Ozimkowski, \& Miller, 2009; Seligman et al., 2005; Tugade \& Fredrickson, 2004). Therefore, another explanation for the insignificant findings of the present study, and some previous intervention studies, may be the moderation of the intervention's influence by the original affective state of individuals. In other words, a clinically depressed or 'at risk' sample may have shown more detectable improvements than the 'normal' population used in the present study (floor effect). Consequently, future studies should involve the testing of PPIs with samples of differing levels of dysphoria (i.e., with both depressed and normal samples) in order to determine whether there is a threshold of positive affect, which, if surpassed, makes detecting intervention effects difficult.

\section{Group Differences in Psychological Well-being Variables, Resilience, Happiness and}

\section{Reduced Depression: Hypothesis 2}

The first hypothesis that building positive emotions would positively impact on outcomes of psychological well-being (i.e. resilience, happiness and reduced depression) was not supported by the data collected in the present study. Additionally, the second hypothesis was not supported by the current study. Contrary to the researcher's expectations, and 
previous research that has indicated PPIs are successful in increasing resilience and psychological well-being outcomes (Froh et al., 2008; Gillham et al., 2007) and decrease depression (Sheldon \& Lyubomirsky, 2006; Notter, 2013), participants who completed the app did not display increases in psychological outcomes (i.e., subjective happiness, gratitude and reduced depression). The nonsignificant results in the current research indicated that the self-directed smartphone app did not increase outcomes of positive psychological well-being (i.e., subjective happiness, gratitude and reduced depression). The reason for these results may be that the intervention did not increase positive emotions, and it is possible that the lack of increase in positive emotion may preclude the development of adaptive resources and subsequent well-being. In summary, these findings suggest that an abbreviated online version of the PAL programme (Notter, 2013) did not increase the positive emotions of gratitude, savouring and self-esteem.

The second outcome of the present research was that significant differences between the intervention and control group were not found between psychological outcome variables of resilience, subjective happiness and depression. There is existing theoretical and practical evidence to suggest the online delivery of positive psychology programs may be an effective way to increase positive emotions, psychological well-being, and reduce maladaptive outcomes (Manicavasagar, 2014; Seligman, Steen, Park, \& Peterson, 2005). Therefore, the fact that the present study showed little support for this view indicates that further theory and empirical study of the use of PPIs to increase resilience and well-being is warranted.

Of note, research studies specifically focused on some of the measures taken here have suggested that investigating the mechanisms by which PPIs influence change would be productive. Since we have longitudinal data in the present case, the naturally occurring linkages between variables will next be examined. In the present study, it was proposed that adaptive coping would predict an increase in resilience, which in turn was expected to predict increased psychological well-being in the adolescent participants.

\section{Mediation of the Relationships between Adaptive Coping and Psychological Well-being,} (Subjective Happiness, Gratitude, and Reduced Depression and Aggression): Hypothesis 3

The third prediction of this study was that the positive psychological dynamic of resilience would be important in explaining the relationship between adaptive coping and psychological well-being (Frederickson, 1998; 2000; Notter, 2013). The path model results in 
Figure 1 provide support for this mediational hypothesis. As predicted, the mediational pathways, which originated with adaptive coping, passed through resilience and predicted improved positive psychological outcomes of subjective happiness, gratitude and diminished depression, were all statistically significant (for the entire present sample), with the exception of the outcome of aggression. Notably, the three indirect pathways that predicted psychological wellbeing for adolescents indicated that resilience played a crucial role in mediating the effects of adaptive coping on positive psychological outcomes of young people. These three pathways demonstrated the importance of resilience as an intermediary of the relationship between adaptive coping and positive psychological outcomes.

Furthermore, this finding is significant in terms of the pre-existing literature that has shown the importance of resilience for the promotion of long-term psychological outcomes (Cohn et al., 2009; Fredrickson, 1998; 2001). The finding that resilience played a critical role in the attainment of psychological outcomes is congruent with previous research, which has shown a strong association between resilience and other variables that signal positive psychological well-being outcomes for adolescents (Masten, 2001; Notter, 2013). The present study builds upon these findings, as it suggests that resilience is a crucial predictor of increased psychological well-being for adolescents.

Additionally, the current study indicates that adaptive coping may play an important role in the development of resilience and consequent increased well-being. The present findings show that, as predicted, a positive relationship was identified between adaptive coping and resilience, at T1 $(r=.33)$ and at $\mathrm{T} 2(r=.27)$, supporting the notion that resilience is, at least to some extent, a result of the development of adaptive coping resources. Not only does this finding indicate that resilience in adolescents is the outcome of adopting adaptive coping strategies earlier in adolescence - it is also congruent with the 'broaden and build' theory of positive emotion, as it showed that adaptive coping helped build positive resources (Fredrickson, 1998; 2010). Fredrickson's theory proposes that adaptive resources encourage cognitions and behaviours that promote positive outcomes. The current finding indicates that the possession of adaptive resources meant individuals had more resources with which to deal with challenges (i.e., increased resilience), which led to higher positive psychological outcomes such as subjective happiness, gratitude and less depression for those individuals. 
Specifically, this result stresses the importance of resilience on indicators of positive psychological outcomes (i.e. subjective happiness, gratitude and reduced depression) (Fredrickson, 1998; 2010). These findings suggest that when adolescents are taught to adopt adaptive coping styles they become more resilient over time, so that they cope better psychologically. In this way, it appears that resilience reflects adaptive ways of coping, and also plays a crucial role in promoting positive psychological outcomes of young people. These findings support previous research that has shown that effective coping strategies have been identified as critical for resilient individuals (Coutu, 2002; Dumont \& Provost, 1999; Everall et al., 2006; Jones \& Bright, 2001). Our research is consistent with that of Compas and colleagues (2001), which identified resilience as an outcome of using adaptive coping processes in response to a stressor.

The fact that the mediation hypothesis in this current study was based upon longitudinal data has implications for research on the consequential outcomes of teaching adaptive coping strategies to young people. Considerable research has shown that adolescents are flexible in their coping styles when compared to adults (Phillips et al., 1992). Therefore, emphasis on fostering adaptive coping styles in adolescence not only increases the likelihood of interventions reaching young people before maladaptive ways of coping become routinized and automatic, but may also increase the frequency of their adaptive responses in the future (Contu, 2002). The present findings are consistent with considerable research that has shown resilience to be predictive of positive outcomes, and to lessen maladaptive outcomes for adolescents (Compas et al., 2001; Constantine, Benard, \& Diaz, 1999; Masten, 2001).

These findings suggest resilience has a crucial influence on psychological outcomes for adolescents. As predicted, gratitude increased as a result of increased adaptive coping strategies and increased resilience. The present finding that happiness increased was in line with studies that have supported the links between coping strategies, happiness and well-being among adolescents (Farrer, 2013). The present results indicated that the outcome of depression was reduced for those individuals high in adaptive coping and resilience. This prediction was expected because individuals who use adaptive coping strategies have lower levels of the detrimental effects of life stressors (Jose \& Huntsinger, 2009; Nolen-Hoeksema, 1994). Contrary to expectation, aggression was not diminished for those individuals high in adaptive coping and resilience. It is possible that no benefit was obtained because mean levels of aggression were already low (see Tables 1 and 2) and they could not be reduced any further (floor effect). 


\section{Limitations of the Present Study}

There were some limitations in the creation of the app, the methodology, and the analyses performed which may have impacted on the results of the study. These issues are outlined below.

Small sample size. The sample size used in the present study was small and not equally representative of both genders. Statistical analyses were limited due to the small sample of adolescents recruited from the high schools that agreed to participate, and consequently only large effect sizes were potentially identifiable. Research has found that the small sample sizes characteristic of OPPI studies result in significant limits on the clarity and robustness of statistical analyses (Lyubomirsky, 2009; Mitchell et al., 2009; Murray et al., 2013, Parks, 2014; Sergeant \& Mongrain, 2009). A larger sample would have allowed a more confident interpretation of the results, and made it possible to evaluate the efficacy of the app more conclusively. As it stands, the sample size used was not sufficient to determine the effectiveness of the intervention definitively.

Non-random assignment of participants to groups. Participants were not randomly assorted into the experimental and control groups due to time and resource constraints. The control group used in the current investigation came from a large allmale school, and thus the experimental and control groups differed by gender, decile, and potentially other characteristics. It is possible that these differences may have mitigated against the validity of the quasi-experiment.

Attrition. Another major limitation of this study was the high attrition rate (41.1\%). Interestingly, this level of attrition was consistent with previous literature, which indicated that Internet studies are typically characterised by high attrition rates compared to interventions involving face-to-face contact (Mitchell, Vella-Brodrick, \& Klein, 2010). Attrition rates in the literature range from 29\% (Seligman et al., 2005) and up to 79\% for Shapira and Mongrain's (2014) successful online optimism intervention. The high drop-out rates seen here may have resulted from the relatively anonymous nature of this intervention. That is, although participants received text message and email reminders to complete activities, there was no direct human contact from a facilitator or staff member after the initial introduction to the app. The present findings are consistent with the report by Shapira (2012), who argued that lack of human contact may negatively impact on participant motivation and 
engagement. Future research should collect data on the reasons for attrition in these interventions, as this data would have implications for studies such as the current one, because it may provide suggestions for how to increase motivation and ways to reduce attrition.

Researchers have suggested that moderating variables rather than problems with the content may explain high drop-out rates and resultant non-significant intervention effects in OPPI studies (Parks, 2010). In Notter's (2013) PAL programme, participants reported valuing peer engagement as a key benefit. Groupbased training was considered (i.e. similar to that used in the PAL programme) when designing the Happy Wings app; however, it was not feasible within the constraints of time, resources and finances. It was acknowledged from the outset that the present online intervention would involve less face-to-face interaction as compared with PAL, where facilitator and group processes were identified by both facilitators and participants as being influential (Notter, 2013). Instead of personal contact we sought to make the intervention engaging by injecting game-like characteristics in the app; for example, app users received rewards (i.e. 'berries' to represent reward tokens) for engaging in the app. The present study was limited in resources and this prevented the inclusion of other "gamification", elements in the app. Examples of potential ways to increase gamification include personalising the bird icon or developing a variety of attractive 'rewards' over and above the berries used in the present intervention.

Interestingly, an examination of individuals' self-reports of motivation showed that individuals cited the graphics and feeding the bird as motivators, and a commitment to succeeding in the challenge to complete the quests, as being an effective motivator. These results are consistent with previous studies that have found that online PPIs can be highly engaging, namely those that use interactive activities to motivate participants in a way that contributes to the efficacy of the programme (McGonigal, 2011).

Adherence. Some health researchers have acknowledged the importance of examining how adherence to Internet interventions affects outcomes (Eysenbach et al., 2011). To date, most intervention studies have not established accurate ways to measure the effect of intervention adherence, and historically few studies have looked at reasons for dropout, or

7 "Gamification" is a new term that describes the purpose of creating enjoyable and entertaining experiences with the aim of improving individuals' participation. 
examined ways to deal with missing data (Eysenbach et al., 2011). One study, named "Bite Back", stands as an exception as a well-being intervention for young people (Manicavasagar, 2014). This study examined the effect of motivation by measuring participants' self-reports regarding the suitability of the app for them. They concluded that individuals with high levels of reported adherence showed significant decreases in maladaptive outcomes and improvements in wellbeing compared to users with low levels of adherence, who reported no significant improvements (Manicavasagar, 2014). It appears that it is possible to measure the impact of adherence, and this would allow researchers to obtain a more accurate measure of intervention efficacy by excluding participants who did not significantly engage with the programme.

Previous studies have examined the impact of motivation in order to gauge participant engagement with an intervention. Such studies have examined time spent completing activities on a website or percentages of activities completed as an indicator of 'motivation'. Given that in the present study the activities were short in duration, measuring time spent on them (i.e. as was used as a measure of motivation by Manicavasagar, 2014) would not have been an appropriate measure of motivation. Participants in the present study were asked about their motivation to complete the app in the feedback forms, and the majority of participants reported that they felt motivated to complete all of the quests in the app. The data showed that those individuals who completed at least some of the app went on to complete a high number of activities overall. However, these findings have limited generalisability, as they provide an indication only of those individuals who completed both the app and feedback forms. There were no incentives to complete the feedback form. Thus, it could be argued that those individuals who took the time to complete the feedback form had sufficiently high motivation overall. Therefore, it cannot be ascertained whether participants who did not complete the feedback forms would have responded in the same manner. Secondly, a potential weakness of the study was that some participants had more contact with the researcher than others, if they, or their parents chose to make contact and ask questions about the app. Future studies should be more prescriptive in defining the amount of support from the researcher. This may help to ensure a similar level of interaction across all participants.

It will be important for future research to obtain more sensitive and accurate measures of adherence and motivation. Shapira and Mongrain's (2010) findings showed that 
demographic factors predicted dropout at the post-test, as in traditional PPI studies (Geratly et al., 2010). Shapira and Mongrain's (2010) found that women, and individuals of Caucasian identity were reported as more likely to adhere to the intervention. This finding may indicate one way that moderating variables may impact on intervention adherence, and subsequently effect the efficacy of the intervention (i.e. there is less chance of intervention exercises being effective if participants do not adhere). For example, previous studies have shown individuals with more motivation at baseline (Dickerhoof, 2007) showed more psychological well-being after completing the intervention than those who did not complete the intervention. An examination of possible moderating features was not undertaken as part of the current study. As previously mentioned, the activities and intervention in the current study were short, the intervention was new, and developing a sound measure of motivation was beyond the focus of the study. However, in retrospect, a better understanding of the relationship between motivation and participant characteristics on the non-significant results of this study would contribute to the rigour of this study. This research supports the previous findings that suggest that enhancing adherence may be key to improving intervention effectiveness (Layous \& Lyubomirsky, 2013).

Moderating variables. The findings in the present study showed the app to be less effective than its 'parent' programme: PAL (Notter, 2013). This finding was consistent with research by Sin and Lyubomirsky (2009) that suggests PPIs may not translate well into online formats as individuals do not experience the same level of interaction that they would receive in a one-on-one or group-based sessions. Other research has supported this view, indicating that participants using self-directed OPPIs are not subject to the same type of encouragement or feedback that may maximise participation in traditional programmes (Parks, 2014). Intervention studies have long acknowledged the effects of the 'therapeutic alliance', identifying this relationship as critical in positively impacting on intervention outcomes (Ilardi \& Craighead, 2004; Shapira, 2009). These findings are supported by recent OPPI studies that suggest the lack of face-to-face contact limits efficacy (Rosental et al., 2014; Sergeant \& Mongrain, 2014). A suggestion that would be worthy of further investigation has been to include small amounts of facilitator interaction throughout an OPPI intervention. As previously stated, some level of interaction should be employed to determine whether this support is beneficial for participants' motivation and adherence. A prediction could be made 
that those studies offering some facilitator input would be more strongly associated with engagement and, consequently, increased positive psychological outcomes.

The functionality of the exercises. Additionally, this study was subject to limitations because the gratitude component used in the app reportedly did not function properly for everyone. Reports from the feedback forms indicated that for half the individuals the app 'stuck' or froze on Quest 3: Be Grateful. This problem meant that the timer on the app temporarily froze and prevented individuals from progressing from Quest 3 to Quest 4. Several students emailed the researcher and were given a solution to resolve this issue. However, it is unclear how many students did not complete the entire app because of this problem. The feedback forms completed by participants at the end of the study indicated that the preferred modules were Quest 1, Happy Album and Quest 2, Your Strengths. It is noteworthy that these quests were more popular than either of the two gratitude quests (Quest 3, Be Grateful and Quest 4, Feed It Back). It is possible that this lower popularity rating might have resulted from the effect of this bug in the app. However, the data that we obtained in the present study was insufficient to determine the impact of this bug on the efficacy of the intervention overall. Future research would benefit from eliminating such technical issues and, as mentioned previously, distinguishing the efficacy of individual components within this multi-component intervention.

\section{Conclusions}

A wait-list control online intervention was delivered to adolescents to investigate whether electronic applications impact on positive emotions and indicators of psychological well-being compared with those who do not complete the intervention. Two MANOVAs demonstrated that there were no significant differences between intervention and control groups on positive emotions or well-being indicators. An important characteristic of this study was that it is the first known of its kind, namely an online positive psychological intervention delivered via a smartphone using positive, intentional activities. The results suggest that an entirely self-directed intervention of this type and length was not effective. Although these results are disappointing at some level, they provide valuable insight into this field of research.

The present findings suggest that motivation and engagement of the participants may be crucial for intervention success. Therefore, this study supports the employment of further 
research that would advance the standards of OPPIs. These studies should increase engagement and motivation by designing programs specifically for the populations to which they are targeted; for example, individual measurement of components of multicomponent intervention to distinguish efficacy of separate interventions, and continued measurement of factors that impact on intervention efficacy (i.e. motivation and engagement). The present results indicated that participants possessed different levels of motivation and engagement (see ‘feedback forms', Appendix C). For example, 90\% of participants reported being motivated, however, it is likely that those who did not complete were not motivated or engaged, and participants' completed varying amounts of the app. Taken together these findings may provide support for literature around theories of motivation and person-activity fit, which have identified these as possible reasons for intervention success (Lyubomirsky \& Layous, 2014). This research suggests new avenues of research regarding how self-directed OPPIs could be run with adolescents, strongly implicating the importance of facilitator engagement or contact (e.g. a small amount of face-to-face guidance from clinicians or teachers). The students reported favourable experiences while using technology. Feedback from participants indicated that the app was enjoyed, and although the current study does not support the use of OPPI for enhancing the psychological well-being of adolescents in this sample, future research exploring the factors discussed in the limitations section may support the notion of technology as a potential resource to deliver such interventions in future.

Another noteworthy result in this study was the longitudinal mediation finding that supported previous literature on pathways to well-being. This research indicated that adaptive coping strategies were critical resources that built greater resilience in adolescence, which in turn enhanced psychological well-being. This result suggested that teaching adaptive coping skills may help in the development of positive resources (i.e. resilience), that in turn positively impact on adolescents' psychological wellbeing and protect them from maladaptive outcomes in future (Notter, 2013; Sandier, Wolchik, MacKinnon, Ayers, \& Roosa, 1997). It will be useful for researchers to use large-scale longitudinal research to map the pathways to well-being in successful interventions. Although the present study did not yield evidence that the intervention was effective, it is hoped that a careful evaluation of the strengths and weaknesses of the study may enable the successful launch of a similar but effective OPPI in the future. 
Appendix A

User Registration

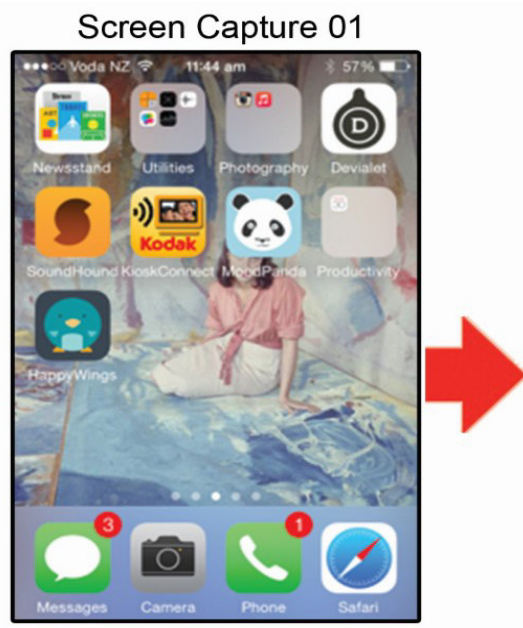

Screen Capture 02

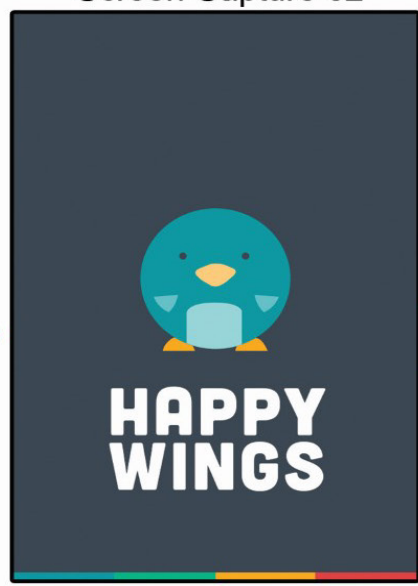

Screen Capture 06
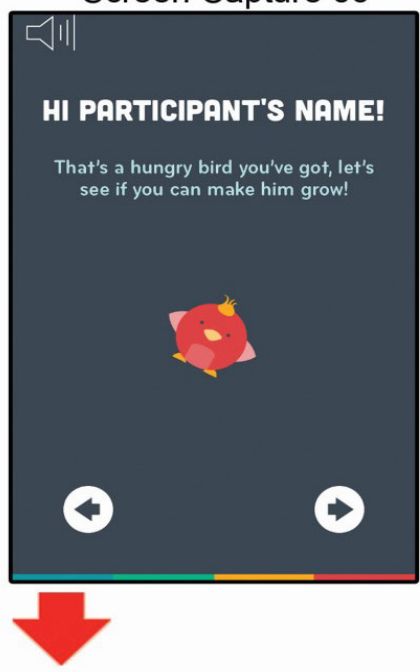

Screen Capture 07

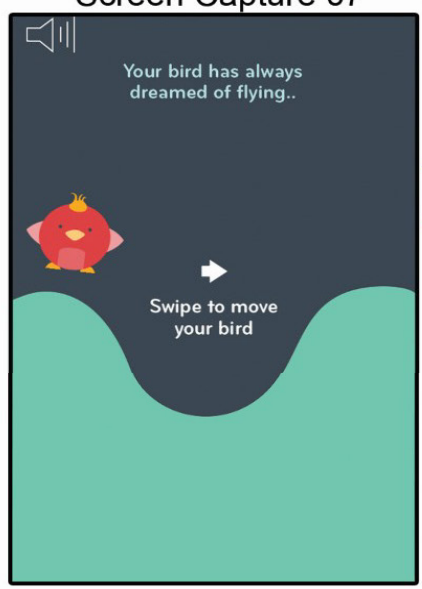

Screen Capture 05

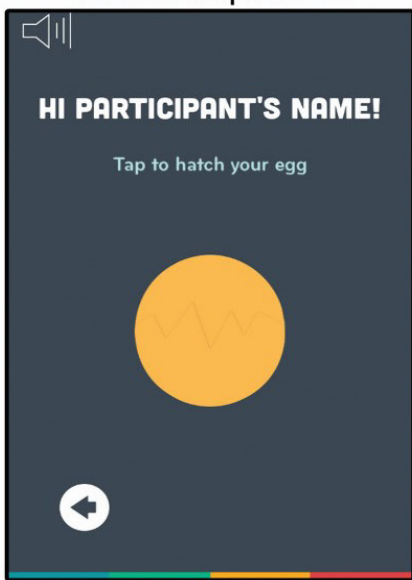

Screen Capture 08

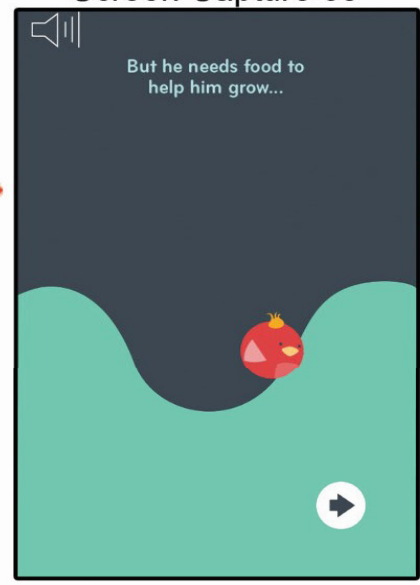

Screen Capture 03

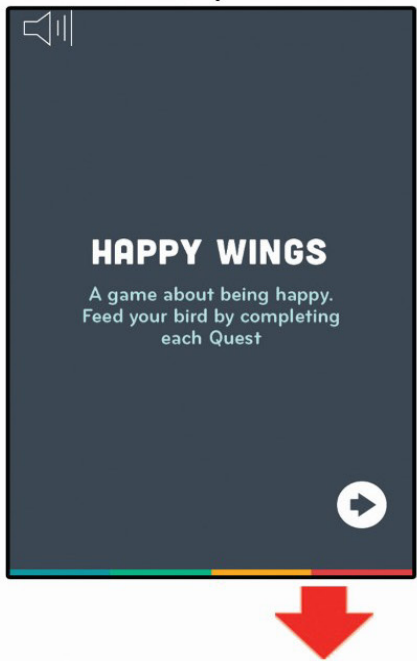

Screen Capture 04

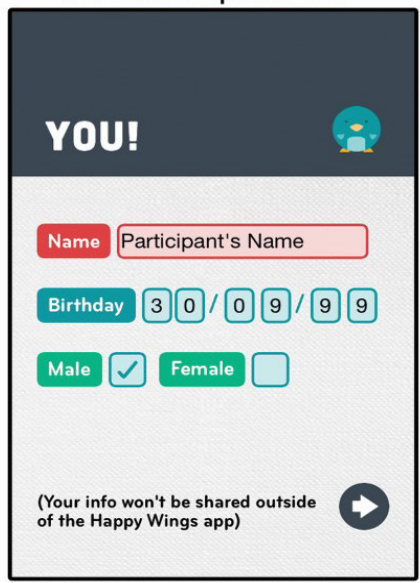

Screen Capture 09

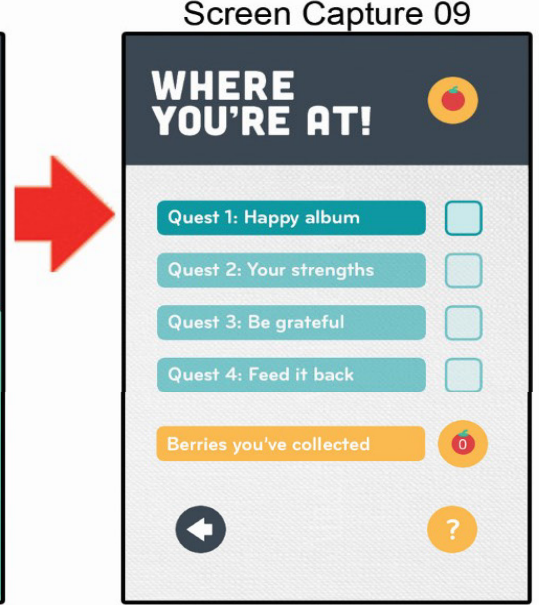




\section{A.1 Quest 01: Happy Album}
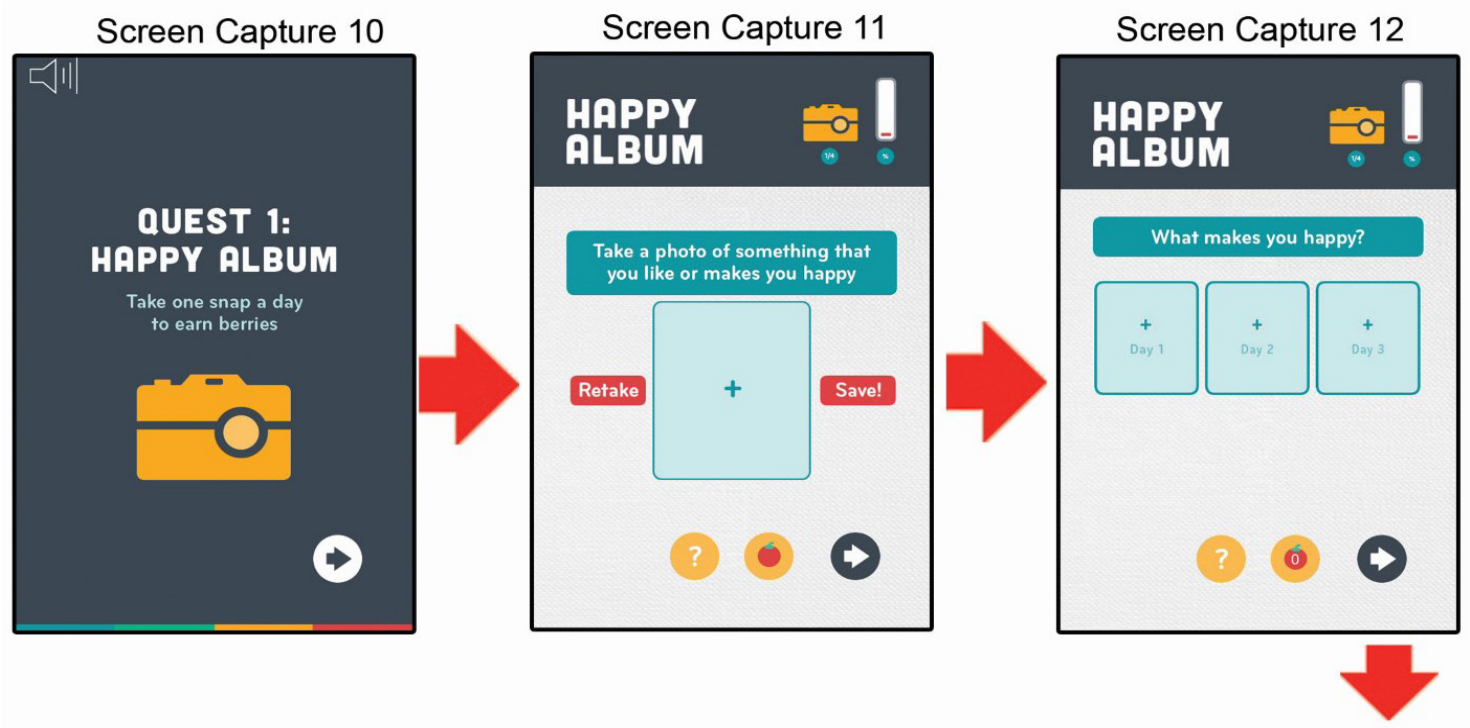

Screen Capture 15

Screen Capture 14
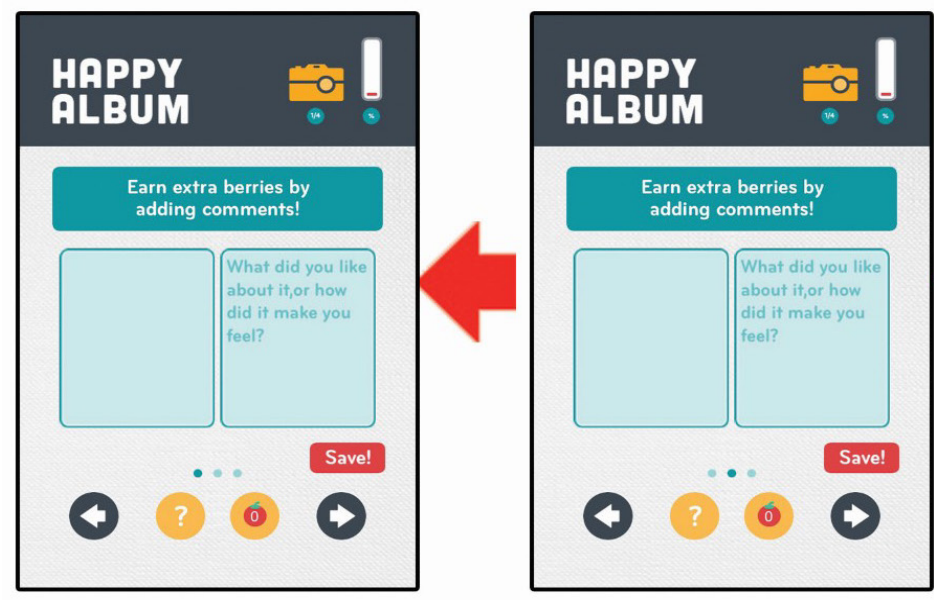

Screen Capture 13
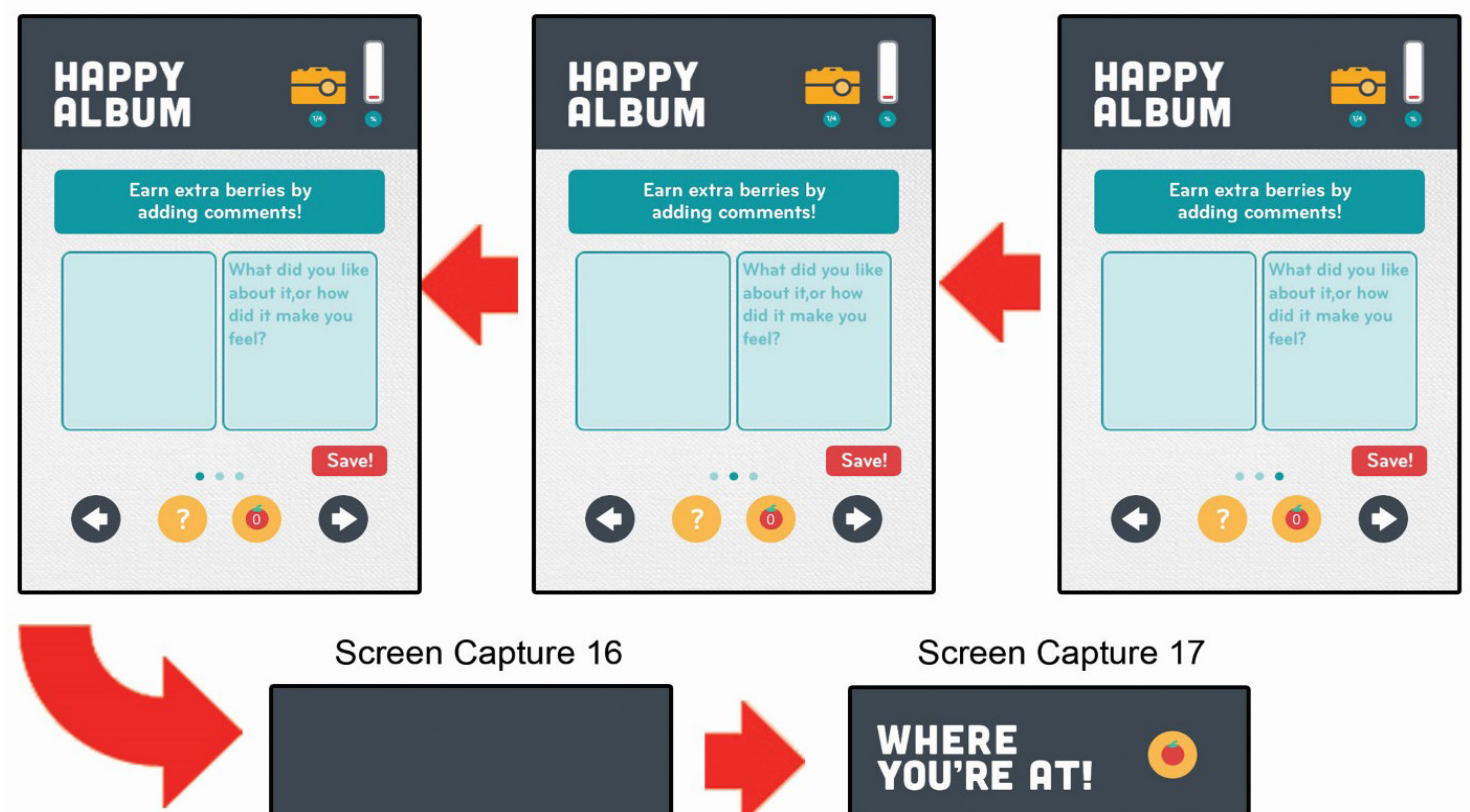

Screen Capture 16

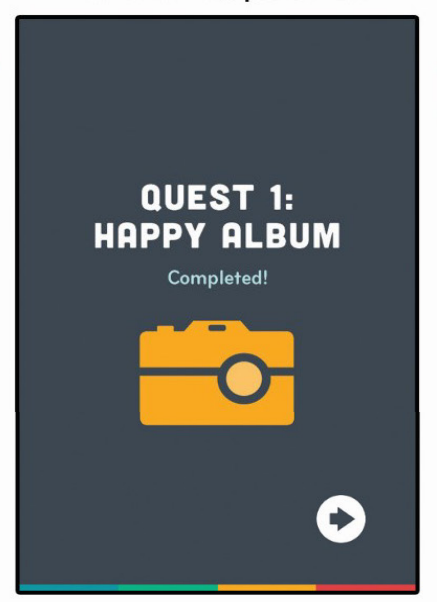

Screen Capture 17

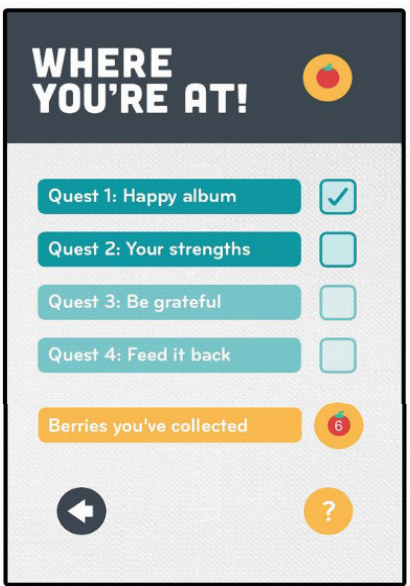




\section{A.2 Quest 2: Your Strengths}
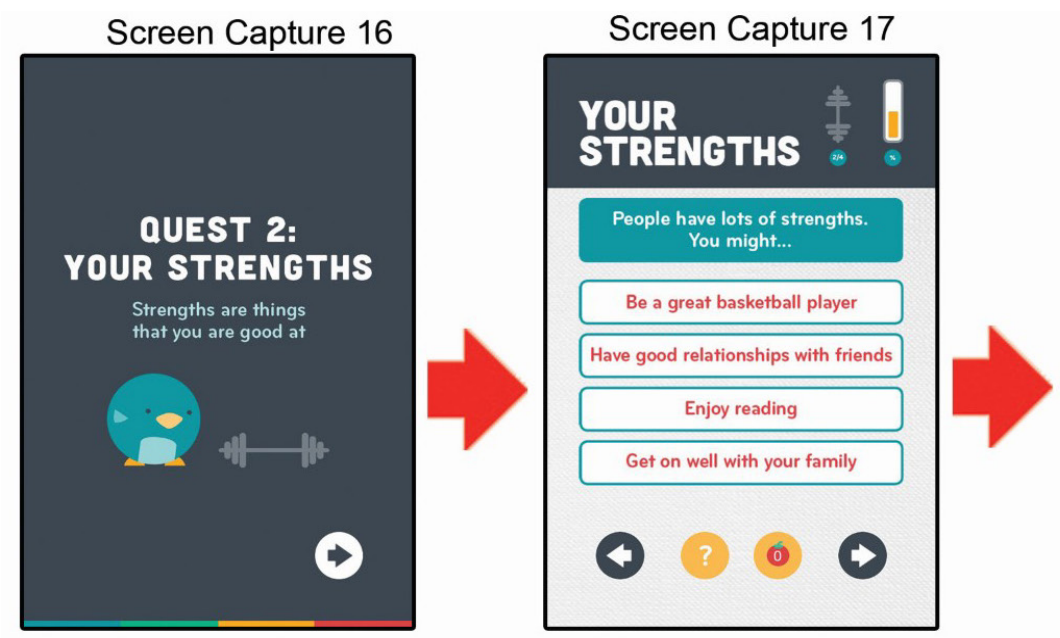

Screen Capture 18
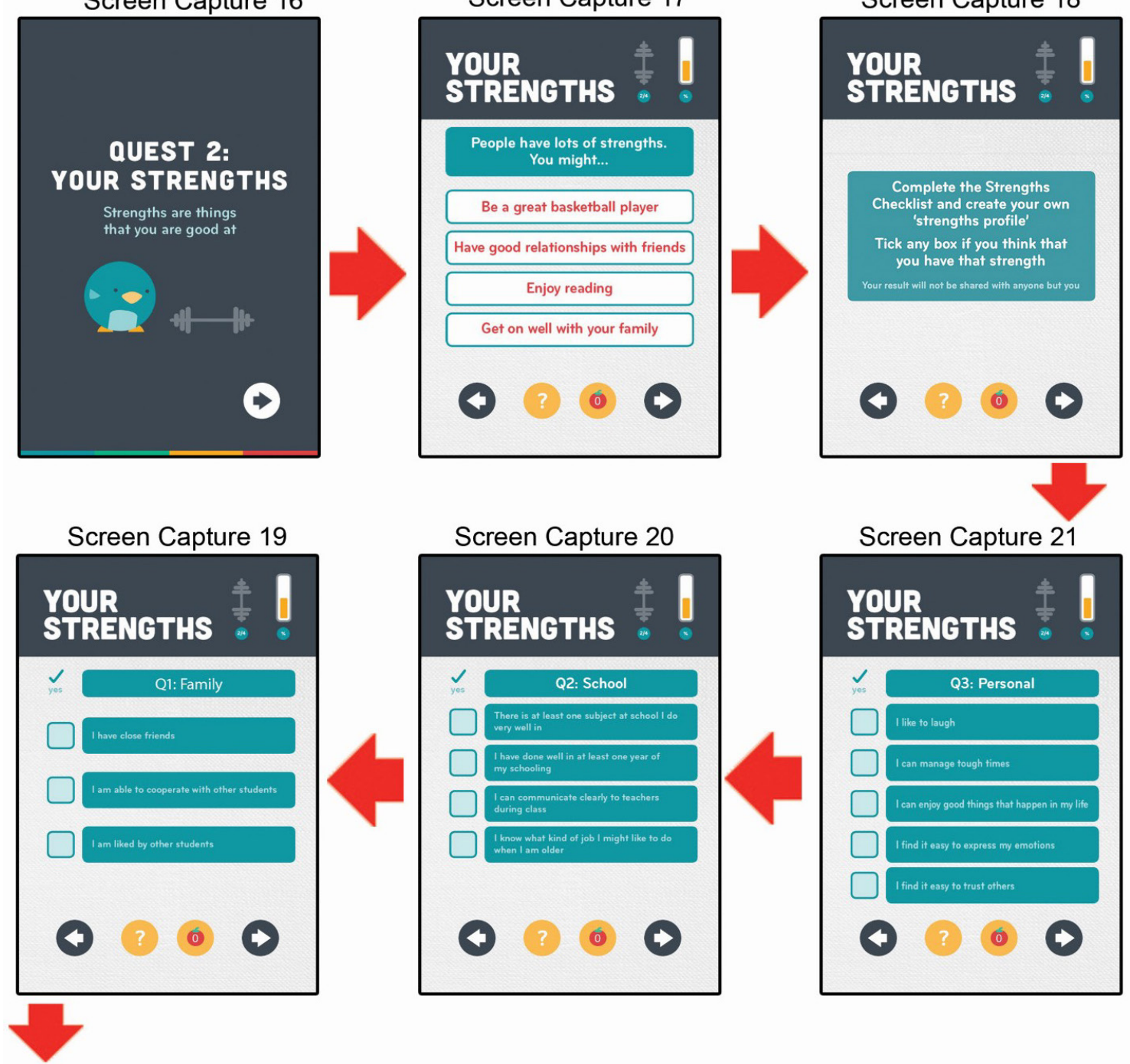

Screen Capture 21

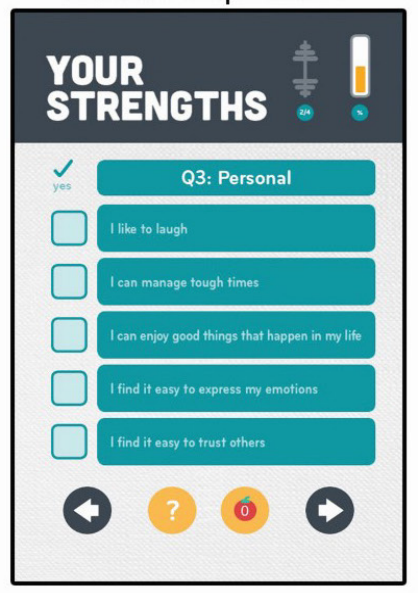

Screen Capture 22
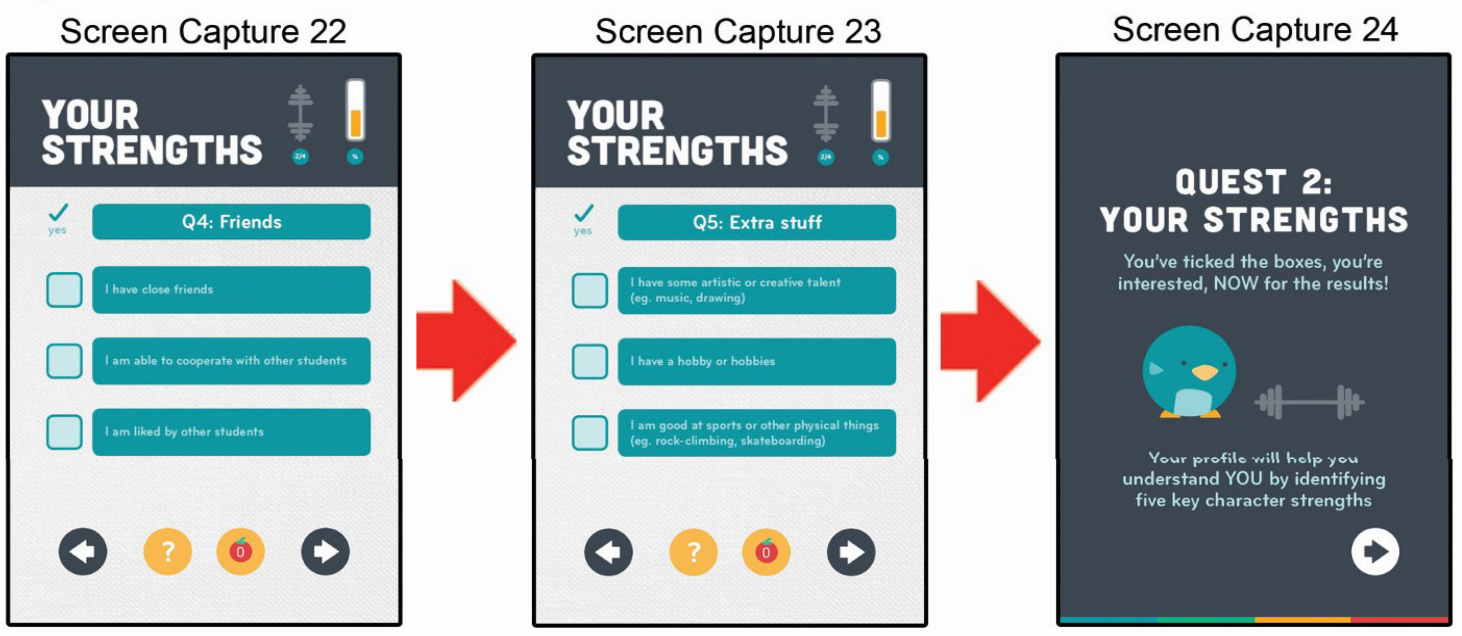
Screen Capture 25

YIIl
YOUR
STRENGTHS :

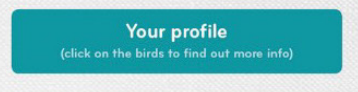

8

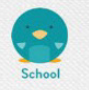

18

4

(3) $\triangle$
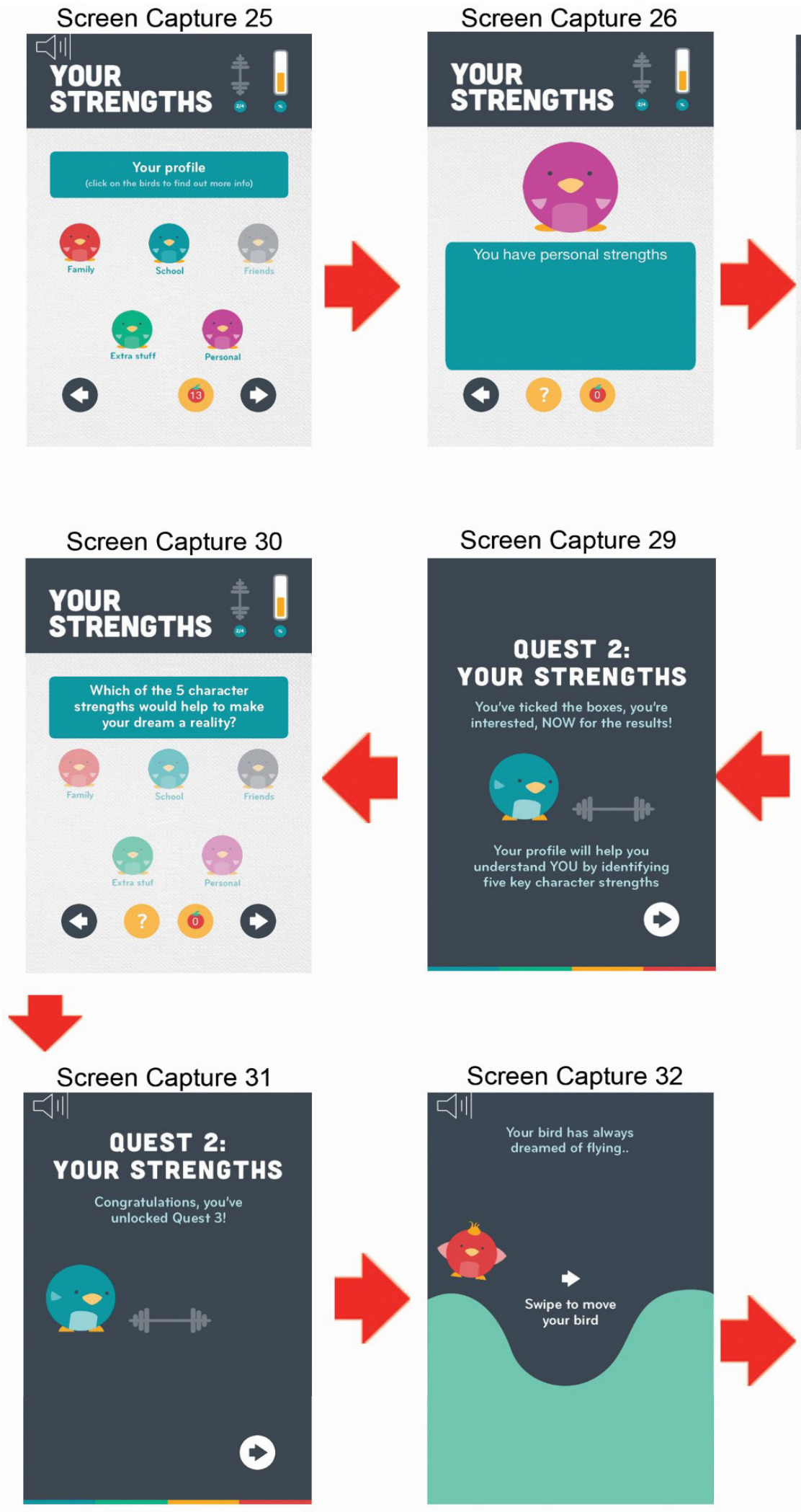

Screen Capture 32

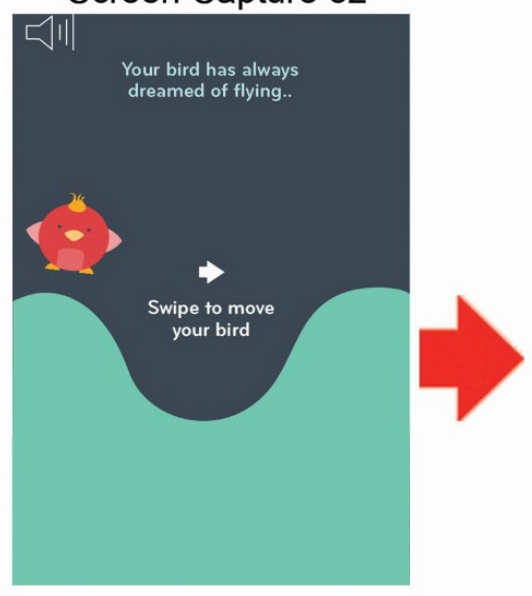

Screen Capture 27
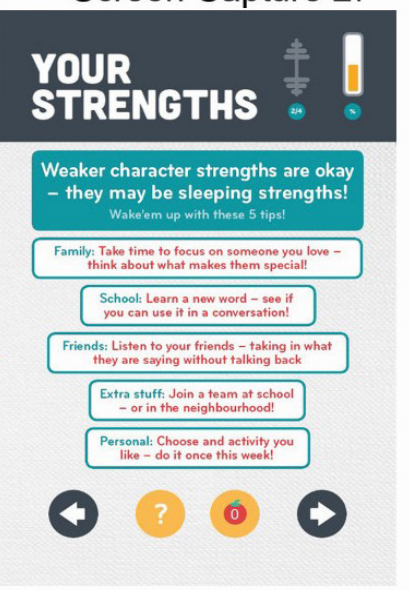

Screen Capture 28

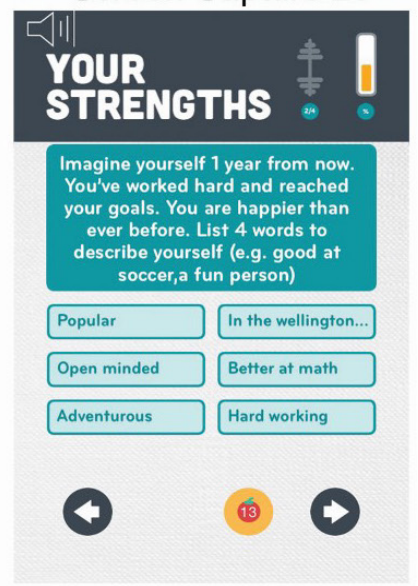

Screen Capture 33

\section{WHERE YOURE AT!}

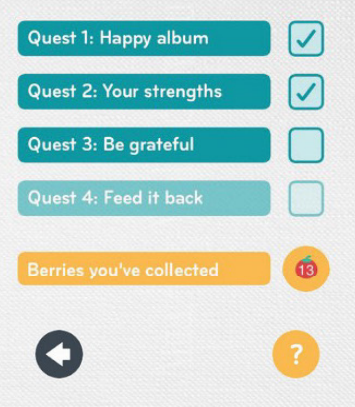




\section{A.3 Quest 03: Be grateful}

Screen Capture 34

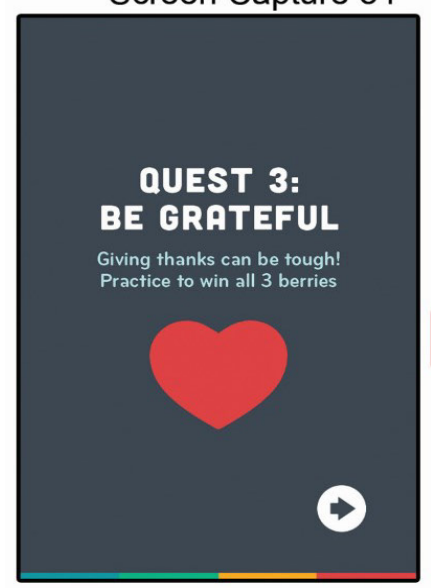

Screen Capture 39

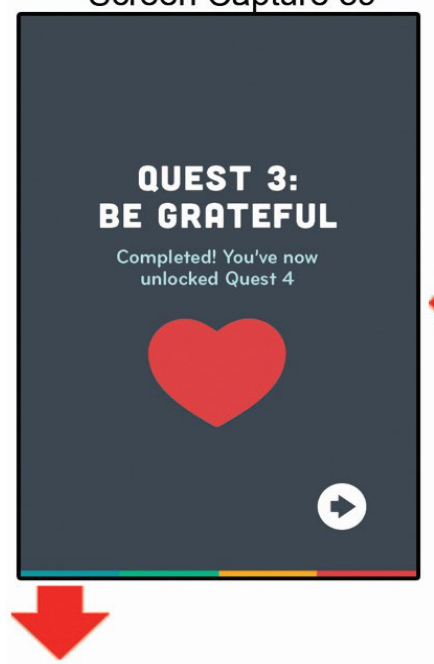

Screen Capture 40

\section{WHERE \\ YOURE AT!}

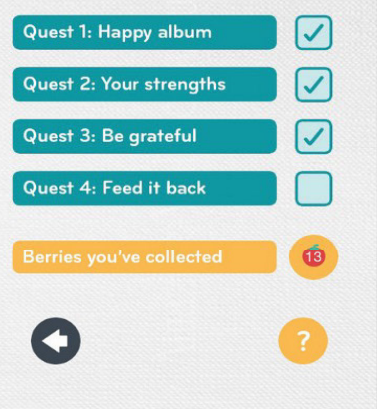

Screen Capture 35

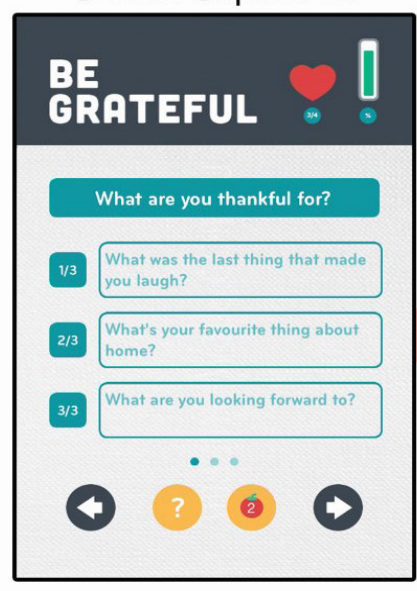

Screen Capture 38

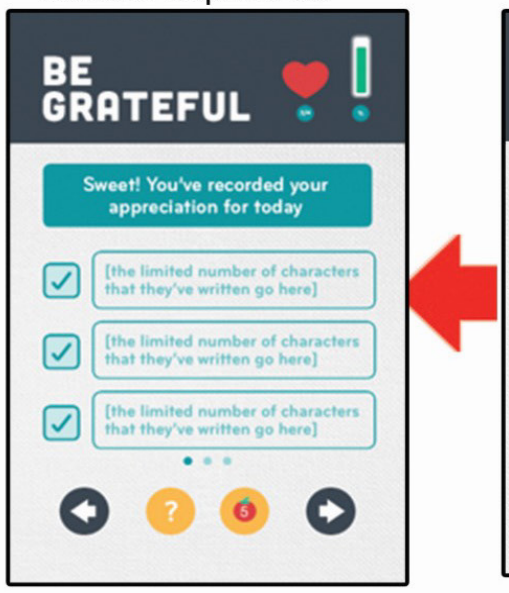

Screen Capture 36

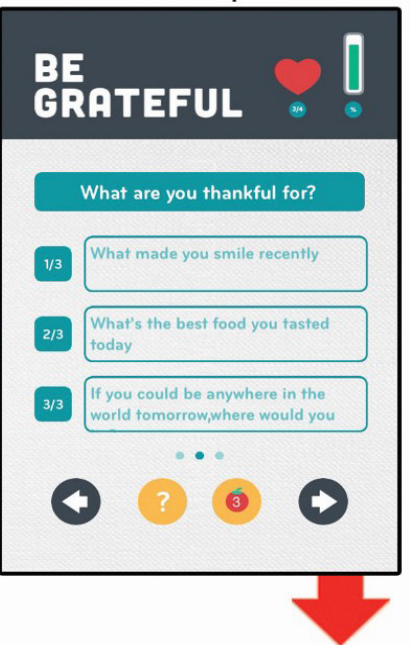

Screen Capture 37
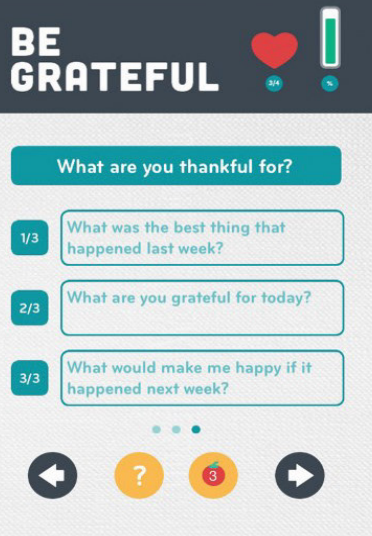
A.4 Quest 04: Feed it back
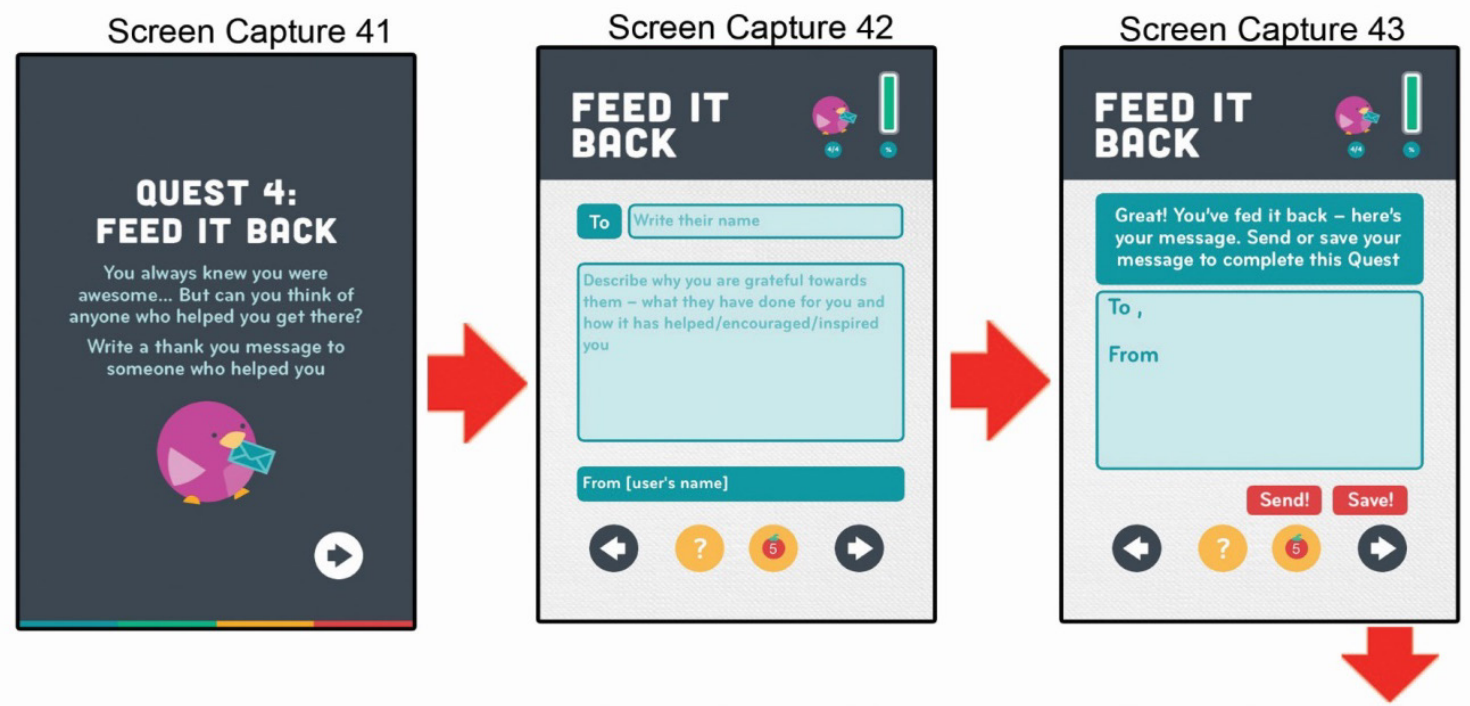

Screen Capture 45

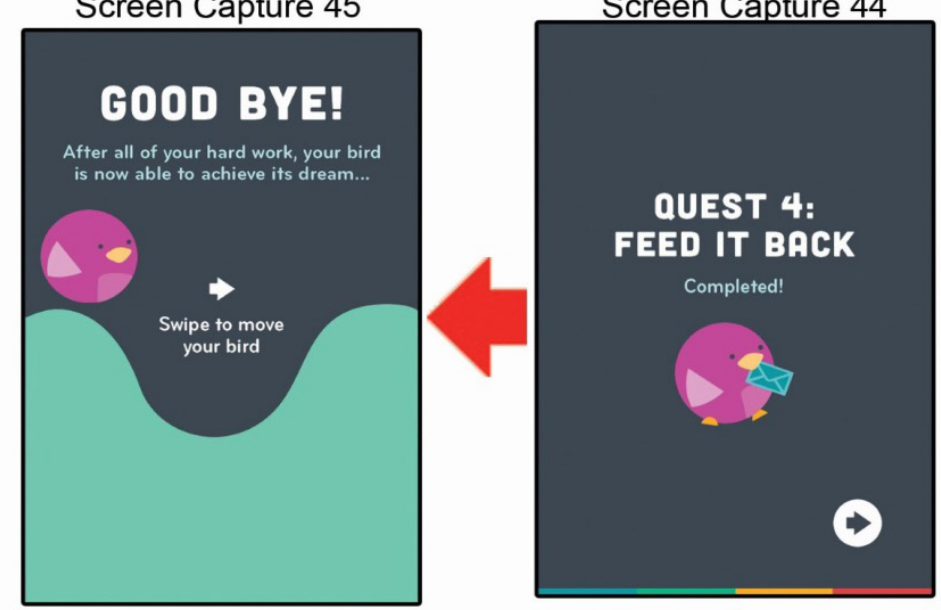


A.5 Intermittently Appearing Screens

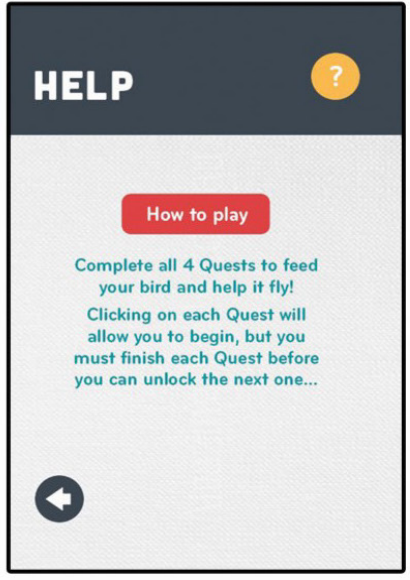

Screen Capture 46

Participants could select the '?' icon at any time, to see this screen.

Screen Capture 43

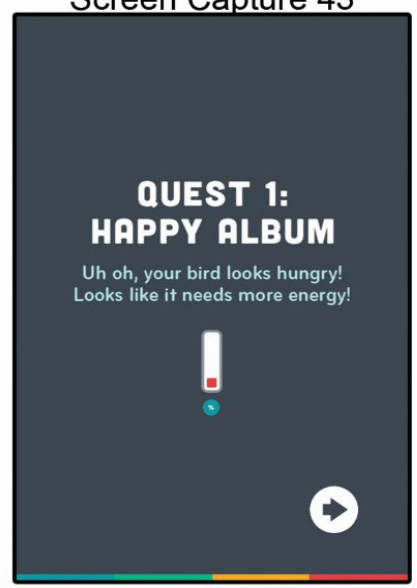

Screen Capture 48

This screen appears intermittently when partici-pant has not finished
Screen Capture 42

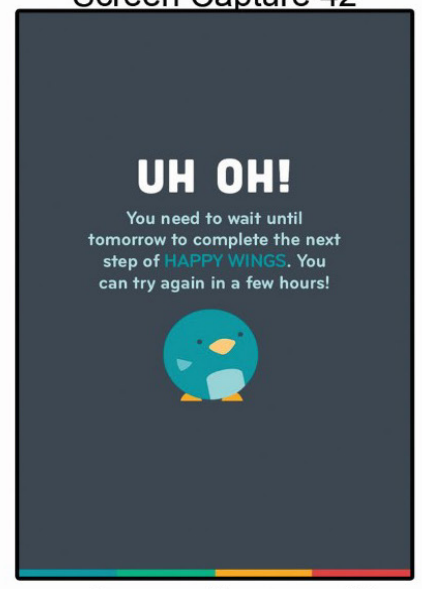

Screen Capture 47 This screen appeared any time a participant at-tempted to access a locked quest.

\section{Screen Capture 45}

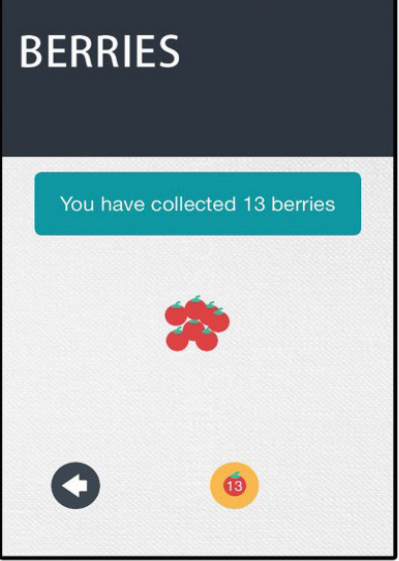

Screen Capture 49

This screen appeared, any time a participant clicked the berry icon. 


\section{Appendix B}

\section{Evaluation of Participants' Feelings about the App}

I used qualitative methods to gain an understanding of how the app was received and experienced by participants. It was important to identify; a) Whether the app ran without crashing, b) what motivated participants to complete the app, and c) suggested improvements. This feedback was important in order to obtain an evaluation of the app.

The following qualitative results were drawn from the 30 feedback forms that were completed by participants upon finishing the app (see appendix B for feedback form). I analysed data using NVivo (Version 10.1), as it allowed efficient thematic organisation of the data. The forms were coded and percentages calculated for each of the 15 questions. It should be taken into consideration that not all participants completed these forms, and some questions were not answered by all participants.

The types of responses and dominant themes are detailed below:

\section{What Apple Device did Participants use to Run the App? Participants could enter} unlimited text. I wanted to know what devices had been used, in case different models had responded differently to the app, and to inform future studies of any findings particular to using smart-phone based interventions with adolescents. Devices used by all participants can be seen in Figure B1.

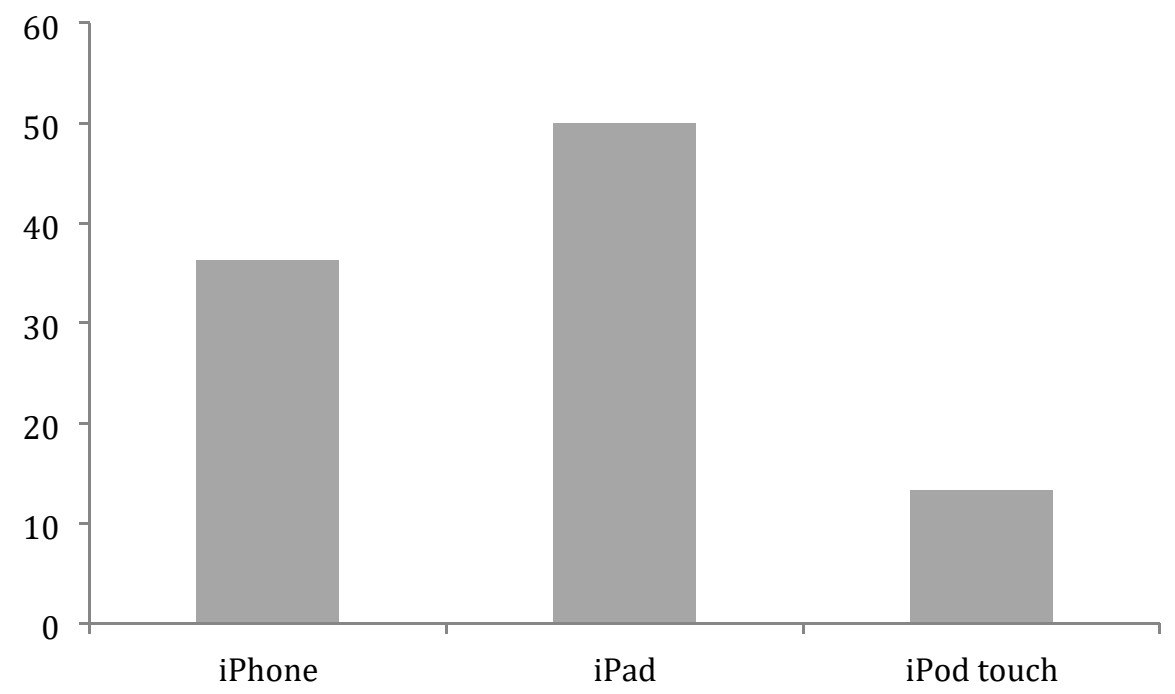

Figure B.1. Devices used by participants to run the app 
Did the App Run Smoothly? Participants could select one of the following: $1=$ $Y E S, 2=N O$

Fifty-three percent of participants said "yes" the app ran smoothly, whereas the rest said "no", and noted that the app got stuck at least once (see below).

If no, where did it crash/get stuck? Participants could select one of the following:

1= Quest 1,2 = Quest 2, 3= Quest 3, $4=$ Quest 4

Forty-seven percent of participants said the app stuck on Quest 3. A technical problem meant that the app froze for some participants on Quest 3. I gave these participants a solution to fix this problem, if it occurred ${ }^{8}$ ). Figure B2 shows how participants responded when asked where the app got stuck.

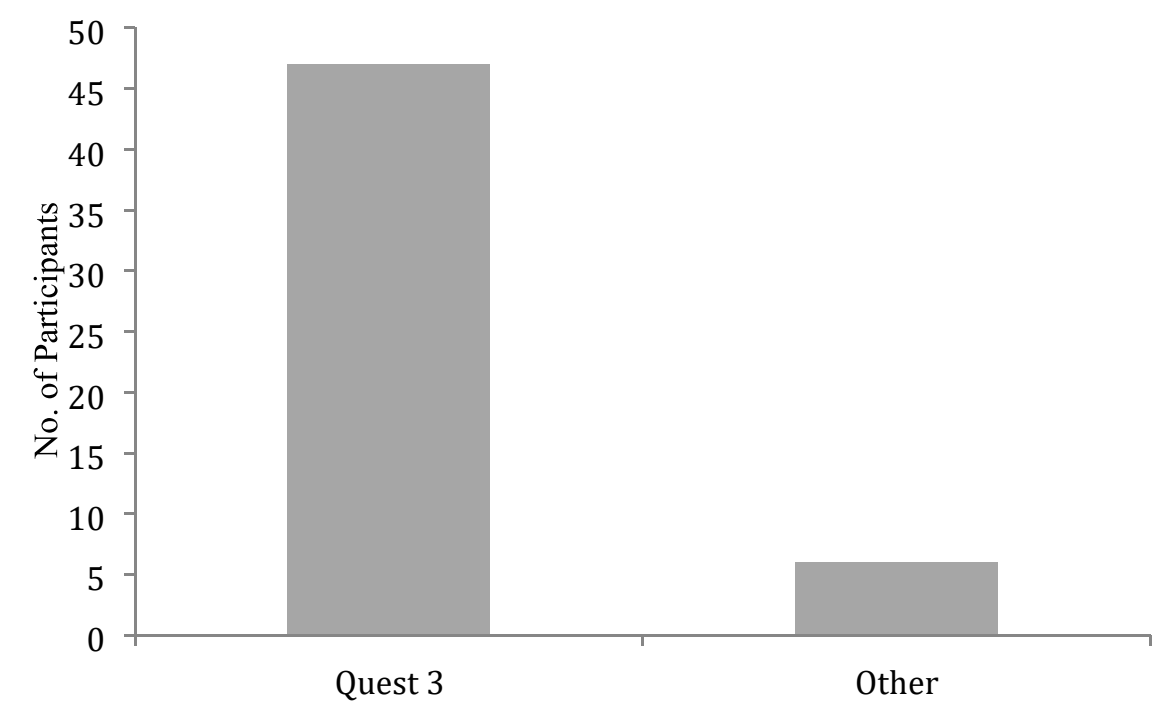

Figure B.2. How participants responded when asked where the app got stuck

\section{Did Participants Remember to do the App Every Day?}

Participants could select one of the following: $1=Y E S, 2=N O$

\footnotetext{
Participants were told to change the time and date on their iPhone to 1 or two days ahead. This tricked the app into moving on and they could then complete it.
} 


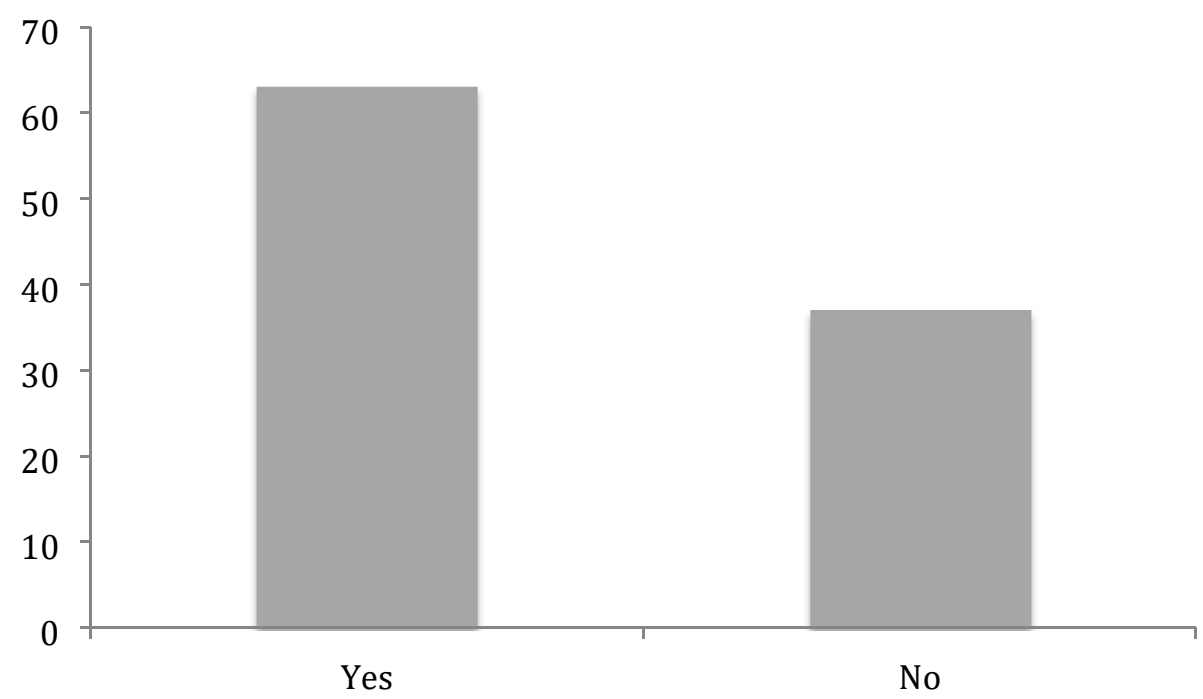

Figure B.3. How participants responded when asked if they remembered to do the app every day

Over half the participants said they remembered to do the app every day

(63\%). The others (37\%) said "no" they did not remember. These findings indicate that some participants did not complete the app regularly; a finding which may provide support for the use of regular reminders inside to app. This finding provides further support for the importance of motivation and engagement for the success of PPIs (Kazdin \& Blase, 2011; Parks, 2014).

Did Participants Feel Motivated to Complete the App? Participants could select one of the following: $1=Y E S, 2=N O$

Ninety percent of the students who completed the feedback forms reported they felt motivated to complete the app. Ten percent said they did not feel motivated. This suggests the majority of participants who completed the feedback form felt motivated to complete the app. This finding should be viewed with caution as the effort taken to complete this form may indicate these participants were among the most committed students.

What Motivated Participants to Complete the App? Participants could enter unlimited text 


\section{Content Categories}

Seven themes were derived from the data; (1) Prizes, (2) Helping others, (3) Accomplishment, (4) Fun (4) Prizes, (6), Feed bird and make it fly (7) See if it would impact happiness. Figure B3 shows that individuals commented most frequently on 'prizes', this suggests the $\$ 15$ supermarket voucher and iPod touch draws were the primary motivation to complete the app; a finding that supports previous research on online interventions that indicates face-to-face contact is key for motivation (Kazdin \& Blase, 2012). Participants also commented on an interest in the impact of the research (i.e. "The possible positive impact to society in future"), and accomplishment (i.e. "To feed the bird and just to know that I accomplished something.") They also mentioned that it was fun, or they enjoyed doing it (i.e. "I enjoyed it, I enjoyed the questions." and curiosity (i.e. "Seeing what would happen at the end").

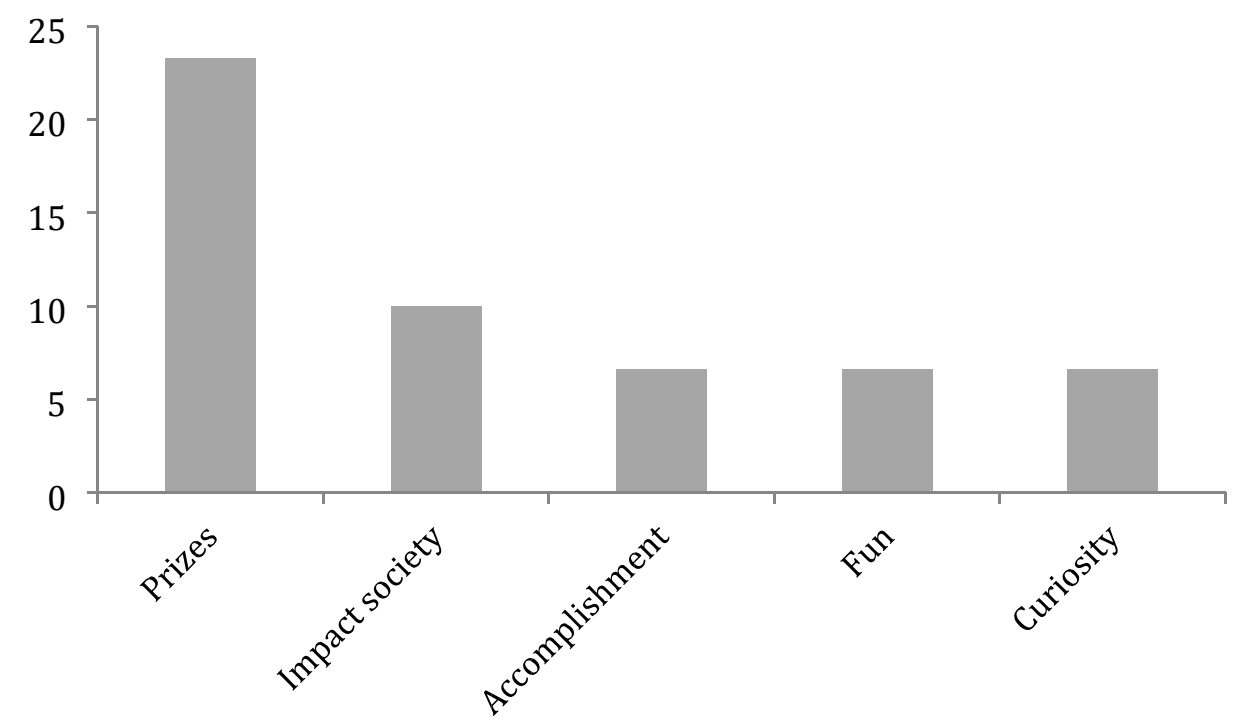

Figure B.4. Reasons participants gave when asked why they felt motivated to complete the app

What Prevented Participants from Wanting to Complete the App? (Participants could enter unlimited characters)

I wanted to know what kinds of things had prevented participants from completing the app, in order to identify possible barriers (i.e. motivation or usability issues). I hoped that by doing so I could make suggestions for future use of such an app. 


\section{Content Categories}

Seven themes were derived from the data; (1) Too long to complete; (2) technical issue in Quest 3 ;(3) Forgot; (4) No time; (5) Too long to log in (6) Nothing

(7). Seven participants left this question blank. Table B1 shows response percentages for all categories, and indicates that individuals commented most frequently on the app taking too long to do (i.e. "Not enough spare time", "It takes forever for the days to pass."). This may indicate participants found the frequency or duration of activities off-putting. This finding is in line with previous online positive psychology interventions (OPPIs) that suggest such features moderate the success of online interventions (Kazdin \& Blase, 2012; Lyubomirsky \& Layous, 2013).

Table B.1

How participants responded when asked what prevented them from completing the app.

\begin{tabular}{lc}
\hline What prevented participants completing the app? & $\%$ \\
\hline Too long to complete & 40 \\
Technical issue in Quest 3 & 30 \\
Forgot & 15 \\
No time & 8 \\
Too long to log in & 5 \\
Nothing & 2 \\
\hline
\end{tabular}

What level of Difficulty did Participants Rate the Quests? Participants could select one of the following: 1 = very difficult, 2 =difficult, 3 = somewhat difficult, $4=$ neutral, $5=$ somewhat easy, $6=$ easy, $7=$ very easy 


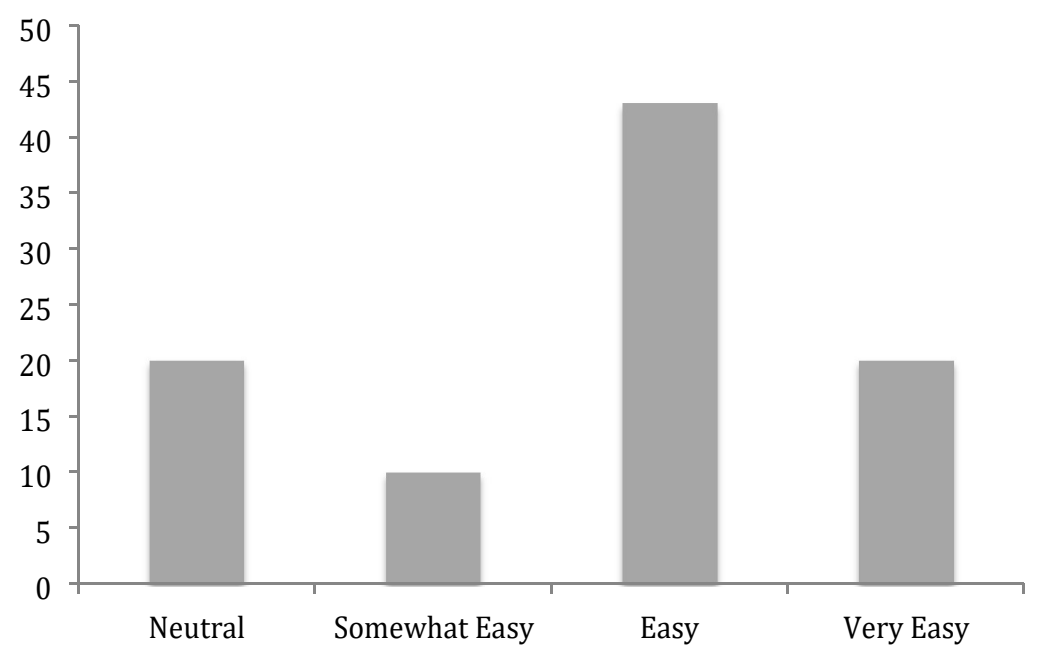

Figure B.5. shows how participants responded when asked to rate the level of difficulty of the quests

The most frequent response was "easy" (43\%), followed by neutral (20\%) and "very easy" (20\%), lastly, "somewhat easy" (10\%). It is noteworthy that no participants mentioned finding the app difficult. It would be worthwhile for future studies to investigate different levels of difficulty (and for specific age groups), in order to identify optimum activities for adolescents.

Were the Quests an Appropriate Length? Participants could select one of the following: 1 = too long, $2=$ ok, 3 = good length, $4=$ too short

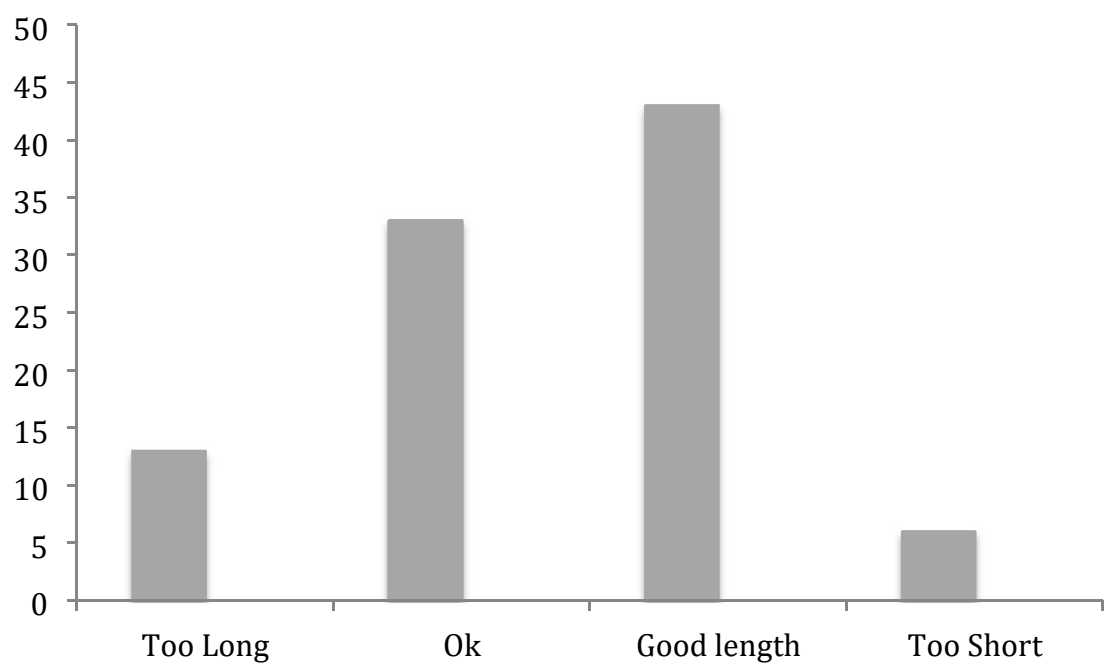

Figure B.6. shows how participants responded when about activity length 
13\% said "too long”, $33 \%$ said "ok", $43 \%$ said "good length", and 6\% said "too short". This finding may indicate that brief positive activities (5-10 minutes per day) may be an appreciated length for a similar such intervention in future.

How Much did Participants Enjoy the App? Participants could select one of the following: 1 = very much, $2=$ some, $3=$ a little, $4=$ not at all

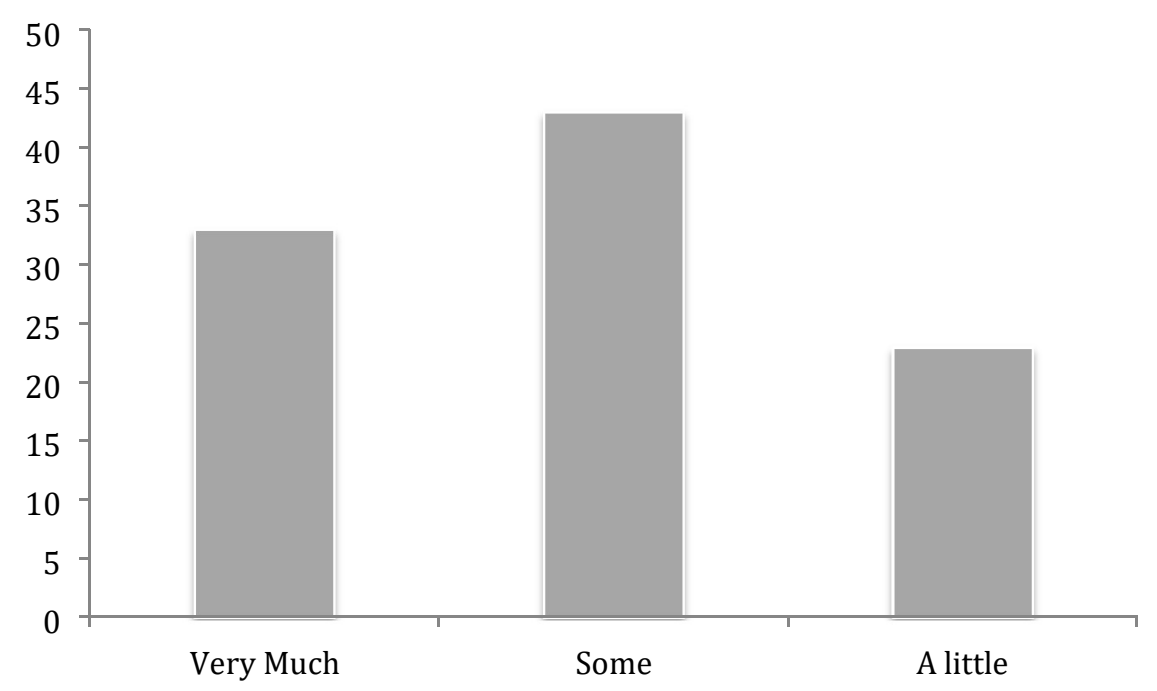

Figure B.7. This shows how participants responded when asked how much they enjoyed the app.

Findings indicated participants felt neutral about the app (i.e. $23 \%$ said "some" $23 \%$ said "a little", and 33 \% said they enjoyed the app "very much".

Which quest did participants enjoy the most? Participants could select one of the following: 1 = Happy album, 2 = Your Strengths, 3 = Be Grateful, $4=$ Feed It back 


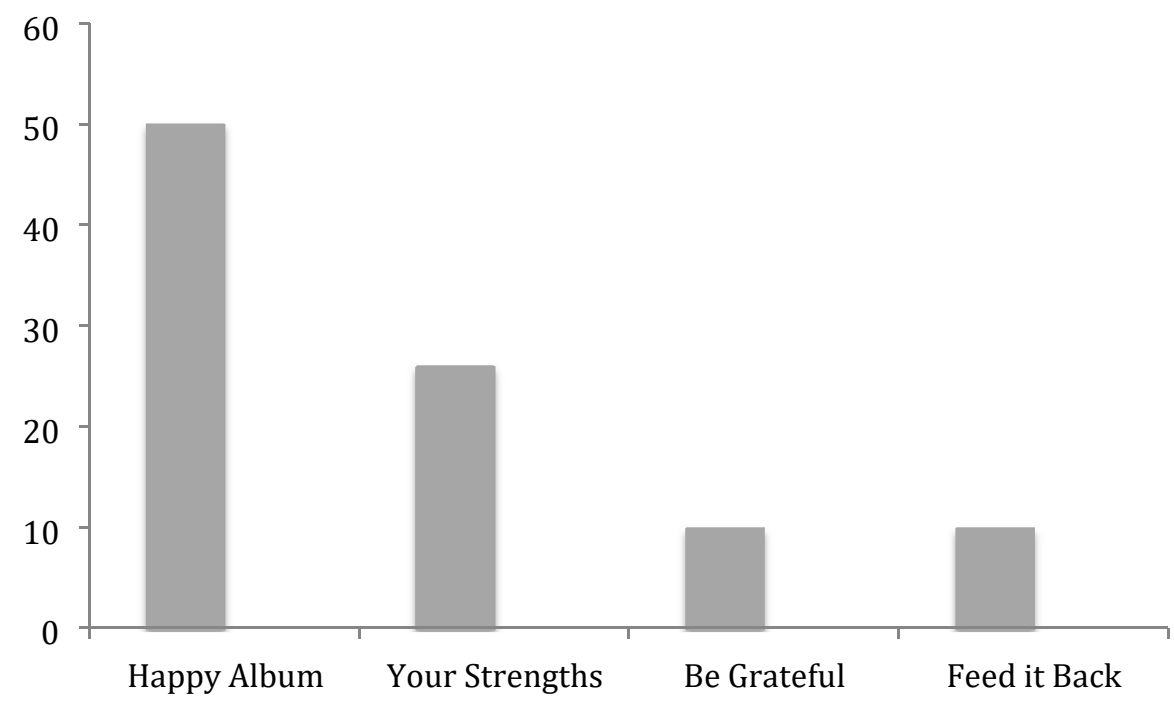

Figure B.8. This shows how participants responded when asked which Quest they enjoyed the most (1-4).

Fifty percent of participants said "Happy Album" (Quest 1), followed by "Your Strengths" (Quest 2). "Be Grateful", and "Feed it Back" were reported as less popular It is possible that the participants became tired of completing the app, by these last two quests. An alternate explanation could be simply that these first two quests were more appealing, it might be useful for future research to identify which activities are most enjoyed, as it is otherwise unlikely that individuals will self motivate to complete an intervention.

What Age Group would Participants Recommend the App for? Participants could select one of the following $1=8-9$ years, $2=9-11$ years, $3=10-12$ years, $4=12-13$ years, $5=13-15$ years 


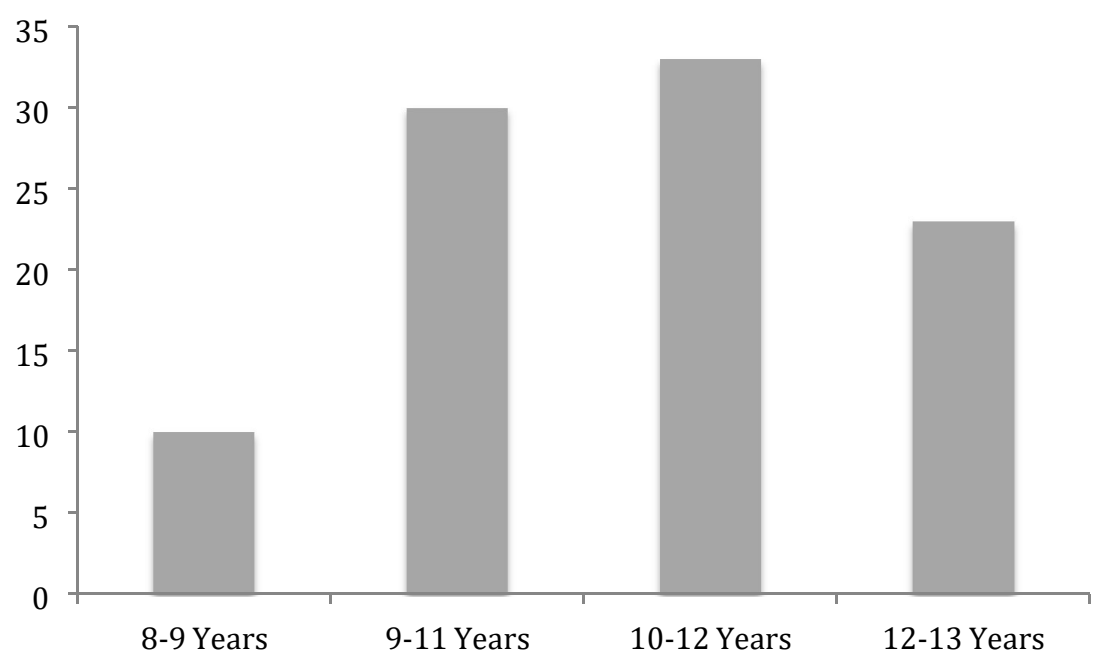

Figure B.9. How participants responded when asked what age group they would recommend the app for.

These findings show that most participants said between 9 and 12 years (30\% said, "911 ", and 30\% said " $12-13$ ". This finding might be useful for future use of this app or similar activities with adolescents.

What would Participants Change about the App? (Participants could enter unlimited text). The types of participant responses for this question are presented below.

\section{Example responses:}

"Maybe make it [THE TIMER] twelve hours instead of 24."

"Maybe the way it says come back next time you should still have that but then be able to do other stuff like games or even feed your bird the berries."

"Make the bird actions at the end more interesting." 


\author{
Appendix C \\ Participant and Parent Consent Form
}

\title{
Happy Wings: A Positive Psychology iPhone App
}

\section{Dear participant and parent}

- You're being asked to take part in a research study about how an app can increase positive emotion such as gratitude and happiness in young people.

- This study is based on Positive Approaches to Life (PAL), a positive psychology programme tested with New Zealand high school students found to increase positive emotion. Interventions show that an increase in positive emotions can provide many benefits, including enhancing academic success and promoting positive social relationships.

- This research has been approved by the School of Psychology Human Ethics Committee under delegated authority of Victoria University of Wellington's Human Ethics Committee.

\section{Who'll take part in the Study?}

- Students aged 10-15 years and have regular access to an Apple iPhone (4, 4s, 5/5s, iTouch 4/5, \& iPad).

\section{If I agree to take part, what will I be asked to do?}

- You'll meet with the researcher during school lunch-time in your lecture theatre. You'll be asked to fill in a questionnaire with some questions about how you feel, e.g. "I have so much in life to be thankful for." It will only take 10-15 minutes of your time.

- Next the researcher will help you download the App (Happy Wings) to your phone and show you how it works.

- You'll be asked to do one Happy Wings Activity every day for one week. Activities will take 5-10 minutes. You'll receive reminders inside the App to keep up with the Happy Wings Quests.

- You can leave the study at any time if you or your parents want to. Just call PHONE NUMBER or email EMAIL ADDRESS OF RESEARCHER. 


\section{How will things I say be kept private?}

- The records of the study will be confidential. Your name and personal details will be coded with a User ID; so, the researcher can see answers but not who wrote them.

- Access to the research records will be limited to the lead researcher and other competent researchers. The data may be used for journal articles, conference presentations, or be part of student research.

- However, please be aware that should you report something which causes the researchers concern for your or others' safety, you may be referred to your school Dean or pastoral carer.

\section{Who can I contact if I have questions?}

Contact: Sarah Hudson, the researcher in charge of this study: call: [PHONE

NUMBER], text: [CELLPHONE] or email: [EMAIL]

\section{YES I want to test Happy Wings, what now?}

Do these 3 things:

1. Read this form and get your parents to sign it (everyone under the age of 16 must have permission of their parents/caregivers to help test Happy Wings).

2. Sign this form yourself

3. Give the signed consent form to at the School office (if you don't you can't participate)

The researcher will contact you via email, or text to arrange a time to meet at your school, in room [ROOM NUMBER] and give you the App. 


\section{School of Psychology, Victoria University of Wellington}

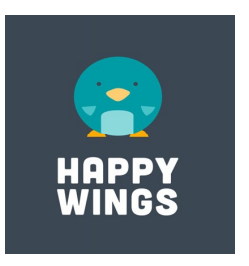

\section{Happy Wings: A Positive Psychology iPhone App: 0000020972}

Researcher: Sarah Hudson: [EMAIL ADDRESS]

Please fill out this form, \& return it to [NAME], at [PLACE] by [DATE] By signing it you agree that you understand:

- You may withdraw at any time until the end of data collection.

- Your information will be confidential; your name will not be associated with your answers.

Name:

School:

School Year:

Email Address:

Cell-phone number:

Parent/Caregiver Name:

Parent/Caregiver Signature:

Your Signature: 


\section{References}

Abbott, R. A., Ploubidis, G. B., Huppert, F. A., Kuh, D., Wadsworth, M. E. J., \& Croudace, T. J. (2006). Psychometric evaluation and predictive validity of Ryff's psychological well-being items in a UK birth cohort sample of women. Health and Quality of Life Outcomes, 4(76). doi:10.1186/1477-7525-4-76

Algoe, S. B., Haidt, J., \& Gable, S. L. (2008). Beyond reciprocity: Gratitude and relationships in everyday life. Emotion, 8, 425-429.

Andersson, G., \& Cuijpers, P. (2009). 'Internet-based and other computerized psychological treatments for adult depression: A meta-analysis'. Cognitive Behaviour Therapy, 38(4), 196-205.

Apley, M. H. ed., Adaptation Level Theory: A Symposium, New York: Academic Press, 1971, pp 287-302

Arbuckle, J. L. (2011). IBM SPSS Amos 20 user's guide. Armonk, NY: IBM.

Ashby, F. G., Isen, A. M., \& Turken, A. U. (1999). A neuropsychological theory of positive affect and its influence on cognition. Psychological Review, 106(3), 529-50.

Benzies, K., \& Mychasiuk, R. (2009), Fostering family resiliency: A review of the key protective factors. Child \& Family Social Work, 14, 103-114. DOI:10.1111/j.13652206.2008.00586.x

Bernard, M., \& Walton, K. (2011). The effect of You Can Do It! Education in six schools on student perceptions of wellbeing, teaching, learning and relationships. Journal of Student Wellbeing, 5, 22-37.

Birmaher, B., Ryan, N.D., Williamson, D. E., Brent, D. A., Kaufman, J., Dahl, R. E., ... Nelson, B. (1996). Childhood and adolescent depression: A review of the past 10 years, part I. J Am Acad Child Adolesc Psychiatry 35, 1427-1439. 
Blomfield, C. J., \& Barber, B. L. (2009). Performing on the stage, the field, or both? Australian adolescent extracurricular activity participation and self-concept. Journal of Adolescence, 32(3), 733-739, ISSN 0140-1971. Retrieved from http://dx.doi.org/10.1016/j.adolescence.2009.01.003.

Boehm, J. K., Lyubomirsky, S., \& Sheldon, K. M. (2011). A longitudinal experimental study comparing the effectiveness of happiness-enhancing strategies in Anglo Americans and Asian Americans. Cognition \& Emotion, 25, 1263-1272. doi: $10.1080 / 02699931.2010 .541227$

Bolier, L., Haverman, M., Westerhof, G. J., Riper, H., Smit, F., \& Bohlmeijer, E. (2013). Positive psychology interventions: A meta-analysis of randomized controlled studies. BMC Public Health, 13, 119. doi:http://dx.doi.org/10.1186/1471-2458-13-119

Braun, V. \& Clarke, V. (2006) Using thematic analysis in psychology. Qualitative Research in Psychology. 3(2): 77-101

Bromley, E., Johnson, J.G., \& Cohen, P. (2006). Personality strengths in adolescence and decreased risk of developing mental health problems in early adulthood. Comprehensive Psychiatry, 47, 315-324.

Bronfenbrenner, U. (1979). The ecology of human development: Experiments by nature and design. Cambridge, MA: Harvard University Press.

Bronfenbrenner, U. (2005). Making human beings human: Bioecological perspectives on human development. Thousand Oaks, CA: Sage Publications.

Bryan, T., Mathur, S., \& Sullivan, K. (1996). The impact of positive mood on learning. Learn-ing Disabilities Quarterly, 19, 153-162.

Bryant, F. B., \& Veroff, J. (2007). Savoring: A new model of positive experience. Mahwah, NJ: Lawrence Erlbaum Associates.

Bryant, F. B. (1989). A four-factor model of perceived control: Avoiding, coping, obtaining, and savoring. Journal of Personality, 57, 773-797. 
Cafasso, L. L., Bryant, F. B., \& Jose, P. E. (1994). A scale for measuring children's savoring beliefs. Paper presented at the 102nd annual American Psychological Association convention.

Campbell, A. J., \& Robards, F. (2013). Using technologies safely and effectively to promote young people's well-being: A better practice guide for services. Young and Well Cooperative Research Centre. URL: http://www.youngandwellcrc.org.au/ knowledgehub/publications/using-technologies-safely-effectively-promote-youngpeopleswellbeing/

Campbell-Sills L., Cohan S. L, \& Stein, M. B. (2005) Relationship between resilience to personality, coping, and psychiatric symptoms in young adults. Behaviour Research and Therapy, 44, 585-599. doi: 10.1016/j.brat.2005.05.001.

Campbell-Sills L., \& Stein, M. B. (2007). Psychometric analysis and refinement of the Connor-Davidson Resilience Scale (CD-RISC): Validation of a 10-item measure of resilience. Journal of Traumatic Stress, 20, 1019-1028.

Carruthers, C., \& Hood, C. (2004). The power of the positive: Leisure and well-being. Therapeutic Recreation Journal: Special Issue on Health and Health Promotion, 38, $225-245$.

David Cella and the PROMIS Health Organization (2013) on behalf of the National Institute for Neurological Disorders and Stroke (NINDS). The PROMIS Domain Framework http://www.nihpromis.org/measures/domainframework website last accessed 10 Feb. 2012

Chua, L., Milfont, T., \& Jose, P. (2014). Coping Skills Help Explain How Future-Oriented Adolescents Accrue Greater Well-Being Over Time. Journal of Youth and Adolescence, 1-14. http://doi.org/10.1007/s10964-014-0230-8

Cohn, M. A., Fredrickson, B. L., Brown, S. L., Mikels, J. A., \& Conway, A. M. (2009). Happiness unpacked: Positive emotions increase life satisfaction by building resilience. Emotion (Washington, D.C.), 9(3), 361-8. doi:10.1037/a0015952 
Compas, B., Connor-Smith, J., Saltzman, H., Thomsen, A., \& Wadsworth, M. (2001). Coping with stress during childhood and adolescence: Problems, progress, and potential in theory and research. Psychological Bulletin, 127(1), 87-127.

Compas, B. E., Connor-Smith, J. K., Saltzman, H., Thomsen, A. H., \& Wadsworth, M. E. (2001). Coping with stress during childhood and adolescence: Progress, problems, and potential in theory and research. Psychological Bulletin, 127, 87-127.

Constantine, N. A., Benard, B., \& Diaz, M. (1999). Measuring protective factors and resilience traits in youth: The Healthy Kids Resilience Assessment. Paper presented at the Seventh Annual Meeting of the Society for Prevention Research. New Orleans, LA.

Coutu, D. (2002). How resilience works. Harvard Business Review, 46-55.

Csikszentmihalyi, M. (2000). Beyond boredom and anxiety. Experiencing flow in work and play. San Francisco: Jossey-Bass. (Original work published 1975).

Csikszentmihalyi, M. (1999). If we are so rich, why aren't we happy? American Psychologist, 54(10), 821-827.

Davidson, R. J. (2000). Affective style, psychopathology, and resilience: Brain mechanisms and plasticity. American Psychologist, 55, 1196-1214.

Davidson, T. M., Yuen, E. K., Felton, J. W., McCauley, J., Gros, K. S., \& Ruggiero, K. J. (2014). Feasibility assessment of a brief, web-based behavioral activation intervention for adolescents with depressed mood. International Journal of Psychiatry in Medicine, 48(1), 69-82. Retrieved from http://search.proquest.com/docview/1627118317?accountid=14782

Dempster, A. P., Laird, N. M., \& Rubin, D. B. (1977). Maximum Likelihood from Incomplete Data via the EM Algorithm. Journal of the Royal Statistical Society. Series B (Methodological), 39(1), 1-38. http://doi.org/10.2307/2984875

Derryberry, D., \& Tucker, D. M. (1994). Motivating the focus of attention. In P.M. Neidenthal \& S. Kitayama (Eds.), The heart's eye: Emotional influences in perception and attention (pp. 167-196). San Diego: Academic Press. 
Dickerhoof, R. M. (2007). Expressing optimism and gratitude: A longitudinal investigation of cognitive strategies to increase well-being. Dissertation Abstracts International, 68, 4174 (UMI No. 3270426).

Diener, E. (1984). Subjective well-being. Psychological Bulletin, 95(3), 542-575.

Diener, E. (1994). Assessing subjective well-being: Progress and opportunities. Social Indicators Research, 31, 103-157. http://dx.doi.org/10.1007/BF01207052

Diener, E. (2009). The collected works of Ed Diener (Vols. 1-3). The Netherlands: Springer.

Diener, E., \& Diener, C. (1996). Most people are happy. Psychological Science, 7, 181-185

Diener, E., \& Emmons, R. A. (1984). The independence of positive and negative affect. Journal of Personality and Social Psychology, 47(5), 1105-1117. http://dx.doi.org/10.1037/0022-3514.47.5.1105

Diener, E., Emmons, R. A., Larsen, R. J., \& Griffin, S. (1985). The satisfaction with life scale. Journal of Personality Assessment, 49(1), 71-5. doi:10.1207/s15327752jpa4901_13

Diener, E., Suh, E. M., Lucas, R. E., \& Smith, H. L. (1999). Subjective well-being: Three decades of progress. Psychological Bulletin, 125, 276-302.

Dumont, M., \& Provost, M. A. (1999). Resilience in adolescents: Protective role of social support, coping strategies, self-esteem, and social activities on experience of stress and depression. Journal of Youth and Adolescence, 28(3), 343-363. Retrieved from http://search.proquest.com/docview/204651242?accountid=14782

Durlak, J. A., Weissberg, R. P., Dymnicki, A. B., Taylor, R. D., Schellinger, K. B. (2011, Jan-Feb). The impact of enhancing students' social and emotional learning. Child Development, 82(1), 405-32. doi:10.1111/j.1467-8624.2010.01564.x.

Elliott, S.A, \& Brown, J.S.L. (2002). What are we doing to waiting list controls? Behaviour Research and Therapy, 40(9), 1047-1052. 
Emmons, R. A., \& McCullough, M. E. (2003). Counting blessings versus burdens: An experimental investigation of gratitude and subjective well-being in daily life. Journal of Personality and Social Psychology, 84(2), 377-389. doi:10.1037/00223514.84.2.377

Emmons, R. A., \& Sheldon, C. M. (2002) Gratitude and the science of positive psychology. In C. R Snyder \& S. J. Lopez (Eds.), Handbook of Positive Psychology (pp. 459471). New York, NY: Oxford University Press.

Erikson, E.H. (1968). Identity: Youth and Crisis. NewYork: Norton.

Everall, R., Altrows, J., \& Paulson, B. (2006). 'Creating a future: A study of resilience in suicidal female adolescents'. Journal of Counseling and Development, 84, pp. 461470.

Eysenbach, G., Webb, T., Botelho, R., Cugelman, B., Thelwall, M., \& Dawes, P. (2011). Online Interventions for Social Marketing Health Behavior Change Campaigns: A Meta-Analysis of Psychological Architectures and Adherence Factors. Journal of Medical Internet Research, 13(1).

Farrer, H. (2013). Building happiness, resilience and motivation in adolescents: a positive psychology curriculum for well-being, by Ruth MacConville and Tina Rae, London and Philadelphia, Jessica Kingsley, 2012, 255. ISBN 978-1-84905-261-0. Emotional and Behavioural Difficulties, 18(2), 233-234. http://doi.org/10.1080/13632752.2013.786949

Fleming, T. M., Dixon, R. S., \& Merry, S. N. (2012). “It's mean!” The views of young people alienated from mainstream education on depression, help seeking and computerised therapy. Advances in Mental Health, 10(2), 195-203. http://doi.org/10.5172/jamh.2011.10.2.195

Folkman, S., \& Moskowitz, J. T. (2000). Positive affect and the other side of coping. American Psychologist, 55(6), 647-654. doi:http://dx.doi.org/10.1037/0003-647

Folkman, S., \& Moskowitz, J. T. (2004). Coping: Pitfalls and promise. Annual Review of Psychology, 55, 745-774. 
Fredrickson, B. L. (1998). What good are positive emotions? Review of General Psychology: Special Issue: New Directions in Research on Emotion, 2, 300-319.

Fredrickson, B. L. (2001). The role of positive emotions in positive psychology: The broaden and-build theory of positive emotions. American Psychologist: Special Issue, 56, 218-226.

Fredrickson, B. L., Mancuso, R. A., Branigan, C., \& Tugade, M. M. (2000). The undoing effect of positive emotions. Motivation and Emotion, 24, 237-258.

Fredrickson, B. L., Cohn, M. A., Coffey, K. A., Pek, J., \& Finkel, S. M. (2008). Open hearts build lives: Positive emotions, induced through loving-kindness meditation, build consequential personal resources. Journal of Personality and Social Psychology, 95, 1045-1062.

Fredrickson, B. L., \& Levenson, R. W. (1998). Positive emotions speed recovery from the cardiovascular sequelae of negative emotions. Cognition and Emotion, 12, 191-220.

Froh, J., Bono, G., \& Emmons, R. (2010). Being grateful is beyond good manners: Gratitude and motivation to contribute to society among early adolescents. Motivation and Emotion, 34, 144-157.

Froh, J. J., Kashdan, T. B., Ozimkowski, K. M., \& Miller, N. (2009). Who benefits the most from a gratitude intervention in children and adolescents? Examining positive affect as a moderator. The Journal of Positive Psychology, 4(5), 408-422. doi:10.1080/17439760902992464

Froh, J. J., Kashdan, T. B., Yurkewicz, C., Fan, J., Allen, J., \& Glowacki, J. (2010). The benefits of passion and absorption in activities: Engaged living in adolescents and its role in psychological well-being. The Journal of Positive Psychology, 5(4), 311-332. doi:10.1080/17439760.2010.498624.

Froh, J. J., Sefick, W. J., \& Emmons, R. A. (2008). Counting blessings in early adolescents: an experimental study of gratitude and subjective well-being. Journal of School Psychology, 46(2), 213-233. doi:10.1016/j.jsp.2007.03.005 
Froh, J. J., Yurkewicz, C., \& Kashdan, T. B. (2009). Gratitude and subjective well-being in early adolescence: Examining gender differences. Journal of Adolescence, 32, 633650.

Frost and Sullivan (2013). Over two thirds of Australians aged 15-65 currently own a smartphone, finds Frost \&Sullivan. [press release] 21 August, 2012. Retrieved from http://www.frost.com/prod/servlet/press-release.pag?docid=265312994

Gable, S. L., \& Haidt, J. (2005). What (and why) is positive psychology? Review of General Psychology, 9, 103-110. doi:http://dx.doi.org/10.1037/1089-2680.9.2.103

Gellatly, J., Bower, P., Hennessy, S., Richards, D., Gilbody, S., \& Lovell, K. (2007). What makes self-help interventions effective in the management of depressive symptoms? Meta-analysis and meta-regression. Psychological Medicine, 37, 1217-1228.

Geraghty, A. W. A., Wood, A. M., \& Hyland, M. E. (2010). Dissociating the facets of hope: Agency and pathways predict dropout from unguided self-help therapy in opposite directions. Journal of Research in Personality, 44(1), 155-158. doi:10.1016/j.jrp.2009.12.003

Gentzler, A. L., Morey, J. N., Palmer, C. A., \& Yi, C. Y. (2012). Young adolescents' responses to positive events: Associations with positive affect and adjustment. The Journal of Early Adolescence. doi:10.1177/0272431612462629

Gillham, J. E., Reivich, K. J., Freres, D. R., Chaplin, T. M., Shatté, A. J., Samuels, B., ... Seligman, M. E. P. (2007). School-based prevention of depressive symptoms: A randomized controlled study of the effectiveness and specificity of the Penn Resiliency Program. Journal of Consulting and Clinical Psychology, 75(1), 9-19. doi:10.1037/0022-006X.75.1.9

Grant, A. M. \& Schwartz, B. (2011). "Too Much Of A Good Thing: The Challenge And Opportunity Of The Inverted U'. Perspectives On Psychological Science, 6(1), 61-76. http://works.swarthmore.edu/fac-psychology/107 
Gross, J. J., Richards, J. M., \& John, O. P. (2006). Emotion regulation in everyday life. In D. K. Snyder, J. A. Simpson, \& J. N. Hughes (Eds.), Emotion regulation in families: Pathways to dysfunction and health (pp. 13-35). Washington, DC: American Psychological Association.

Hart, D., \& Carlo, G. (2005). Moral development in adolescence. Journal of Research on Adolescence, 15, 223-233. doi:10.1111/j.1532-7795.2005.00094.x.123

Hjemdal, O., Friborg, O., Stiles, T. C., Martinussen, M., \& Rosenvinge, J. H. (2006). A new scale for adolescent resilience: Grasping the central protective resources behind healthy development. Measurement and Evaluation in Counseling and Development, 39, 84-96.

Huntsinger, C. S., \& Jose, P. E. (2009). Parental involvement in children's schooling: Different meanings in different cultures. Early Childhood Research Quarterly, 24(4), 398-410. http://doi.org/10.1016/j.ecresq.2009.07.006

Hurley, D. B., \& Kwon, P. (2012). Results of a study to increase savoring the moment: Differential impact on positive and negative outcomes. Journal of Happiness Studies, $13,579-588$.

Ilardi, S. S., \& Craighead, W. E. (1994). The role of nonspecific factors in cognitivebehavior therapy for depression. Clinical Psychology: Science \& Practice, 1, $138-156$.

Isen, A. M. (1987). Positive affect, cognitive processes, and social behavior. Advances in Experimental Social Psychology, 20, 203-253.

Janoff-Bulman, R., \& Berger, A. R. (2000). The other side of trauma: Towards a psychology of appreciation. In J. H. Harvey \& E. D. Miller (Eds.), Loss and trauma: General and close relationship perspectives (pp. 29-44). Philadelphia: BrunnerRoutledge.

Jones, F., \& Bright, J. (2001). Stress: Myth, theory and research. Sydney: Persons Education Ltd. 
Jose, P. (2013). Doing statistical mediation and moderation(Methodology in the social sciences). New York: The Guilford Press.

Jose, P. E., Bee, P. E., Lim, T., \& Bryant, F. B. (2012) Does savoring increase happiness? A daily diary study. The Journal of Positive Psychology, 7(3), 176-187. doi: $10.1080 / 17439760.2012 .671345$

Jose, P. E., \& Pryor, J. (2010). New Zealand youth benefit from being connected to their family, school, peer group and community. Youth Studies Australia, 29(4), 30-37.

Kazdin, A. E., \& Blase, S. (2011). Rebooting psychotherapy research and practice to reduce the burden of mental illness. Perspectives on Psychological Science, 6, 21-37.

Kline, R. B. (2005). Principles and Practice of Structural Equation Modeling (2nd ed.). New York: Guilford

Langston, C. A. (1994). Capitalizing on and coping with daily-life events: Expressive responses to positive events. Journal of Personality and Social Psychology, 67, 11121125.

Layous, K. S. (2014). Benefits, mechanisms, and new directions for teaching gratitude to children. School Psychology Review, 43(2), 153-159.

Layous, K., Chancellor, J., \& Lyubomirsky, S. (2014). Positive activities as protective factors against mental health conditions. Journal of Abnormal Psychology, 123(1), 312. doi:http://dx.doi.org/10.1037/a0034709

Layous, K., Nelson, S. K., \& Lyubomirsky, S. (2012). What is the optimal way to deliver a positive activity intervention? The case of writing about one's best possible selves. Journal of Happiness Studies. Advance online publication. doi:10.1007/s10902-0129346-2.

Lazarus, R. S. (1993). From psychological stress to the emotions: A history of changing outlooks. Annual Review of Psychology, 44, 1-21.

Lazarus, R.S., \& Folkman, S. (1984). Stress, appraisal and coping. New York: Springer. 
Linley, P. A. (2008). Average to A? Realising strengths in yourself and others. Coventry: CAPP Press.

Linley, P. A., Joseph, S., Harrington, S., \& Wood, A. M. (2006). Positive Psychology: Past, present, and (possible) future. The Journal of Positive Psychology, 1(1), 3-16. doi:10.1080/17439760500372796

Linley, P. A., Nielsen, K. M., Wood, A. M., Gillett, R., \& Biswas-Diener, R., (2010). Using signature strengths in pursuit of goals: Effects on goal progress, need satisfaction, and well-being, and implications for coaching psychologists. International Coaching Psychology Review, 5(1), 8-17.

Louis, M. C. (2011). Strengths interventions in higher education: The effect of identification versus development approaches on implicit self-theory. The Journal of Positive Psychology, 6(3), 204-215.

Lyubomirsky, S. (2007). The how to of happiness: A scientific approach to getting the life you want. New York: The Penguin Press.

Lyubomirsky, S. (2001). Why are some people happier than others? The role of cognitive and motivational processes in well-being. American Psychologist, 56, 239-249.

Lyubomirsky, S., \& Layous, K. (2013). How do simple positive activities increase wellbeing? Current Directions in Psychological Science, 22, 57-62. doi:10.1177/0963721412469809

Lyubomirsky, S., Dickerhoof, R., Boehm, J. K., \& Sheldon, K. M. (2011). Becoming happier takes both a will and a proper way: An experimental longitudinal intervention to boost well-being. Emotion, 11(2), 391-402. doi:http://dx.doi.org/10.1037/a0022575

Lyubomirsky, S., King, L., \& Diener, E. (2005). The benefits of frequent positive affect: Doeshappiness lead to success? Psychological Bulletin, 131, 803-855.

Lyubomirsky, S., \& Lepper, H. S. (1999). A measure of subjective happiness: preliminary reliability and construct validation. Social Indicators Research, 137-155. 
Lyubomirsky, S., Sheldon, K. M., \& Schkade, D. (2005). Pursuing happiness: The architecture of sustainable change. Review of General Psychology, 9(2), 111-131. doi:10.1037/1089-2680.9.2.111

MacConville, R., \& Rae, T. (2013). Building happiness, resilience and motivation in adolescents: A positive psychology curriculum for well-being. Emotional and Behavioural Difficulties, 18(2), 233-234. http://doi.org/10.1080/13632752.2013.786949

Manicavasagar V., Horswood, D., Burckhardt, R., Lum, A., Hadzi-Pavlovic, D., \& Parker, G. (2014). Feasibility and effectiveness of a web-wased positive psychology program for youth mental health: Randomized controlled trial. Journal of Medical Internet Research, 16(6), 140.

Masten, A. S. (2001). Ordinary magic: Resilience processes in development. American Psychologist, 56(3), 227-238. doi:10.1037//0003-066X.56.3.227

Masselink, J. (2013, August 30). An online positive psychology intervention to promote resilience. Retrieved from http://essay.utwente.nl/64069/

Masten, A. S., \& Coatsworth, J. D. (1998). The development of competence in favorable and unfavorable environments: Lessons from research on successful children. American Psychologist, 53(2), 205.

Martin, P. R., Reece, J., Lauder, S., \& McClelland, A. (2011). A randomised controlled trial of a social support intervention. Applied Psychology: Health and Well-Being, 3(1), 44-65. doi:10.1111/j.1758-0854.2010.01044.x

McCabe, K., Bray, M. A., Kehle, T. J., Theodore, L. A., \& Gelbar, N. W. (2011).

Promoting happiness and life satisfaction in school children. Canadian Journal of School Psychology, 26(3), 177-192. Retrieved from http://search.proquest.com/docview/901947991 ?accountid=14782 
Mccrone, P., Knapp, M., Proudfoot, J., Ryden, C., Cavanagh, K., Shapiro, D., . . . Tylee, A. (2004). Cost-effectiveness of computerised cognitive-behavioural therapy for anxiety and depression in primary care: Randomised controlled trial. The British Journal of Psychiatry : The Journal of Mental Science, 185, 55-62

McCullough, M. E., Kilpatrick, S. D., Emmons, R. A., \& Larson, D. B. (2001). Is gratitude a moral affect? Psychological Bulletin, 127, 249-266.

McGonigal, J. (2011). Reality is broken: Why games make us better and how they can change the world. New York: Penguin Press.

Meehan, M. P., Durlak, J. A., \& Bryant, F. B. (1993). The relationship of social support to perceived control and subjective mental health in adolescents. Journal of Community Psychology, 21, $49-55$.

Merry, S. N., Stasiak, K., \& Shepherd, M. (2012). SPARX: A computerized self-help intervention for teen depression. The Brown University Child and Adolescent Behavior Letter, p. 3.

Merry, S., McDowell, H., Wild, C. J., Bir, J., \& Cunliffe, R. (2004). A randomized placebocontrolled trial of a school-based depression prevention program. Journal of the American Academy of Child and Adolescent Psychiatry, 43, 538-547.

Miller, G., (2012) The Smartphone Psychology Manifesto. Perspectives on Psychological Science 7(3) 221-237

Mitchell, J., Stanimirovic, R., Klein, B., \& Vella-Brodrick, D. (2009). A randomised controlled trial of a self-guided Internet intervention promoting psychological wellbeing. Computers in Human Behavior, 25, 749-760. doi:10.1016/j.chb.2009.02.003

Mitchell, J., Vella-Brodrick, D., \& Klein, B. (2010). Positive psychology and the Internet: A mental health opportunity. Electronic Journal of Applied Psychology, 6(2), 30-41. 
Mongrain, M., Chin, J., \& Shapira, L. B. (2011). Practicing compassion increases happiness and self-esteem. Journal of Happiness Studies, 12, 963-981. doi:10.1007/s10902-0109239-1

Munoz, R. F. (2010). Using evidence-based internet interventions to reduce health disparities worldwide. Journal of Medical Internet Research, 12(5), 60. PM:21169162

Murray, E., White, I. R., Varagunam, M., Godfrey, C., Khadjesari, Z., \& McCambridge, J. (2013). Attrition revisited: Adherence and retention in a web-based alcohol trial. Journal of Medical Internet Research, 15, 162.

Nolen-Hoeksema, S. (1991). Responses to depression and their effects on the duration of depressive episodes. Journal of Abnormal Psychology, 100, 569-582.

Norem, J. K., \& Chang, E. C. (2002). The positive psychology of negative thinking. Journal of Clinical Psychology., 58, 993-1001. doi:10.1002/jclp.10094

Norrish, J., \& Vella-Brodrick, D. (2009). Positive psychology and adolescents: Where are we now? Where to from here? Australian Psychologist, 44(4), 270-278. doi:10.1080/00050060902914103

Notter, O. (2013). Building resilience in at-risk adolescents: Comparing the mechanisms and outcomes of two school-based prevention programmes. Thesis, Victoria University of Wellington.

Oatley, K. \& Jenkins, J. M. (1996). Understanding emotions. Malden, MA: Blackwell Publishers.

Olsson CA, Bond L, Burns JM, Vella-Brodrick DA, Sawyer SM. (2003). Adolescent resilience: a concept analysis. Jounal of Adolescence. 26(1): 1-11.

Parks, A. (2014). A case for the advancement of the design and study of online positive psychological interventions. The Journal of Positive Psychology, 9(6), 502-508.

Parks, A. (2010). Call for proposals: Positive psychology in higher education. The Journal of Positive Psychology, 5(3), 165. 
Parks, A., Della Porta, M., Pierce, R., Zilca, R., Lyubomirsky, S., \& Desteno, David. (2012). Pursuing Happiness in Everyday Life: The Characteristics and Behaviors of Online Happiness Seekers. Emotion, 12(6), 1222-1234.

Park, N., \& Peterson, C. (2006). Moral competence and character strengths among adolescents: The development and validation of the Values in Action Inventory of Strengths for Youth. Journal of Adolescence, 29, 891-909.

Park, N., \& Peterson, C. (2009). Strengths of character in schools. In R. Gilman, E. S. Huebner, \& M. J. Furlong (Eds.), Handbook of positive psychology in schools (pp. 65-76). New York: Routledge.

Park, N., Peterson, C., \& Seligman, M. E. P. (2004). Strengths of character and well-being. Journal of Social and Clinical Psychology, 23, 603-619.

Peterson, C., Park, N., \& Seligman, M. E. P. (2005). Orientations to happiness and life satisfaction: The full life versus the empty life. Journal of Happiness Studies, 6, 2541.

Peterson, C., \& Seligman, M. E. P. (2004). Character strengths and virtues: A handbook and classification. Oxford: Oxford University Press.

Phinney, J. S., Kim-Jo, T., Osorio, S., \& Vilhjalmsdottir, P. (2005). Autonomy and relatedness in adolescent-parent disagreements ethnic and developmental factors. Journal of Adolescent Research, 20(1), 8-39.

Preacher, K., \& Hayes, J. (2004). SPSS and SAS procedures for estimating indirect effects in simple mediation models.Behavior Research Methods, Instruments, \& Computers, $36(4), 717-731$.

Prensky, M. (2001). Digital Natives, Digital Immigrants Part 1. On the Horizon, 9(5), 1-6. http://doi.org/10.1108/10748120110424816

Proctor, C., Maltby, J., \& Linley, A. P. (2011). Strengths use as a predictor of well-being and health related quality of life. Journal of Happiness Studies 10, 583-630. doi:10.1007/s- 10902-009-9181-2. 
Proyer, R. T., Gander, F., Wellenzohn, S., \& Ruch, W. (2013). What good are character strengths beyond subjective well-being? The contribution of the good character on self-reported health oriented behavior, physical fitness, and the subjective health status. The Journal of Positive Psychology, 8, 222-232. doi:10.1080/17439760.2013.77776

Proyer, R. T., Ruch, W., \& Buschor, C. (2013). Testing strengths-based interventions: A preliminary study on the effectiveness of a program targeting curiosity, gratitude, hope, humor, and zest for enhancing life satisfaction. Journal of Happiness Studies, 14, 275-292. doi:10.1007/s10902-012-9331- 9

Rashid, T. (2009). Positive interventions in clinical practice. Journal of Clinical Psychology, 65(5), 461-466. doi:10.1002/jclp

Rosenberg, M. (1965). Society and the adolescent self-image. Princeton, NJ: Princeton University Press.

Rozental, Alexander, Andersson, Gerhard, Boettcher, Johanna, Ebert, David Daniel, Cuijpers, Pim, Knaevelsrud, Christine, . . . Carlbring, Per. (2014). Consensus statement on defining and measuring negative effects of Internet interventions. Internet Interventions - The Application of Information Technology in Mental and Behavioural, $1(1), 12-19$.

Rutter, M., Graham, P., Chadwick, O. F. D., \& Yule, W.(1976). Adolescent turmoil: Fact or fiction? Journal of Child Psychology and Psychiatry, 17, 35-56.

Savage, J. (2011). Increasing Adolescents' Subjective Well-Being: Effects of a Positive Psychology Intervention in Comparison to the Effects of Therapeutic Alliance, Youth Factors, and Expectancy for Change.

Sandier, I., Wolchik, S., MacKinnon, D., Avers, T., \& Roosa, M. (1997). Developing linkages between theory and interventions in stress and coping processes. In Handbook of children's coping: Linking theory and intervention (pp. 3-40). New York: Plenum Press. 
Schmitt, D. P., \& Allik, J. (2005). Simultaneous administration of the Rosenberg SelfEsteem Scale in 53 nations: Exploring the universal and culture-specific features of global self-esteem. Journal of Personality and Social Psychology, 89, 623-642.

Schueller, S. M. (2011). To each his own well-being boosting intervention: Using preference to guide selection. The Journal of Positive Psychology, 6, 300-313.

Schueller, S. M. (2010). Preferences for positive psychology exercises. The Journal of Positive Psychology, 5, 192-203.

Schueller, S. M., \& Parks, A. C. (2012). Disseminating self-help: Positive psychology exercises in an online trial. Journal of Medical Internet Research, 14(3), 63.

Schumacker, R. E., \& Lomax, R. G. (2004). A beginner's guide to structural equation modeling. Mahwah, N.J: Lawrence Erlbaum Associates.

Seligman, M. E. P. (2002). Authentic happiness: Using the new positive psychology to realize your potential for lasting fulfilment. New York, NY: Free Press.

Seligman, M., \& Csikszentmihalyi, M. (2000). Positive psychology: An introduction. American Psychologist, 55, 5-14.

Seligman, M. E. P., Ernst, R. M., Gillham, J., Reivich, K., \& Linkins, M. (2009). Positive education: Positive psychology and classroom interventions. Oxford Review of Education, 35(3), 293-311. doi:10.1080/03054980902934563

Seligman, M. E. P., Steen, T. A., Park, N., \& Peterson, C. (2005). Positive psychology progress: Empirical validation of interventions. American Psychologist, 60, 410-421.

Seligman, M. E. (1990). Learned optimism. New York: Alfred A. Knopf.

Seligman, M. E. P. (2002). Authentic happiness: Using the new positive psychology to realize your potential for lasting fulfilment. New York, NY: Free Press.

Seligman, M., \& Csikszentmihalyi, M. (2000). Positive psychology: An introduction. American Psychologist, 55, 5-14. 
Sergeant, S., \& Mongrain, M. (2011). Are positive psychology exercises helpful for people with depressive personality styles? The Journal of Positive Psychology, 6, 260-272. doi:10.1080/17439760.2011.577089

Schueller, S. M. (2011). Creating a recommendation framework for positive psychology exercises: The netflix model of positive psychology (Order No. 3485623). Retrieved from http://search.proquest.com/docview/908438380?accountid=14782

Seligman, M. E. P., Rashid, T., \& Parks, A. C. (2006). Positive psychotherapy. American Psychologist, 61, 774-788.

Shapira, L. B. (2012). Exploring online loving-kindness and CBT interventions: Do individuals vulnerable to depression improve? (Order No. NS00174). Retrieved from http://search.proquest.com/docview/1517354912?accountid=14782

Shapira, L. B., \& Mongrain, M. (2010). The benefits of self-compassion and optimism exercises for individuals vulnerable to depression. The Journal of Positive Psychology, 5, 377-389. doi:10.1080/17439760.2010.516763

Sheldon, K. M., \& Lyubomirsky, S. (2006b). How to increase and sustain positive emotion: The effects of expressing gratitude and visualizing best possible selves. The Journal of Positive Psychology, 1, 73-82.

Sergeant, S., \& Mongrain, M. (2014). An online optimism intervention reduces depression in pessimistic individuals. Journal of Consulting and Clinical Psychology, 82(2), 263274. doi:http://dx.doi.org/10.1037/a0035536

Sheldon, K. M., \& Lyubomirsky, S. (2006). How to increase and sustain positive emotion: The effects of expressing gratitude and visualizing best possible selves. The Journal of Positive Psychology, 1(2), 73-82.

*Sin, N. L., \& Lyubomirsky, S. (2009). Enhancing well-being and alleviating depressive symptoms with positive psychology interventions: A practice-friendly meta-analysis. Journal of Clinical Psychology, 65(5), 467-487. doi:10.1002/jclp 
Simmel, G. (1950). The sociology of Georg Simmel (K Wolff, Trans). Glencoe, IL: Free Press.

Sawatzky, R., Gadermann, A., \& Pesut, B. (2009). An investigation of the relationships between spirituality, health status and quality of life in adolescents. Applied Research in Quality of Life, 4(1), 5-22. doi:10.1007/s11482-009-9065-y.

Snyder, C. R., \& Lopez, S. J. (2005). Handbook of positive psychology. Oxford: Oxford University Press.

Strauss, A. L., \& Corbin, J. M. (1990). Basics of qualitative research: grounded theory procedures and techniques. Sage Publications.

Suldo, S. M., Savage J. A., Mercer, S. H. (2014). Increasing middle school students' life satisfaction: Efficacy of a positive psychology group intervention. Journal of Happiness Studies, 15, 19-42.

Suldo, S. M. \& Shaffer, E. J. (2008). Looking beyond psychopathology: The dual-factor model of mental health in youth. School Psychology Review, 37 (1), 52 - 68.

Thompson, R. A. (1994,). Emotion regulation: A theme in search of definition. Monographs of the Society for Research in Child Development, 59(2-3), Serial No. 240), 25-52.

Toepfer, S. M., Cichy, K., \& Peters, P. (2011). Letters of gratitude: Further evidence for author benefits. Journal of Happiness Studies, 13(1), 187-201. doi:10.1007/s10902011-9257-

Tomaka, J., Blascovich, J., Kelsey, R., Leitten, C., \& Tesser, Abraham. (1993). Subjective, Physiological, and Behavioral Effects of Threat and Challenge Appraisal. Journal of Personality and Social Psychology, 65(2), 248-260.

Tkach, C., \& Lyubomirsky, S. (2006). How do people pursue happiness?: Relating personality, happiness-increasing strategies, and well-being. Journal of Happiness Studies, 7(2), 183-225. 
Tugade, M. M., \& Fredrickson, B. L. (2004). Resilient individuals use positive emotions to bounce back from negative emotional experiences. Journal of Personality and Social Psychology, 86(2), 320-33. doi:10.1037/0022-3514.86.2.320

Tugade, M. M., Fredrickson, B. L., \& Barrett, L. F. (2004). Psychological resilience and positive emotional granularity: Examining the benefits of positive emotions on coping and health. Journal of Personality, 72(6), 1161-1190. doi:10.1111/j.14676494.2004.00294.x

Richardson T., Stallard, P., \& Velleman, S. (2010). Computerised cognitive behavioural therapy for the prevention and treatment of depression and anxiety in children and adolescents: a systematic review. Clinical Child and Family Psychology., 13, 275290.

Vella-Brodrick, D. A., Park, N. A., \& Peterson, C. (2009). Three ways to be happy: Pleasure, engagement and meaning - Findings from Australian and US samples. Social Indicators Research, 90, 165-179.

Wagnild, G. M., \& Young, H. M. (1993). Development and psychometric validation of the Resilience Scale. Journal of Nursing Measurement, 1, 165-178.

Waller, M. A. (2001). Resilience in ecosystemic context: Evolution of the concept. American Journal of Orthopsychiatry, 71(290-297)

Wang, P. S., Lane, M., Olfson, M., Pincus, H. A., Wells, K. B., \& Kessler, R. C. (2005). Twelve-month use of mental health services in the United States: Results from the national comorbidity survey replication. Archives of General Psychiatry, 62, 629640.10.1001/archpsyc.62.6.629

Wassef, A., Collins, M. L., Ingham, D., \& Mason, G. (1995). In search of effective programs to address students' emotional distress and behavioral problems. Adolescence, 30, 757-777.

Waters, L. (2011). A review of school-based positive psychology interventions. The Australian Educational and Developmental Psychologist, 28, 75-90. doi:10.1375/aedp.28.2.7510.1375/aedp.28.2.75 
Werner, E. E, \& Smith, R. S. (1992). Overcoming the odds: High-risk children from birth to adulthood. New York: Cornell University Press.

Wolin, S. J., \& S. Wolin, S. (1993). The resilient self: How survivors of troubled families rise above adversity. New York: Villard Books.

Wood, A. M., Maltby, J., Gillett, R., Linley, P. A., \& Joseph, S. (2008). The role of gratitude in the development of social support, stress, and depression: Two longitudinal studies. Journal of Research in Personality, 42(4), 854-871. doi:10.1016/j.jrp.2007.11.003 